UNIVERSIDADE DE SÃO PAULO

ESCOLA DE ENFERMAGEM

DÁLETE DELALIBERA CORRÊA DE FARIA MOTA

\title{
FADIGA NO DOENTE COM CÂNCER COLO-RETAL: FATORES DE RISCO E PREDITIVOS
}

SÃO PAULO

2008 
DÁLETE DELALIBERA CORRÊA DE FARIA MOTA

\section{FADIGA NO DOENTE COM CÂNCER COLO-RETAL: FATORES DE RISCO E PREDITIVOS}

Tese apresentada à Escola de Enfermagem da Universidade de São Paulo para obtenção do título de Doutor em Enfermagem

Área de Concentração:

Enfermagem na Saúde do Adulto

Orientadora: Profa Dra Cibele Andrucioli de Mattos Pimenta 


\section{AUTORIZO A REPRODUÇÃO E DIVULGAÇÃO TOTAL OU PARCIAL \\ DESTE TRABALHO, POR QUALQUER MEIO CONVENCIONAL OU \\ ELETRÔNICO, PARA FINS DE ESTUDO E PESQUISA, DESDE QUE CITADA \\ A FONTE.}

São Paulo, 14/01/2008

\section{Catalogação na Publicação (CIP) \\ Biblioteca "Wanda de Aguiar Horta" \\ Escola de Enfermagem da Universidade de São Paulo}

Mota, Dálete Delalibera Corrêa de Faria.

Fadiga em doentes com câncer colo-retal: fatores de risco e preditivos. / Dálete Delalibera Corrêa de Faria Mota. - São Paulo, 2008.

$127 \mathrm{p}$.

Tese (Doutorado) - Escola de Enfermagem da Universidade de São Paulo.

Orientadora: $\operatorname{Prof}^{\mathrm{a}} \mathrm{Dr}^{\mathrm{a}}$ Cibele Andrucioli de Mattos Pimenta.

1. Fadiga (manifestações neurológicas) 2. Neoplasias

colorretais 3. Fatores de risco 4. Assistência paliativa. I. Título. 
$\underline{\text { Dedicatória }}$

Ao meu marido, Alexei, e meu filho, Henry Por encherem minha vida de alegria e amor e por incentivarem a conquista de meus sonhos

Aos meus pais, Josias e Ana Lúcia, e minha irmã, Luciana

Pelo amor e constante apoio em todas as fases da minha vida 


\section{Agradecimentos}

À Deus, pelas incontáveis bênçãos concedidas durante os anos de minha vida dedicados ao desenvolvimento deste estudo.

À Profa. Cibele Andrucioli de Mattos Pimenta, pela orientação desta tese e, principalmente, pelos ensinamentos que me fazem almejar a excelência e o avanço da Enfermagem.

Ao Dr Ricardo Caponero, pela disponibilidade em atender-me e orientar-me com tamanha capacitação.

À Profa. Margaret Fitch, pela oportunidade de estagiar no exterior e desempenhar papéis no cenário da enfermagem internacional e ao Dr. Benedito Mauro Rossi, pela viabilizado a realização da pesquisa no serviço onde atende.

Ao Grupo de Pesquisa do CNPq "Dor, Controle de Sintomas e Cuidados Paliativos", pelas contribuições dadas em todas as fases deste estudo.

À Geana, Marina, Cristina, Karine, pela amizade e companheirismo.

Aos alunos, Juliano dos Santos e Camila Moraes Amaducci, pela compreensão e aceitação em me ter como co-orientadora de suas monografias.

Aos coletadores de dados, Analu Brandão Shiota, Luciana Alves da Silva, Camila Moraes Amaducci e Juliano dos Santos, pela responsabilidade com a qual desempenharam suas tarefas enquanto coletadores de dados.

Às enfermeiras Márcia Naddeo, Olga Cristina SV Carvalho, Érika Maria Monteiro, Elizabeth Chagas Costa e demais membros das equipes de enfermagem dos serviços de oncologia, por compartilhar suas vivências e por colaborar com a coleta de dados.

Aos funcionários da Secretaria de Pós-Graduação, Silvana, Dayse e Tieko, da Secretaria do Departamento ENC, Dora, Beth, Mariza e Rose, e da Biblioteca da Escola de Enfermagem da USP, Nadir e Andréia, pela preciosa ajuda nos momentos necessários.

À Ana Lúcia, pela correção da bibliografia e à Profa Lígia, pela correção do português.

À Fundação CAPES, pela bolsa de doutorado e de estágio de doutorado no exterior, e à FAPESP, pelo financiamento desta pesquisa.

Aos pacientes, pela participação essencial para a realização desta pesquisa.

À todos que colaboraram comigo neste desafio. 
Mota DDCF. Fadiga em doentes com câncer colo-retal: fatores de risco e preditivos [tese]. São Paulo: Escola de Enfermagem, Universidade de São Paulo; 2008. 127 p.

\section{RESUMO}

INTRODUÇÃO: Não existem estudos preditivos sobre fadiga em doentes com câncer colo-retal, embora fadiga seja descrita como freqüente na população oncológica. OBJETIVO: Identificar os fatores de risco e preditivos independentes de fadiga em doentes com câncer colo-retal. MÉTODO: Estudo preditivo que envolveu amostra nãoprobabilística de 157 pacientes adultos ambulatoriais com tumor primário de cólon ou

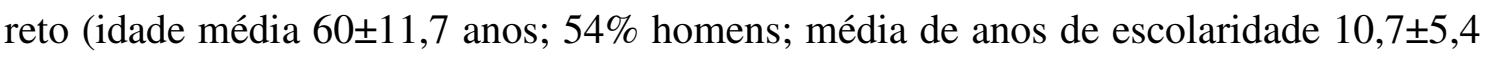
anos; estádio IV 44,8\%), atendidos em quatro serviços de oncologia do município de São Paulo, Brasil (julho/2006 a julho/2007). Os pacientes preencheram a Ficha de Identificação, a Escala de Fadiga de Piper-Revisada (0-10; ponto de corte: $\geq 4 ; \alpha=0,94)$, o Inventário de Depressão de Beck (0-63; ponto de corte: $\geq 13 ; \alpha=0,83$ ), a Escala de Karnofky (0\%-100\%; ponto de corte: $\leq 80)$, a Escala de Prejuízo do Sono (0-10; ponto de corte: $\geq 5)$ e a Escala de Dor $(0-10$; ponto de corte: $\geq 6)$. Os pontos de corte foram estabelecidos pela análise da curva ROC (Receiver Operating Characteristic), com exceção do ponto de corte de fadiga, que foi estabelecido após análise da distribuição dos escores em percentis e do critério proposto pela National Comprehensive Cancer Network. RESULTADOS: Fadiga foi referida por 26,8\% dos doentes. Os fatores de risco para fadiga foram os seguintes: serviço de saúde público, dor, prejuízo do sono, depressão e capacidade funcional prejudicada $(\mathrm{p}<0,05)$. A análise de regressão logística identificou três fatores preditivos: depressão, capacidade funcional e prejuízo do sono. 
A depressão aumentou em 4 vezes a chance de ocorrer fadiga (OR: 4,2; IC95\% 1,6810,39), a capacidade funcional aumentou em 3 vezes (OR: 3,2; IC95\% 1,37-7,51) e o prejuízo do sono também em 3 vezes (OR: 3,2; IC95\% 1,30-8,09). Quando os três fatores preditivos estiveram presentes, a probabilidade de ocorrer fadiga foi de $80 \%$, o que indicou boa capacidade de predição. Quando os três fatores preditivos estiveram ausentes, a probabilidade de ocorrer fadiga foi de $8 \%$. A especificidade e sensibilidade do modelo foram de $81,9 \%$ e $58,6 \%$, respectivamente, indicando baixa chance de falsos positivos e alta chance de falsos negativos. CONCLUSÕES: Depressão, capacidade funcional e prejuízo do sono foram preditores de fadiga. $\mathrm{O}$ estudo disponibiliza tabela de probabilidade de predição de fadiga e propõe que, por meio da avaliação da depressão, da capacidade funcional e do prejuízo do sono, é possível conhecer a probabilidade do paciente ter fadiga, o que é inédito nessa população e de grande utilidade na clínica.

PALAVRAS-CHAVE: Fadiga. Neoplasias colorretais. Fatores de risco. Razão de chances. Cuidados Paliativos. Sintomas. Análise de regressão.Modelos logísticos. 
Mota DDCF. Fatigue in colo-rectal cancer patients: risk and predictive factors [thesis]. São Paulo (SP), Brasil: Escola de Enfermagem, Universidade de São Paulo; 2008. 127p.

\begin{abstract}
INTRODUCTION: There are no studies that identify the predictive factors of fatigue among colo-rectal cancer patients, although fatigue is described as a frequent problem in the oncology setting. AIM: Identify risk factors and independent predictors of fatigue in colo-rectal cancer patients. METHOD: Predictive study that involved nonprobabilistic sample of 157 adult outpatients with primary colon or rectal (mean age $60 \pm 11.7$ years; $54 \%$ male; educational level $10.7 \pm 5.4$ years; cancer stage IV $44.8 \%$ ), recruited from 4 oncology clinics in Sao Paulo, Brazil (July/2006 to July/2007). Patients filled out an Identification Profile, Piper Fatigue Scale-revised (0-10; cut-score: $\geq 4$, $\alpha=0,94)$, Beck Depression Inventory (0-63; cut-score: $\geq 13, \alpha=0,83)$, Karnofsky Scale (0\%-100\%; cut-score: $\leq 80 \%)$, Sleep disturbance scale (0-10; cut-score: $\geq 5)$, and Pain scale $(0-10$; cut-score: $\geq 6)$. The cut scores were established by ROC (Receiver Operating Characteristic) curves, except for fatigue cut-score, which was established after an analysis of the distribution of the scores in percentiles and of the criteria proposed by National Comprehensive Cancer Network. RESULTS: Fatigue was identified by $26.8 \%$ of the patients. The risk factors for fatigue were: public oncology service, pain, sleep disturbance, poor performance status, and depression $(\mathrm{p}<0.05)$. Logistic regression identified three predictors: depression, sleep disturbance, and performance status. Depression increased the chance for fatigue to occur by four times (OR: 4.2; 95\%CI 1.68-10.39), performance status increased by three times (OR: 3.2;
\end{abstract}


95\%CI 1.37-7.51), and sleep disturbance also increased the chance by three times (OR: $3.2 ; 95 \%$ CI 1.30-8.09). When the three factors were present in concomitance, the probability that patients had fatigue was $80 \%$, which was considered a good predictive capacity. When none of the factors were present, the probability that patients had fatigue was $8 \%$. The specificity and sensibility of this model were $81.9 \%$ and $58.6 \%$, respectively, indicating that there is low chance of false positive and high chance of false negatives. CONCLUSIONS: Depression, performance status, and sleep disturbance were predictive factors of fatigue. The study presents a prediction table and proposes that by assessing depression, performance status and sleep disturbance, it is possible to know the probability that a patient will have fatigue. This finding is original and applicable in clinical practice.

KEYWORDS: Fatigue. Colorectal neoplasms. Risk factors. Odds ratio. Palliative care. Symptoms. Regression analysis. Logistic models. 


\section{LISTA DE ILUSTRAÇÕES}

\begin{tabular}{|l|l|l|}
\hline Quadro 1- & Categorização da variável dependente (fadiga). & 45 \\
\hline Quadro 2- & Classificação das variáveis sócio-demográficas. & 47 \\
\hline Quadro 3- & $\begin{array}{l}\text { Classificação das variáveis clínicas, da doença e seu } \\
\text { tratamento }\end{array}$ & 48 \\
\hline Figura 1- & $\begin{array}{l}\text { Curva ROC das variáveis contínuas dor, prejuízo do sono, } \\
\text { depressão e capacidade funcional }\end{array}$ & 68 \\
\hline
\end{tabular}




\section{LISTA DE TABELAS}

\begin{tabular}{|c|c|c|}
\hline Tabela 1- & $\begin{array}{l}\text { Caracterização dos pacientes segundo as variáveis sócio-demográfica, } \\
\text { do câncer e do tratamento. }\end{array}$ & 53 \\
\hline Tabela 2- & Caracterização dos pacientes segundo as variáveis clínicas. & 55 \\
\hline Tabela 3- & $\begin{array}{l}\text { Distribuição dos pacientes segundo a intensidade da fadiga avaliada pela } \\
\text { Escala de Fadiga de Piper-revisada. }\end{array}$ & 56 \\
\hline Tabela 4- & Escore médio de fadiga segundo a Escala de Fadiga de Piper - revisada. & 57 \\
\hline Tabela 5- & Comparação dos escores de fadiga segundo o sexo. & 57 \\
\hline Tabela 6- & Comparação dos escores de fadiga segundo a idade. & 58 \\
\hline Tabela 7- & Comparação dos escores de fadiga segundo a duração do sintoma. & 58 \\
\hline Tabela 8- & Comparação dos escores de fadiga segundo a depressão. & 59 \\
\hline Tabela 9- & Comparação dos escores de fadiga segundo a capacidade funcional. & 60 \\
\hline Tabela 10- & Distribuição dos pacientes segundo duração da fadiga. & 60 \\
\hline Tabela 11- & Causas para fadiga citadas pelos pacientes. & 61 \\
\hline Tabela 12- & Ações que aliviam fadiga relatadas pelos pacientes. & 62 \\
\hline Tabela 13- & Níveis de significância entre fadiga e variáveis sócio-demográficas. & 64 \\
\hline Tabela 14- & $\begin{array}{l}\text { Níveis de significância entre fadiga e variáveis da doença, do seu } \\
\text { tratamento e variáveis clínicas. }\end{array}$ & 65 \\
\hline Tabela 15- & Níveis de significância entre fadiga e sintomas. & 66 \\
\hline Tabela 16- & $\begin{array}{l}\text { Curvas ROC para variáveis contínuas inseridas no modelo de regressão } \\
\text { logística. }\end{array}$ & 67 \\
\hline Tabela 17- & Associação entre os fatores de risco de fadiga. & 68 \\
\hline Tabela 18- & Modelo de regressão logística para fadiga. & 69 \\
\hline Tabela 19- & $\begin{array}{l}\text { Probabilidade de ter fadiga na presença dos fatores preditivos } \\
\text { independentes. }\end{array}$ & 70 \\
\hline
\end{tabular}




\section{SUMÁRIO}

\begin{tabular}{|c|c|c|}
\hline 1 & INTRODUÇÃO & 11 \\
\hline 1.1 & AVALIAÇÃO DA FADIGA & 11 \\
\hline 1.2 & PREVALÊNCIA, INTENSIDADE E IMPACTO DA FADIGA & 14 \\
\hline 1.3 & FATORES RELACIONADOS Å FADIGA & 17 \\
\hline 1.4 & FADIGA E FATORES PREDITIVOS & 32 \\
\hline 2 & OBJETIVO & 36 \\
\hline 3 & MÉTODO & 37 \\
\hline 3.1 & TIPO DE ESTUDO E AMOSTRA & 37 \\
\hline 3.2 & LOCAL E PERÍODO & 37 \\
\hline 3.3 & ASPECTOS ÉTICOS & 38 \\
\hline 3.4 & PROCEDIMENTOS DE COLETA DE DADOS & 39 \\
\hline 3.5 & $\begin{array}{l}\text { INSTRUMENTOS: CARACTERÍSTICAS E PROPRIEDADES } \\
\text { PSICOMÉTRICAS }\end{array}$ & 40 \\
\hline 3.5.1 & Ficha de Identificação & 40 \\
\hline 3.5 .2 & Escala de Fadiga de Piper - revisada & 41 \\
\hline 3.5.3 & Escala de Karnofsky & 44 \\
\hline 3.5 .4 & Inventário de Depressão de Beck & 44 \\
\hline 3.5 .5 & Classificação e pontos de corte & 45 \\
\hline 3.6 & ANÁLISE DOS DADOS & 49 \\
\hline 4 & RESULTADOS & 52 \\
\hline 4.1 & CARACTERIZAÇÃO DA POPULAÇÃO & 52 \\
\hline 4.2 & CARACTERIZAÇÃO DA FADIGA & 56 \\
\hline 4.3 & $\begin{array}{l}\text { IDENTIFICAÇÃO DOS FATORES DE RISCO E DOS FATORES } \\
\text { PREDITIVOS }\end{array}$ & 63 \\
\hline 5 & DISCUSSÃO & 71 \\
\hline 6 & CONCLUSÕES & 100 \\
\hline \multirow[t]{2}{*}{7} & REFERÊNCIAS BIBLIOGRÁFICAS & 101 \\
\hline & ANEXOS & 112 \\
\hline
\end{tabular}




\section{INTRODUÇÃO}

Por muito tempo a fadiga no paciente com câncer foi estudada como um sintoma isolado de outros fatores. Buscou-se conhecer a sua prevalência em diferentes grupos populacionais, a sua evolução segundo o curso da doença e seu comportamento frente a diferentes tratamentos para o câncer ou intervenções para seu manejo. À medida que esse conhecimento se solidificou e notou-se a relevância do sintoma no cenário da oncologia, novos estudos começaram a buscar os fatores que poderiam predizer a fadiga e sua intensidade. O presente estudo identificou os fatores de risco e os fatores preditivos da fadiga em doentes com câncer colo-retal. A identificação dos fatores preditivos de fadiga possibilita a prevenção, o diagnóstico precoce e o desenvolvimento de ações para seu controle.

\subsection{AVALIAÇÃO DA FADIGA}

A avaliação de fadiga é crucial para a identificação dos fatores preditivos de fadiga e identificar pacientes verdadeiramente fatigados é um desafio pois fadiga é um sintoma complexo, multidimensional e subjetivo.

Existem diversos instrumentos para avaliação de fadiga e a análise detalhada de grande parte desses instrumentos foi realizada em revisão sistemática (Mota, Pimenta, 2006; Mota, 2003). Identificaram-se 18 instrumentos de auto-relato e metade deles 
avaliavam múltiplas dimensões da fadiga. Ser um instrumento multidimensional é uma característica importante para instrumentos que avaliam construtos multidimensionais como a fadiga, pois possibilita a obtenção de um retrato mais preciso do fenômeno, tanto quantitativo como qualitativo.

A avaliação de fadiga está intimamente relacionada à definição da mesma. Fadiga pode ser definida como "uma sensação física desagradável, com sintomas cognitivos e emocionais descritos como cansaço, e que não é aliviada com o emprego de estratégias usuais de restauração de energia. A fadiga varia em duração e intensidade e reduz, em diferentes graus, a habilidade para desenvolver as atividades de vida diária" (Mota, Cruz, Pimenta, 2005). Essa conceituação de fadiga é fruto de análise do conceito do fenômeno, acrescido da análise do conjunto de instrumentos de fadiga publicados na literatura internacional.

No Brasil, as publicações sobre validade de instrumentos para avaliação de fadiga referem-se a duas escalas: o Pictograma de Fadiga e a Chalder Fatigue Scale. O Pictograma de Fadiga é um instrumento ilustrado com dois itens que avaliam a intensidade e o impacto do cansaço (Mota, Pimenta, Fitch, 2007). Sua confiabilidade e validade foram satisfatórias entre pacientes com câncer, porém algumas modificações serão testadas em estudos futuros (Mota, Pimenta, Fitch, 2007). A Chalder Fatigue Scale - versão brasileira contém 11 itens distribuídos em duas dimensões (física e mental). As suas propriedades psicométricas foram consideradas adequadas em pacientes com Síndrome da Fadiga Crônica (Cho et al., 2007). Apesar de serem válidos e confiáveis, esses dois instrumentos apresentam limitações referentes à avaliação das dimensões da fadiga. Por isso, optou-se por traduzir e validar um outro instrumento de auto-relato para avaliação de fadiga que avaliasse maior número de dimensões do 
sintoma, que tivesse extensão mediana (entre 15 e 30 itens) e que fosse utilizado internacionalmente.

A tradução e validação de instrumentos internacionais padronizados para avaliação de fenômenos subjetivos possuem vantagens comparadas à ação de construir instrumentos novos. Destacam-se os fatos de permitir a comparação de resultados com estudos de outros países e de permitir o aprimoramento de um instrumento existente.

O instrumento escolhido foi a Piper Fatigue Scale - Revised. É um instrumento multidimensional de auto-relato para a avaliação de fadiga criado em 1998 (Piper et al., 1998) a partir do Piper Fatigue Scale (Piper et al., 1989). Na versão original, possui 22 itens distribuídos em quatro dimensões (comportamental, afetiva, sensorial e cognitiva/emocional). Ter múltiplas dimensões é uma característica importante pois permite o reconhecimento da expressão da fadiga na vida do indivíduo. A escala parte do pressuposto de que o indivíduo esteja fatigado, porém oferece a oportunidade de resposta nula, podendo ser aplicada em todos, mesmo que não se tenha certeza de que esteja sentindo fadiga.

Foi validado, inicialmente, em pacientes com câncer e é nesse grupo populacional que apresenta maior número de estudos, mas é possível utilizá-lo em outros grupos populacionais. Como exemplo, esse instrumento se mostrou adequado na avaliação de fadiga de pacientes com síndrome pós-polio (Strohschein et al., 2003), com vírus da imunodeficiência humana (Breitbart et al., 2001) e até mesmo de indivíduos saudáveis (Clark et al., 2006). Até o momento, sabe-se que a Piper Fatigue Scale Revised foi validada em francês (Gledhill et al., 2002), alemão (Dagnelie et al., 2006), sueco (Ostlund, Gustavsson, Furst, 2007), grego (Lavdaniti et al., 2006) e chinês (So, Dodgson, Tai, 2003). 
Uma síntese do processo de validação da Piper Fatigue Scale - Revised está descrita no Método (páginas 31 a 33) e em artigo enviado para publicação (Mota, Pimenta, Piper, 2008). Acredita-se que esse instrumento permitirá retratar com acurácia a fadiga em nosso país.

\subsection{Prevalência, intensidade e impacto da fadiga}

A prevalência de fadiga é indiscutivelmente alta. Em revisão sistemática que buscou determinar a ocorrência de fadiga no paciente com câncer, foram incluídos 27 estudos e se observou que a prevalência do sintoma variou entre $4 \%$ e $91 \%$, dependendo da população estudada e método de avaliação (Lawrence et al., 2004). A revisão do presente estudo também encontrou grande variação conforme se observa nos relatos a seguir.

Em revisão de literatura sobre fadiga em mulheres recebendo quimioterapia adjuvante para câncer de mama, que envolveu 23 estudos com tamanhos de amostras que variaram entre 14 e 3910 mulheres, observou-se prevalência de fadiga entre $32 \%$ a 99\%, e foi mais alta nos dois primeiros dias após a infusão do quimioterápico (De Jong et al., 2002). Depois do tratamento quimioterápico, a fadiga esteve presente em $49 \%$ das mulheres com câncer de mama (Goldstein et al., 2006). Setenta e cinco por cento dos pacientes com melanoma metastático $(n=12)$ recebendo bioquimioterapia referiram fadiga moderada ou intensa (Fu et al., 2002). Dos 97 pacientes fazendo tratamento radioterápico para tumores em diferentes sítios, 54\% referiram fadiga moderada ou intensa (Smets et al., 1996) e, em pacientes com câncer de pulmão em tratamento radioterápico $(\mathrm{n}=50), 78 \%$ referiram fadiga durante o tratamento (Hickok et al., 1996). 
Em homens com diferentes tipos de câncer $(n=180)$, a prevalência de fadiga foi 44\% (Hwang et al., 2003). Em pacientes idosos com câncer não submetidos a tratamento $(\mathrm{n}=77), 72,7 \%$ relataram fadiga e, em $99 \%$ dos casos, ela esteve presente na semana anterior à avaliação (Respini et al., 2003). Em outro estudo que envolveu 839 idosos com diferentes tipos de câncer, a fadiga apresentou prevalência de $29 \%$ entre a $6^{a}$ e $8^{\mathrm{a}}$ semana após o diagnóstico (Given et al., 2001). Um ano após o diagnóstico do câncer, a prevalência da fadiga foi igual a $26 \%$ nessa mesma população (Given et al., 2001).

A intensidade da fadiga foi descrita em vários estudos e, como muitas escalas de fadiga não têm ponto de corte, a prevalência nem sempre está descrita.

Em estudo com 354 pacientes com diferentes sítios de câncer, a intensidade média de fadiga foi 3,9, em escala de 0 a 10 (Anderson et al., 2003). Em estudo com 180 homens com diferentes cânceres, a intensidade média foi de 2,6, em escala de 0 a 10 (Hwang et al., 2003). Em estudo envolvendo 246 pacientes com leucemia (aguda e crônica) ou linfoma não-Hodgkin, a prevalência de fadiga intensa ( $\geq 7$, em escala de 0 a 10) foi de $50 \%$. O escore médio de fadiga entre aqueles com leucemia aguda $(6,9)$ foi superior ao dos pacientes com linfoma $(5,8)$, e naqueles com leucemia crônica $(6,1)$, a intensidade da fadiga não diferiu estatisticamente dos demais grupos (Wang et al., 2002).

A prevalência e a intensidade da fadiga em cuidados paliativos são também significativas. Estudos envolvendo pacientes em cuidados paliativos observaram prevalência que variou entre 57\% a 90\% (Herrinton et al., 2007; Walsh, Rybicki, 2006; Jenkins et al., 2000; Stone et al., 1999; Sarna, Brecht, 1997) e a fadiga foi intensa (Jenkins et al., 2000; Stone et al., 1999; Sarna, Brecht, 1997). 
Fadiga parece persistir mesmo após a "cura" da doença. Em estudo envolvendo 144 mulheres livres de câncer de mama há 3 anos, fadiga esteve presente em 36,7\% das vezes e o escore médio total foi 17,1 , em escala de 0 a 60 (maior o escore, maior a fadiga, Sugawara et al., 2005). Outro estudo com sobreviventes de câncer de mama há 6 meses $(n=69)$ identificou prevalência de fadiga em 19\% das mulheres (Young, White, 2006). A prevalência de fadiga entre mulheres tratadas e curadas de câncer de mama $(\mathrm{n}=150)$ foi de aproximadamente $40 \%$ das referiram fadiga intensa 29 meses, em média, após término do tratamento curativo, que foi mais alta que a prevalência entre mulheres sadias, que foi de 11\% (Servaes, Verhagen, Bleijenberg, 2002a). Outro estudo indicou que a intensidade de fadiga após 2,5 anos do término da radioterapia foi semelhante à do início do tratamento e inferior à do final (Geinitz et al., 2004).

Em 92 pacientes livres de linfoma Hodgkin a fadiga foi observada em 26\% dos sujeitos e a fadiga total média foi 14,6, em escala de 0 a 33 (Knobel et al., 2001). Estudo com 170 pacientes tratados e sem evidência de doença óssea ou partes moles identificou prevalência de fadiga em $58 \%$ deles, sendo que $28 \%$ apresentaram fadiga intensa (Servaes et al., 2003).

No Brasil, estudos de prevalência sobre fadiga na área oncológica são em pequeno número. Em pacientes com câncer de laringe $(n=11)$, aproximadamente $45 \%$ apresentaram sensação de cansaço no corpo todo e mais de $80 \%$ referiram alguma sensação de cansaço mental (Coelho, Sawada, 1999). Em mulheres com câncer de mama ( $\mathrm{n}=20)$ iniciando tratamento adjuvante, o escore médio da fadiga foi 42,3 antes do tratamento e 35,2 após o $3^{\circ}$ ciclo, segundo escala que varia de 0 a 52 (quanto maior o escore, menor a fadiga; Liberman et al., 2004).

Além de prevalência e magnitude, a fadiga merece atenção por ser sintoma que causa sofrimento, limitação da funcionalidade e prejuízo à qualidade de vida. A 
sensação de fadiga leva o indivíduo fatigado a pensar que está doente ou incapacitado, sendo interpretada como uma forma de sofrimento (Olsson, Lexell, Söderberg, 2005). A fadiga sentida por pessoas com câncer é relatada como causa de maior sofrimento que a fadiga vivida no dia-a-dia por pessoas saudáveis. Ela se caracteriza por ser mais intensa, duradoura, difícil de ser aliviada, de início mais rápido, por demandar mais energia e acometer os domínios físico, social, espiritual, psicológico e cognitivo (Holley, 2000).

A intensidade da fadiga pode predizer a sobrevida e a qualidade de vida. Há estudo ( $n=200)$ que observou que fadiga/astenia, qualidade de vida e a estimativa de tempo de vida dado pelo oncologista predisseram a sobrevida (Llobera et al., 2000). Em outro estudo envolvendo 180 pacientes com câncer, a fadiga avaliada junto à capacidade funcional, ao estadiamento do câncer e à quantidade de outros sintomas também predisse tempo de sobrevida (Hwang et al., 2003). Entre 1.588 mulheres sobreviventes de câncer de mama acompanhadas durante 12,9 anos, em média, observou-se que menores alterações emocionais e de fadiga predisseram maior tempo livre de câncer de mama e sobrevida (Groenvold et al., 2007). Ainda, somente a fadiga foi capaz de explicar 53\% da variação da qualidade de vida, em estudo com 64 pacientes com câncer de mama ou pulmão (Dagnelie et al., 2007).

\subsection{Fatores relacionados à fadiga}

Em estudos sobre cluster ou agrupamento de sintomas em doentes oncológicos, fadiga, freqüentemente, é um dos sintomas observados. Esses agrupamentos, de dois ou mais sintomas, têm demonstrado importante impacto na funcionalidade e qualidade de vida dos doentes. A fadiga, em geral, está agrupada à depressão, à dor e à insônia (Donovan, Jacobsen, 2007; Fox, Lyon, 2006; Dodd, Miaskowski, Lee, 2004; Dodd, 
Miaskowski, Paul, 2001). A depender do local do tumor ou estadiamento da doença, outros sintomas podem ser somados como, por exemplo, em pacientes com glioma avançado, a alteração cognitiva (Fox, Lyon, Farace, 2007) e, em doentes terminais, anorexia, falta de energia, xerostomia, saciedade precoce, perda de peso e alteração de paladar (Walsh, Rybicki, 2006).

Tais agrupamentos mostram a co-ocorrência de sintomas mas, muitas vezes, não esclarecem as relações entre eles. Portanto, é importante identificar quais os principais fatores de risco para fadiga para que se possa preveni-la, diagnosticá-la e tratá-la. Diversos fatores são apontados na literatura e a forma como concorrem para a etiologia e magnitude da fadiga pode ser explicada por teorias abrangentes sobre fadiga no paciente com câncer como o Modelo Integrado de Fadiga de Piper, que combina fatores causais e agravantes revelados por diversas disciplinas e apresenta o impacto multidimensional do sintoma, e a Hipótese Entrópica Psicobiológica de Winningham, que discute que qualquer sintoma que diminua a atividade pode aumentar a percepção de fadiga, reduzindo a funcionalidade e promovendo a incapacidade (Burke, 1998).

Observa-se que as teorias citadas reconhecem a multicausalidade do fenômeno, isto é, não é apenas um fator que leva o indivíduo com câncer a se sentir fatigado. Os fatores causais ou agravantes da fadiga, segundo a literatura, são de ordem cultural, ambiental, sócio-demográfica, física, fisiológica, emocional, cognitiva, relacionada à própria doença e ao seu tratamento. A seguir será apresentada a estratégia utilizada para revisão da literatura e os achados sobre os fatores de risco para fadiga no paciente com câncer. 


\section{Estratégia de Revisão da literatura}

Para revisar a literatura sobre fatores relacionados à fadiga, realizou-se busca nas bases de dados PUBMED, CINAHL, EMBASE e LILACS sem limitação do tempo de publicação, utilizando a estratégia PICO. PICO é o acrônimo para P=patient, I= intervention, $\mathrm{C}=$ control ou comparison e $\mathrm{O}=$ outcome, confome apresentado por (Bernardo, Nobre, 2006). Os descritores utilizados e a forma como foram inseridos para busca dos dados foram:

$\mathbf{P}=$ (fatigue $\mathrm{OR}$ tiredness $\mathrm{OR}$ asthenia) AND (cancer OR cancers OR neoplasm OR neoplasms OR tumors OR tumor) AND (depression OR Depressive Disorder OR Major Depressive Disorder OR Dysthymic Disorder OR anxiety OR Anxiety Disorders OR pain OR sleep OR Sleep Initiation and Maintenance Disorders OR Karnofsky Performance Status OR Activities of Daily Living OR Self Care OR Antidepressive Agents OR anemia OR hemoglobins OR Age Factors OR Marital Status OR Educational Status OR Socioeconomic Factors OR Income OR Chemotherapy, Adjuvant OR Chemotherapy, Cancer, Regional Perfusion OR Radiotherapy OR Radiotherapy, Adjuvant OR Neoadjuvant Therapy OR Palliative Care OR Complementary Therapies) AND (correlation OR association OR prediction OR review)

$\mathbf{O}=($ correlation $\mathrm{OR}$ association $\mathrm{OR}$ prediction $\mathrm{OR}$ review $)$

Na base CINAHL, 304, na base EMBASE, 92 e no LILACS, 02 artigos. Na base PUBMED foram levantados 952 artigos e, após limitar a busca para pesquisa envolvendo seres humanos e adultos, o número de artigos levantados reduziu para 421. Observou-se que 108 artigos eram duplicados, totalizando 711. Após a leitura dos resumos, foram selecionados os artigos que descreveram fatores de risco ou preditivos de fadiga. Os artigos encontrados estão descritos a seguir. 


\section{Fadiga e Variáveis Sócio-Demográficas}

Considerando a totalidade de publicações sobre fadiga, poucos estudos objetivaram avaliar a relação entre fadiga e variáveis sócio-demográficas como sexo, idade, nível educacional, estado civil, trabalho, renda per capita e cor da pele. Essas variáveis são freqüentemente usadas apenas para caracterização das populações do estudo. Observou-se que muitos resultados são contraditórios e por isso ainda não há clareza sobre a relação entre tais variáveis e a fadiga.

Dos estudos que avaliaram a relação entre fadiga e sexo em pacientes com tumores diferentes, oito não encontraram relação entre as variáveis (Munch et al., 2006; Brown, McMillan, Milroy, 2005; Anderson et al., 2003; Servaes et al., 2003; Wang et al., 2002; Stone et al., 1999; Galloway, Graydon, 1996; Hickok et al., 1996) e três encontraram associação entre fadiga e sexo feminino. Em estudo com 102 pacientes com doença oncológica avançada em tratamento paliativo domiciliário, as mulheres pareceram ter maior prevalência e fadiga mais intensa que homens, independentemente da capacidade funcional, nível educacional, condições de moradia, qualidade de vida e depressão (Husain et al., 2007). Estudo com 455 pacientes ambulatoriais com câncer também identificou relação entre sexo e fadiga, sendo as mulheres mais fatigadas que os homens (Akechi et al., 1999). Entre pacientes idosos com câncer (n=77 e n=839), as mulheres também referiram mais fadiga que os homens (Respini et al., 2003; Given et al., 2001). Em revisão de literatura sobre a relação entre sexo e fadiga, a pesquisadora critica o pequeno número de estudos encontrados e a inconsistência dos dados (Miaskowski, 2004), e a revisão realizada no presente estudo suscita as mesmas críticas.

Idade e fadiga não apresentaram relação em estudos envolvendo sobreviventes de câncer de cabeça e pescoço, tumores ósseos ou de partes moles, pacientes póscirurgia de extirpação do câncer, pacientes com câncer avançado e pacientes em 
tratamento antineoplásico para câncer de próstata, mama, pulmão, linfoma e leucemia (Husain et al., 2007; Munch et al., 2006; Rogers et al., 2006; Brown, McMillan, Milroy, 2005; Dimeo et al., 2004; Gélinas, Fillion, 2004; Hwang et al., 2003; Servaes et al., 2003; Vordermark et al., 2002; Wang et al., 2002; Given et al., 2001; Stone et al., 1999; Galloway, Graydon, 1996; Hickok et al., 1996). Em mulheres recebendo tratamento adjuvante para câncer de mama, dois estudos observaram correlações negativas entre intensidade de fadiga e idade, isto é, pessoas mais jovens apresentaram mais fadiga (De Jong et al., 2002), assim como em um estudo com sobreviventes de câncer de mama (Young, White, 2006). Um estudo observou correlação positiva, isto é, mulheres mais velhas relataram fadiga mais intensa (So, Dodgson, Tai, 2003).

Estudos que testaram a relação entre nível de escolaridade e fadiga também apresentaram resultados contraditórios. Em estudo envolvendo pacientes ambulatoriais com câncer $(n=455)$, aqueles com nível de escolaridade mais alto apresentaram fadiga mais intensa (Akechi et al., 1999). Já entre sobreviventes de câncer (n=170), pacientes recebendo cuidados paliativos $(n=102 ; n=130)$, idosos com câncer $(n=77)$, pacientes submetidos à cirurgia para extirpação do câncer $(n=40)$, em tratamento antineoplásico para leucemia e linfoma $(n=228)$ e tratamento para câncer de mama $(n=103)$, e em sobreviventes de câncer de mama (n=69), as variáveis escolaridade e fadiga não se relacionaram (Husain et al., 2007; Munch et al., 2006; Young, White, 2006; Gélinas, Fillion, 2004; Respini et al., 2003; Servaes et al, 2003; Wang et al., 2002; Galloway, Graydon, 1996).

A relação entre viver ou não com companheiro e fadiga foi pouco investigada. Dois estudos mostraram que aqueles que vivem sozinhos referem mais fadiga (De Jong et al., 2004; Akechi et al., 1999). Outros não observaram relação entre fadiga e viver com companheiro (Husain et al., 2007; Munch et al., 2006; Young, White, 2006; 
Gélinas, Fillion, 2004; Respini et al., 2003; Wang et al., 2002; Hickok et al., 1996). Ainda, um estudo mostrou que as pacientes casadas apresentaram fadiga mais intensa que as solteiras, divorciadas ou viúvas (So, Dodgson, Tai, 2003).

Alguns estudos mostraram que aqueles que não trabalhavam ou desempenhavam serviços domésticos relataram mais fadiga comparados aos que trabalhavam em período integral fora de casa (Sugawara et al., 2005; So, Dodgson, Tai, 2003; Akechi et al., 1999). Outros não encontraram relação entre fadiga e estar ou não empregado (Young, White, 2006; Hickok et al., 1996).

E enquanto um estudo observou fadiga mais intensa entre pessoas com menor renda (So, Dodgson, Tai, 2003), outro não encontrou correlação entre fadiga e questões financeiras (Stone et al., 1999).

A questão da etnia foi pouco investigada. Estudos que pesquisaram fadiga em indivíduos brancos, latinos, negros não-latinos, asiáticos e indígenas americanos não encontraram correlação (Wang et al., 2002; Hickok et al., 1996).

\section{Fadiga, ansiedade e depressão}

Alterações do humor são freqüentes nos doentes com câncer, e depressão e ansiedade são as mais estudadas. Os estudos são consistentes na observação de correlação entre fadiga e depressão e fadiga e ansiedade e é importante lembrar que estudos de correlação indicam o comportamento de um fator frente a outro e não a sua relação causal.

A prevalência de depressão em pacientes com câncer variou entre $14 \%$ e $21 \%$ (Wilson et al., 2007; Montazeri et al., 2001) e sua correlação com a fadiga, em geral, foi moderada, variando de r=0,29 a r=0,84 (Munch et al., 2006; Young, White, 2006; Brown, McMillan, Milroy, 2005; Carpenter et al., 2004; Dimeo et al., 2004, 1997; 
Liberman et al., 2004; Hwang et al., 2003; Respini et al., 2003; Servaes et al. 2003; Kuo, Ma, 2002; Loge et al., 2000; Okuyama et al., 2000; Smets et al., 1996).

A prevalência de ansiedade variou entre $14 \%$ e $29 \%$ (Wilson et al., 2007; Montazeri et al., 2001) e sua correlação com fadiga também foi moderada, variando entre $r=0,23$ e r=0,70 (Munch et al., 2006; Young, White, 2006; Liberman et al., 2004; Servaes et al., 2003; Kuo, Ma, 2002; Loge et al., 2000; Okuyama et al., 2000; Dimeo et al., 1997; Smets et al., 1996). A ansiedade, apesar de comum, é menos explorada que a depressão, porém os resultados das pesquisas demonstram correlação positiva entre fadiga e ansiedade, assim como entre fadiga e depressão (Tsai et al., 2007).

\section{Fadiga e outros Sintomas}

Sintomas como alteração de sono, dor, redução de apetite e dispnéia, entre outros, são comuns no paciente com câncer e suas relações com fadiga foram exploradas em algumas pesquisas. Observou-se, assim como em outros fatores, que os estudos não esclarecem as relações entre as variáveis e fadiga.

Alteração do sono é o sintoma que apresentou relação mais forte com fadiga e estudos mostraram correlações moderadas, que variam entre $r=0,28$ e $r=0,50$, a depender da fase e tratamentos para o câncer (Carpenter et al., 2004; Anderson et al., 2003; Servaes et al. 2003; Kuo, Ma, 2002; Wang et al., 2002; Stone et al., 1999). Interessante notar que nem sempre foi importante o número de horas de sono mas sim a sua qualidade (Anderson et al., 2003; Hwang et al., 2003).

A relação entre dor e fadiga também se mostrou positiva, mas a força da correlação varia de moderada a fraca ( $\mathrm{r}=0,21$ a r=0,47; Gélinas, Fillion, 2004; Hwang et al., 2003; Kuo, Ma, 2002; Wang et al., 2002; Stone et al., 1999, Kaasa et al., 1999). Estudo prospectivo com pacientes terminais observou que a correlação entre fadiga e 
dor tendeu a diminuir com a aproximação da morte (Kaasa et al., 1999) e um estudo, também envolvendo pacientes terminais, não encontrou correlação significativa entre dor e fadiga (Echteld et al., 2007).

A relação entre constipação e fadiga tende a ser mais fraca, variando entre $\mathrm{r}=0,31$ e $\mathrm{r}=0,28$ em pacientes com doença avançada e em pacientes em tratamento antineoplásico (Hwang et al., 2003; Kuo, Ma, 2002; Stone et al., 1999). O uso de opióides, no primeiro caso, e de quimioterápicos, no segundo, podem causar alterações importantes no funcionamento intestinal, que influem na apreciação de fadiga. Diarréia não apresentou relação com fadiga em pacientes com câncer avançado (Stone et al., 1999), o que pareceu estranho. Em pacientes com leucemia ou linfoma, sintomas gastrointestinais apresentaram alta correlação com fadiga (Wang et al., 2002).

Estudos encontraram correlação positiva entre dispnéia e fadiga (Hwang et al., 2003; Kuo, Ma, 2002; Stone et al., 1999) e não observaram relação entre Índice de Massa Corporal e fadiga (Brown, McMillan, Milroy, 2005; Kuo, Ma, 2002; Stone et al., 1999). Um estudo encontrou correlação negativa entre peso e fadiga (Morant et al., 1993). Perda de peso e fadiga não se correlacionaram em dois estudos (Wang et al., 2002; Morant et al., 1993), mas em um estudo observou-se associação entre esses fatores (Hwang et al., 2003). Há que se atentar se essas correlações ocorreram em pacientes com peso acima ou abaixo do normal.

Um estudo encontrou correlação positiva entre anorexia e fadiga $(r=0,46)$ em pacientes com câncer avançado (Stone et al., 1999). Estudo que analisou uso de suplemento alimentar em 225 pacientes com diferentes tipos de câncer encontrou nesses menor intensidade de fadiga que naqueles que não o fizeram (Lis et al., 2006).

Fadiga e alterações cognitivas não se relacionaram em indivíduos idosos com câncer $(n=77)$, nem em 110 mulheres em tratamento adjuvante para câncer de mama 
(Respini et al., 2003; Tchen et al., 2003). Mas observou-se correlação positiva entre alteração cognitiva (confusão mental) e fadiga em pacientes com câncer de pulmão (n=73), em tratamento químio ou radioterápico (n=60; Holzner et al., 2002; Kuo, Ma, 2002). Associação entre dificuldade em manter concentração e fadiga foi observada em homens (n=180) com diferentes sítios de câncer (Hwang et al., 2003).

\section{Fadiga e Variáveis Fisiológicas}

Os fatores fisiológicos, também denominados de marcadores bioquímicos, são aspectos objetivos que podem se alterar por diversos motivos no doente com câncer. São poucos os estudos que buscaram relacionar fadiga e fatores fisiológicos, provavelmente porque, a depender do fator a ser mensurado, exigem-se recursos materiais e tecnológicos avançados e dispendiosos. Contudo, acredita-se que a investigação entre tais relações poderá fornecer informações preciosas para a melhor compreensão e controle da fadiga

O fator fisiológico mais estudado é a hemoglobina. Anemia ocorre, aproximadamente, em $34 \%$ dos pacientes $(n=421)$ com tumores sólidos em fase avançada (Herrinton et al., 2007). Em anemia leve (hemoglobina inferior a 11,0 mg/dl), observou-se correlação negativa, isto é, a valores menores de hemoglobina, correspondeu fadiga mais intensa (Stone et al., 2005; Respini et al., 2003; Wang et al., 2002; Glaus, Müller, 2000). Estudo que comparou fadiga de pacientes que receberam transfusão sanguínea por causa de anemia e pacientes que não a receberam identificou que os que receberam transfusão tiveram fadiga consideravelmente mais intensa (Wang et al., 2002).

Questiona-se exatamente o mecanismo pelo qual a anemia causaria a fadiga e, em geral, acredita-se que ocorreria hipóxia tecidual e, consequentemente, 
funcionamento inadequado de algum órgão. Seguindo esse raciocínio, testou-se se a curva de dissociação da oxihemoglobina estaria associada à fadiga e observou-se que o $\mathrm{P}_{50}$ (pressão parcial de oxigênio em que ocorre a saturação de $50 \%$ das hemoglobinas) não se relacionou à fadiga (Stone et al., 2005).

Além da hemoglobina, em alguns estudos com pacientes com câncer observouse correlação negativa entre fadiga e outros elementos hematológicos como hematócrito, plaquetas, tamanho das células vermelhas (RDW - red cell distribution width), número de leucócitos e eritropoetina (Stone et al., 2005; Morant et al., 1993). Poucos estudos não observaram a correlação entre fadiga e hemoglobina e fadiga e células brancas (Brown, McMillan, Milroy, 2005; Dimeo et al., 2004).

Outros marcadores biológicos estão sendo investigados. Estudo de 1993 (n=61) não encontrou correlação entre fadiga e cortisol, plaquetas, sódio sérico, albumina e hormônios da tireóide (Morant et al., 1993). Estudo mais recente, com pacientes em tratamento quimioterápico por neoplasia de mama $(n=22)$, mostrou que a diminuição nos níveis de cortisol, melatonina ou serotonina e aumento nos níveis de bilirrubina, estavam associados à piora da fadiga (Payne et al., 2006). Interleucinas 1b, 2 e 6 não apresentaram correlação estatisticamente significante com fadiga (Gélinas, Fillion, 2004; Morant et al., 1993).

Estudo com 28 pacientes com câncer sem tratamento mostrou relação negativa entre fadiga e sódio e fadiga e albumina, e relação positiva entre fadiga e proteína reativa C (Stone et al., 2005). Nesse mesmo estudo, fadiga não se correlacionou com fosfatase alcalina, bilirrubina, cálcio, creatinina, fosfato, potássio e uréia (Stone et al., 2005). Estudo com 228 pacientes em tratamento para leucemia e linfoma também identificou associação entre albumina e fadiga (Wang et al., 2002). A relação positiva entre fadiga e proteína reativa $\mathrm{C}$ também foi encontrada em estudo com 38 pacientes 
com câncer de pulmão avançado, mas não se identificou relação entre fadiga e albumina e creatinina (Brown, McMillan, Milroy, 2005). Estudo com 31 pacientes com câncer não encontrou correlação entre fadiga e proteína reativa $C$, fator de necrose tumoral, ferritina, mas encontrou correlação entre fadiga e ferro sérico (Morant et al., 1993).

Em estudo com 71 pacientes com tumores hematológicos, observou-se que a fadiga não se associou a indicadores de função hepática ou tireoideana e nem a citocinas, albumina, proteína reativa C, interleucinas 1 e 6 (Dimeo et al., 2004). Outro estudo, envolvendo 180 homens com diferentes cânceres, observou associação entre fadiga e hemoglobina e sódio, e não observou relação entre fadiga e albumina, creatinina, cálcio, potássio e bilirrubina (Hwang et al., 2003).

A administração de melatonina associada a cuidados de suporte reduziu a prevalência de fadiga, comparada ao grupo que recebeu apenas cuidados de suporte (Lissoni, 2002).

Um fator que pode estar relacionado à fadiga é a exposição ao sol. Estudo com 63 mulheres com câncer de mama recém-diagnósticas, recebendo tratamento neoadjuvante, observou correlação negativa entre fadiga e exposição solar, isto é, as pacientes que se expuseram menos à luz intensa sentiram-se mais fatigadas (Liu et al., 2005). Nesse estudo não se mensuraram fatores como melatonina, serotonina, entre outros, mas a hipótese foi de que pacientes que se expõem menos à luz, apresentam mais dificuldades de ter um sono repousante e pior humor, o que pode levar à fadiga (Liu et al., 2005).

\section{Fadiga e o Câncer}

Existem hipóteses de que locais de tumores e tumores mais avançados apresentam maior propensão à fadiga. A intensidade de fadiga foi menor naqueles com 
câncer de próstata e mais intensa naqueles com câncer de pulmão e cabeça e pescoço, todos recebendo radioterapia (Hickok et al., 2005). Fadiga em pacientes com câncer de pulmão também foi mais intensa que a fadiga de pacientes com câncer colo-retal ou câncer de ovário (Holzner et al., 2002). Pacientes com metástase óssea, o que indica câncer avançado, apresentaram mais fadiga que sobreviventes de linfoma tipo Hodgkin (Kaasa et al., 1999). E quando se comparou a fadiga de pacientes no último mês de vida com a de pacientes não vivendo esse mesmo momento, a intensidade da fadiga foi mais alta nos terminais (Kaasa et al., 1999). O estadiamento do câncer se relacionou à fadiga em homens ( $n=180)$ com diferentes sítios de câncer (Hwang et al., 2003).

Não só o local do tumor mas também o seu tamanho pode apresentar relação com presença e intensidade de sintomas, incluindo fadiga, conforme observado em estudo envolvendo pacientes com câncer renal (Schips et al., 2003).

Alguns estudos contradizem essa relação entre sítio, estadiamento do tumor e intensidade de fadiga. Estudo em doentes em cuidados paliativos, o sítio do tumor e o estadiamento não se relacionaram com fadiga (Stone et al., 1999); em pacientes com diferentes tumores hematológicos não se observou relação entre o tipo de tumor e fadiga (Dimeo et al., 2004); em pacientes com linfoma, também não houve correlação entre estadiamento da doença e fadiga (Knobel et al., 2001); e entre pacientes com câncer de pulmão avançado, não se observou correlação entre fadiga e presença de doença metastática (Brown, McMillan, Milroy, 2005). Em mulheres em tratamento quimioterápico para câncer de mama (n=63), o aumento da intensidade da fadiga não se relacionou ao estadiamento do tumor (Liu et al., 2005). 


\section{Fadiga e os Tratamentos para o Câncer}

Quimioterapia e a radioterapia oncológicas são das principais causas de fadiga. A citotoxicidade dos tratamentos quimioterápicos e a necrose de tecido gerada pelas sessões de radioterapia exigem maior gasto energético do organismo para eliminar e repor tais células. Os efeitos adversos causados por esses tratamentos, como náuseas e vômitos, anemia e supressão imunológica, entre outros, prejudicam o transporte de oxigênio e dióxido de carbono, assim como o estado nutricional e de hidratação, agravando a manifestação do sintoma (Winningham, 1996).

De modo geral, a fadiga piora com o decorrer do tratamento e com a associação de tratamentos, variando a evolução da progressão do sintoma e o tempo de sua recuperação.

Em estudo com 157 mulheres com câncer de mama recebendo quimioterapia adjuvante foi possível observar, ao longo do tratamento, aumento no número de mulheres fatigadas, aumento na intensidade do sintoma e prejuízo na funcionalidade (De Jong et al., 2004). O aumento significativo da fadiga ao longo do tratamento quimioterápico também foi observado entre 63 pacientes com câncer de mama (Liu et al., 2005) e, em estudo com 180 homens com diferentes cânceres, observou-se associação entre fadiga e tratamento ativo para o câncer (Hwang et al., 2003). Já em estudo em que a quimioterapia tinha propósito paliativo, o tratamento das mulheres com câncer de mama (n=300) não piorou a fadiga e nem a aliviou, embora tenha aliviado outros sintomas como dor e dispnéia (Geels et al., 2000).

O tipo de droga utilizada para o tratamento quimioterápico não se associou à fadiga (Liu et al., 2005). No entanto, observou-se que, quando o tratamento quimioterápico foi combinado ao tratamento radioterápico ou outras modalidades de 
tratamentos anti-câncer, a fadiga se intensificou (Young, White, 2006; De Jong et al., 2004).

Fadiga é também freqüente nos tratamentos radioterápicos. Doentes em tratamento radioterápico $(\mathrm{n}=27)$ referem que a fadiga piorou na primeira e segunda semanas de tratamento, principalmente no final de tarde e à noite, permanecendo estável até o final da terapia (Molassiotis, Chan, 2004). Homens com câncer de próstata apresentaram piora progressiva da fadiga durante tratamento radioterápico, independentemente da dose e frações de irradiação (Truong et al., 2006). De 372 pacientes com diferentes cânceres, 57\% apresentaram algum grau de fadiga antes do início do tratamento e $70 \%$ dos que não sentiram fadiga no início a referiram durante a radioterapia (Hickok et al., 2005). Resultado semelhante foi observado em estudo com 60 mulheres em radioterapia para câncer de útero. Houve aumento significativo da fadiga após o início do tratamento, e ela se manteve até o seu término (Ahlberg, Ekman, Gaston-Johansson, 2005). Um estudo apenas relatou que não houve aumento da fadiga durante o tratamento radioterápico de pacientes com câncer de pulmão $(n=45)$ em tratamento ambulatorial (Beach et al., 2001).

É possível que novas técnicas de radioterapia possam ser menos indutoras de fadiga. Dezoito por cento das mulheres com câncer de mama $(\mathrm{n}=90)$ submetidas à radioterapia com técnica diferenciada (prone accelerated intensity modulated) referiram fadiga após término do tratamento (Formenti et al., 2007), índice inferior aos descritos para radioterapia clássica (Hickok et al., 1996; Smets et al., 1996).

Interessante observar que a fadiga como efeito indesejável dos tratamentos empregados no tratamento do câncer não melhora após a finalização da terapia. Isso pôde ser observado por estudos com mulheres tratadas para câncer de mama (n=69 e $\mathrm{n}=176)$ e em pacientes com tumores hematológicos $(\mathrm{n}=71)$ que referiram que a fadiga 
não se associou ao tempo desde o término do tratamento (Goldstein et al., 2006; Young, White, 2006; Dimeo et al., 2004).

A relação entre o tipo de cirurgia e fadiga não é clara. Estudo com 150 mulheres tratadas e sem evidência de câncer de mama e estudo com 176 mulheres pós-tratamento de câncer de mama sugeriram que a intensidade da fadiga não teve relação com o tipo de cirurgia, nem com o esquema de tratamento realizado (Goldstein et al., 2006; Servaes, Verhagen, Bleijenberg, 2002b). No entanto, em 157 mulheres em tratamento para o câncer de mama, a fadiga das pacientes submetidas às grandes cirurgias, como mastectomia, foi mais intensa que naquelas submetidas às cirurgias menores, como quadrantectomia (De Jong et al., 2004).

Outra questão relacionada à fadiga e cirurgia para o câncer refere-se ao período de internação e tempo após cirurgia. Em pacientes submetidos à cirurgia para extirpação do câncer $(n=40)$ a fadiga foi mais intensa naqueles com maior período de internação (Galloway, Graydon, 1996). E idosos com menos de 40 dias da cirurgia apresentaram mais fadiga que os idosos com maior tempo de recuperação da cirurgia (Given et al., 2001). Fadiga, dor, alteração da auto-imagem e insônia foram os quatro sintomas mais prevalentes, intensos e responsáveis por grande sofrimento em mulheres idosas submetidas à cirurgia de câncer de mama (Kenefick, 2006).

Estudo que explorou a relação entre hormonioterapia e fadiga observou que homens com câncer de próstata, recebendo tratamento hormonal, apresentaram piora da fadiga após 6 meses de tratamento (Pirl et al., 2007). Esse resultado reforça o conhecimento de que os tratamentos oncológicos (cirurgias, quimio, radio e hormonioterapia) causam fadiga. 


\section{Fadiga, Co-morbidades e medicamentos}

O paciente com câncer, em geral, também apresenta co-morbidades e faz uso de diversos outros medicamentos além dos anti-neoplásicos, o que parece agravar fadiga.

Estudo com 839 idosos com câncer observou que aqueles que tinham 3 doenças ou mais em co-morbidade referiram mais fadiga que os que tinham duas doenças ou menos em co-morbidade (Given et al., 2001). Entre pacientes tratados para linfoma Hodgkin, aqueles com problemas cardíacos ou hipotireoidismo não apresentaram associação com fadiga, mas aqueles com disfunção respiratória apresentaram associação com o sintoma (Knobel et al., 2001).

Em estudo envolvendo 38 pacientes com câncer de pulmão avançado, não se observou correlação entre fadiga e uso e dose de opióides ou antiinflamatórios, hormonais ou não (Brown, McMillan, Milroy, 2005). Em pacientes com diferentes cânceres em fase avançada, a dose de opióides e antiinflamatórios também não se associaram à fadiga (Stone et al., 1999). Já em outro estudo com 228 pacientes em tratamento para leucemia e linfoma, o uso de opióides se associou à fadiga em (Wang et al., 2002), assim como no estudo com homens (n=180) com diferentes cânceres (Hwang et al., 2003). A fadiga de mulheres sobreviventes de câncer de mama (n=69) não se associou ao tratamento de reposição hormonal (Young, White, 2006).

\subsection{Fadiga e Fatores Preditivos}

Dentre o grande número de fatores relacionados à fadiga no paciente com câncer, estudos buscam identificar aqueles com maior probabilidade de ser causa e

agravante do sintoma. Esses fatores são denominados de fatores preditivos independentes e existem dois métodos diferentes para sua identificação. Um deles é a 
regressão múltipla, ou linear, que inclui a fadiga (variável dependente) em escala contínua e os fatores de risco (variáveis independentes) em escalas ordinais ou contínuas. O outro método de se identificar fatores preditivos é a regressão logística, que inclui a fadiga (variável dependente) de modo dicotômico e os fatores de risco (variáveis independentes) em qualquer escala (nominal, ordinal ou contínua). Já existem publicações que utilizaram ambos os métodos e elas estão descritas a seguir.

Em estudo de regressão múltipla com 95 pacientes com câncer avançado em diversas localidades, observou-se que dor e dispnéia explicaram $30 \%$ da variação do escore de fadiga (Stone et al. 1999). Em outro estudo, com 100 pacientes com câncer avançado, a análise de regressão múltipla mostrou que perda de apetite, depressão, dispnéia, uso de opióides e o nível de hemoglobina explicaram 38\% da variação do escore de fadiga (Echteld et al., 2007). Outro estudo de regressão múltipla especificamente com pacientes com câncer avançado de pulmão $(n=38)$ encontrou que a capacidade funcional, sensação de fraqueza e escores de depressão e ansiedade explicaram 57\% da variação do escore de fadiga (Brown, McMillan, Milroy, 2005). Em pacientes com mieloma múltiplo, o comprometimento ósseo, associado a elevado cálcio sérico e baixa hemoglobina foram preditores independentes da fadiga (Wisloff et al., 2006).

Capacidade funcional, depressão, sexo feminino, alta escolaridade, e o fato de ter vínculo empregatício e viver sozinho também foram fatores preditivos de fadiga em estudo com 455 pacientes ambulatoriais com diferentes tumores e explicaram $41 \%$ da variação do escore da fadiga (Akechi et al., 1999). Outro estudo envolvendo 354 pacientes com diferentes tumores identificou $32 \%$ de variação do escore de fadiga devido à alteração do sono e falta de vínculo empregatício (Anderson et al., 2003). E 
entre pacientes com tumores hematológicos, $73 \%$ da varição do escore de fadiga pode ser explicado pela depressão e capacidade funcional (Dimeo et al., 2004).

Depressão, sono, atividade física e atribuições relacionadas ao câncer de mama explicaram 52\% da variação do escore de fadiga de mulheres tratadas e sem evidência de câncer de mama (Servaes, Verhagen, Bleijenberg, 2002a). Outro estudo, também envolvendo mulheres sobreviventes de câncer de mama $(n=103)$, identificou que $41 \%$ da variação do escore de fadiga se deu pelas variáveis dor, estressores relacionados ao câncer e enfrentamento ativo e passivo (Gélinas, Fillion, 2004). E entre 69 sobreviventes de câncer de mama, depressão, ansiedade e crenças sobre a capacidade de desempenhar atividades explicaram 64\% da variação do escores de fadiga (Young, White, 2006).

Em 60 mulheres com câncer uterino, no início do tratamento radioterápico, as variáveis ansiedade, funcionalidade física e capacidade de desempenhar atividades cotidianas explicaram $69 \%$ da variação da fadiga e, após o tratamento, $53 \%$ da variação dos escores de fadiga foi explicada pela intensidade da fadiga no início do tratamento (Ahlberg, Ekman, Gaston-Johansson, 2005).

Do descrito nota-se que, apesar de muitos estudos envolverem doentes com câncer em diversas localizações, o local do tumor não foi fator preditivo e isso chamou a atenção. Estudos que investiguem o sítio do tumor como fator de risco e preditivo ou que se concentrem em doentes com único local de doença são importantes. Não se encontrou estudo sobre doentes com câncer colo-retal.

Menor quantidade de estudos utilizou a regressão logística para identificar fatores preditivos para fadiga. A regressão logística é a análise na qual a variável dependente (fadiga) é categorizada de modo dicotômico (presente e ausente) e as 
variáveis independentes (fatores de risco) são categorizadas em qualquer escala (nominal, ordinal ou contínua).

Estudando-se 170 sobreviventes de diversos tumores ósseos e de partes moles encontrou-se que os fatores preditivos de fadiga moderada/intensa foram os sguintes: o número de complicações pós-tratamento para o câncer, a maior somatização, o menor otimismo, o pior estado geral de saúde e a menor aceitação da doença. Para fadiga intensa os fatores preditivos foram número de complicações pós-tratamento para o câncer, maior somatização e menor otimismo (Servaes et al., 2003). Entre pacientes com leucemia aguda $(n=57)$, a náusea foi fator preditivo e aumentou em 24 vezes a chance de o paciente ter fadiga intensa (Wang et al., 2002). Entre pacientes com linfoma não-Hodgkin $(\mathrm{n}=122)$, a náusea e nível de albumina foram fatores predivos e aumentaram em 5 e 4 vezes, respectivamente, a chance do doente apresentar fadiga intensa (Wang et al., 2002). Em pacientes masculinos com diferentes cânceres $(n=180)$, pacientes com tristeza, tontura, dor, perda de apetite, irritabilidade e dispnéia apresentaram $88 \%$ de probabilidade de ter fadiga (Hwang et al., 2003).

Conforme síntese apresentada, observou-se que ainda não há informação suficiente sobre os principais fatores de risco para a fadiga e, por não se conhecer esses fatores, faltam estratégias efetivas para o diagnóstico e controle da fadiga. Nota-se ainda a ausência de estudos específicos em doentes com câncer colo-retal, que é o segundo mais freqüente no mundo, considerando-se ambos os sexos. $\mathrm{O}$ presente estudo identificou fatores de risco e preditivos de fadiga em pacientes com câncer colo-retal. 


\section{OBJETIVO}

O presente estudo teve o objetivo de identificar os fatores de risco e os fatores preditivos de fadiga em pacientes com câncer de cólon e reto. 


\section{MÉTODO}

\subsection{Tipo de estudo e Amostra}

Trata-se de estudo transversal e preditivo. Constituiu-se uma amostra nãoprobabilística de indivíduos adultos com câncer colo-retal em acompanhamento ambulatorial. Participaram 157 indivíduos que atenderam aos seguintes critérios de inclusão: ter câncer primário de cólon ou reto, idade igual ou superior a 18 anos e capacidade de comunicação e compreensão preservadas.

\subsection{Local e período}

Os dados foram coletados no período de julho de 2006 a julho de 2007, em quatro serviços de oncologia do município de São Paulo. A intenção foi alcançar o tamanho da amostra necessária para a análise de regressão e aumentar a validade externa.

- Clínica de Oncologia Médica. Trata-se de um serviço privado, que oferece consultas médicas, psicológicas e tratamentos sistêmicos (quimioterapia, imunoterapia e hormonioterapia, entre outras) a pacientes oncológicos. Atende, em média, 600 pacientes por mês em consultas médicas e realiza 350 
quimioterapias por mês. Os dados foram coletados no período de julho a novembro de 2006 e a participação dos doentes dessa clínica na amostra correspondeu a $15,3 \%$ dos avaliados $(n=24)$.

- Ambulatório de Oncologia do Hospital Brigadeiro. Trata-se de um serviço público que oferece aproximadamente 400 consultas médicas por mês. Quando indicado, os oncologistas encaminham os pacientes para tratamentos em outras unidades do próprio hospital ou para unidade de internação. Os dados foram coletados no período de julho a dezembro de 2006 e a participação dos doentes dessa instituição na amostra correspondeu a 23,6\% dos pacientes $(n=37)$.

- Clínica de Oncologia do Centro Médico do Hospital Santa Helena. Trata-se de um serviço privado que atende aproximadamente 800 pacientes em consultas e 480 pacientes para tratamento antineoplásico por mês. Os dados foram coletados no período de novembro de 2006 a julho de 2007 e a participação dos doentes dessa instituição na amostra correspondeu a 28,0\%, pacientes $(n=44)$.

- Ambulatório de Cirurgia Pélvica do Hospital do Câncer A.C. Camargo. Trata-se de um serviço privado e público que atende cerca de 2.300 pacientes por mês com tumores colo-retais, urológicos e ortopédicos e sarcomas de partes moles. Os dados foram coletados no período de dezembro de 2006 a maio de 2007 e a participação dos doentes dessa instituição na amostra correspondeu a 33,1\% dos pacientes $(n=52)$.

\subsection{Aspectos Éticos}

O estudo foi aprovado pelos Comitês de Ética em Pesquisa da Escola de Enfermagem da USP (Anexo A), do Hospital Brigadeiro (Anexo B), do Hospital Santa 
Helena (Anexo C), e do Hospital do Câncer A.C. Camargo (Anexo D). Mesmo não existindo Comitê de Ética em Pesquisa na Clínica de Oncologia Médica, o projeto de pesquisa foi analisado e aprovado por um dos médicos oncologistas responsáveis pela Clínica.

Os pacientes foram informados sobre os objetivos da pesquisa. Foi-lhes garantido anonimato, liberdade na participação ou não na pesquisa e na interrupção dessa participação a qualquer momento, sem nenhum prejuízo. Os que consentiram assinaram o Termo de Consentimento Livre Esclarecido (Anexo E), em duas vias.

\subsection{Procedimento de coleta de dados}

A equipe de coleta de dados foi composta por 5 coletadores (a pesquisadora, 3 profissionais de enfermagem e 1 estudante de graduação em enfermagem, bolsista de iniciação científica). O procedimento de coleta foi padronizado e todos foram treinados antes de a iniciarem.

O treinamento consistiu de uma aula com áudio-visual que visou a apresentar os instrumentos que seriam utilizados, a como preenchê-los e discutir a importância da fidedignidade dos dados. Os coletadores foram orientados a ler em voz alta as instruções de cada instrumento, a responder o primeiro item de cada questionário com os pacientes, a lhes explicar termos que verbalizassem ser desconhecido, demonstrar imparcialidade na leitura dos itens para não induzir respostas, e serem imparciais na escolha dos pacientes abordando-os com tranqüilidade e sem pressão para que respondessem aos instrumentos rapidamente. Foram orientados a checar o preenchimento dos instrumentos para evitar itens em branco ou com dupla resposta. Toda a coleta foi supervisionada pela pesquisadora. 
Os pacientes foram encaminhados pelos oncologistas dos serviços aos coletadores e estes, após verificar se atendiam aos critérios de inclusão, entrevistavamnos. Após a assinatura do Termo de Consentimento Livre e Esclarecido, efetuou-se o preenchimento da Ficha de Identificação (Anexo F) por meio de entrevista ou, caso o paciente desejasse, poderia preenchê-la sozinho. Em seguida, os pacientes foram orientados a preencher os instrumentos de auto-relato: Escala de Fadiga de Piperrevisada (Anexo G) e Inventário de Depressão de Beck (Anexo H). Quando o paciente solicitou ajuda, o coletador de dados o auxiliou no preenchimento do instrumento, lendo os itens em voz alta e explicando algum termo desconhecido, conforme treinamento prévio. O coletador acompanhou o preenchimento de todos os instrumentos e, ao final, verificava se havia itens em branco ou rasurados e, se houvesse, solicitava ao paciente que os preenchesse.

\subsection{Instrumentos: características e propriedades psicométricas}

\subsubsection{Ficha de Identificação}

A Ficha de Identificação (Anexo F), utilizada para coletar a maior parte das informações sobre as variáveis independentes do presente estudo, foi composta por questões referentes aos dados sócio-demográficos (nome, sexo, idade, estado civil, cor da pele, escolaridade, ocupação, renda familiar mensal, tipo de serviço de saúde onde recebe atendimento para o tratamento do câncer), dados referentes ao câncer e seu tratamento (estadiamento clínico do câncer, tratamento atual e realização de cirurgia), dados clínicos e de sintomas (Índice de Massa Corporal - IMC, nível de hemoglobina, presença de colostomia, doenças em co-morbidade, uso de medicamentos, presença e intensidade de dor, de prejuízo do sono e capacidade funcional - performance status). 
Os dados que o paciente não soube informar foram buscados no prontuário do paciente e com o médico.

\subsubsection{Escala de Fadiga de Piper - revisada: características e validação para a língua portuguesa}

A Escala de Fadiga de Piper-revisada (Anexo G) foi utilizada para avaliar a fadiga, variável dependente do presente estudo. Como não havia validação em língua portuguesa, houve necessidade de fazê-la durante o desenvolvimento deste estudo, o que foi autorizado pela autora principal (Anexo I).

A validação consistiu da tradução e retrotradução, de análises de confiabilidade (consistência interna e teste-reteste) e validade (análise fatorial, validade convergente, divergente, concorrente e discriminante). As propriedades psicométricas testadas foram consideradas adequadas para uso na população oncológica brasileira (Mota, Pimenta, Piper, 2008).

A versão brasileira da Escala de Fadiga de Piper - revisada é composta por 22 itens distribuídos em três dimensões, conforme resultado da análise fatorial: dimensão comportamental (itens 2 a 7 ), dimensão afetiva (itens 8 a 12 ) e dimensão sensorial/psicológica (itens 13 a 23). Cada item é apresentado em escala numérica que varia de 0 a 10 . O escore total é calculado pela média de todos os itens do instrumento (itens 2 a 23) e os escores das dimensões são calculados pela média dos itens contidos em cada dimensão. O escore total e das dimensões são descritos numa escala numérica de 0 a 10, sendo que quanto maior o resultado, maior a fadiga.

A dimensão comportamental, que corresponde aos itens 02 ao 07 da escala, avalia componentes primariamente relacionados a capacidade funcional que podem ser prejudicados pela fadiga, incluindo questões pessoais (itens 02 e 06), atividades sociais 
(itens 03 e 04) e relacionamento sexual (item 05). Essa dimensão também apresenta um item (item 07) que avalia a intensidade global do fenômeno no momento da entrevista.

A dimensão afetiva, que corresponde aos itens 08 ao 12, busca identificar a interpretação ou o significado atribuído à fadiga. As âncoras dos itens são agradável/desagradável, aceitável/inaceitável, protetora/destruidora, positiva/negativa e normal/anormal.

A dimensão sensorial/psicológica, que corresponde aos itens 13 ao 23, reúne componentes de auto-percepção, emocionais e cognitivos na presença da fadiga. Os itens referentes à auto-percepção (itens 13 a 17) permitem ao indivíduo expressar como ele se sente, utilizando termos cotidianos: forte/fraco, acordado/sonolento, com vida/apático, com vigor/cansado, com energia/sem energia. Os itens referentes à emoção (itens 18 a 20) relacionam-se a sentimentos de ansiedade e depressão. E os itens referentes aos aspectos cognitivos (itens 21 a 23) investigam as funções mentais de memória, concentração e organização de pensamentos, que podem sofrer impacto pela fadiga.

Além dos 22 itens fechados, existem 5 questões abertas adicionais (itens número 1 e 24 a 27) que não são usadas para o cálculo do escore do instrumento. A questão 1 avalia a duração da fadiga; a questão 24 avalia o que o indivíduo acredita causar a fadiga; a questão 25 avalia o que o indivíduo faz para aliviar a fadiga; a questão 26 permite ao indivíduo relatar qualquer outro aspecto sobre a fadiga que ele considere importante; e a questão 27 avalia a presença de outros sintomas e, caso a resposta seja positiva, qual(is) seria(m). As questões abertas permitem obter dados adicionais sobre a fadiga, enriquecendo a qualidade das informações.

Para a validação da Escala de Fadiga de Piper foram entrevistados 584 pacientes oncológicos (157 com câncer colo-retal), 184 cuidadores e 189 estudantes de graduação 
em enfermagem. O método e os resultados estão detalhados no artigo "Measurement of fatigue in Brazilian cancer patients, caregivers and nursing students: A validation study of the Piper Fatigue Scale - Revised”, enviado para publicação (Mota, Pimenta, Piper, 2008).

A análise fatorial identificou três fatores e cada item obteve carga superior a 0,350 em seus respectivos domínios. A validade convergente (correlação entre fadiga e depressão; $\mathrm{r}=0,550, \mathrm{p}<0,001$ ), divergente (correlação entre fadiga e performance status; $\mathrm{r}=0,298, \mathrm{p}<0,001$ ) e concorrente (correlação entre Escala de Fadiga de Piper-revisada e Pictograma de Fadiga; r=0,401, p<0,001) mostraram-se adequadas e satisfatórias. A Escala foi capaz de discriminar os estudantes de enfermagem dos pacientes e acompanhantes, mas não os pacientes dos seus acompanhantes.

A consistência interna foi muito boa visto que o alfa de Cronbach para escala total foi 0,94 e para as subescalas variou entre 0,84 e 0,94 . O teste-reteste mostrou que o instrumento foi estável em situações em que a fadiga não se alterou (Coeficiente de correlação de Pearson= 0,600, $\mathrm{p}<0,001)$.

Um teste adicional foi realizado com os dados dos doentes com câncer coloretal envolvidos neste estudo. Buscou-se avaliar a correlação entre a apreciação da intensidade da fadiga numa escala numérica (0 a 10) e a Escala de Fadiga de Piperrevisada (0 a 10). A escala numérica foi representada pelo item 07 da Escala de Fadiga de Piper-revisada e o escore da Escala de Fadiga de Piper foi recalculado excluindo-se o item 07, isto é, fazendo-se a média dos demais 21 itens da escala. Observou-se resultado muito bom, pois a correlação, testada pelo teste de Pearson, foi $r=0,748(\mathrm{p}<0,001)$. 


\subsubsection{Escala de Karnofsky}

A capacidade funcional foi avaliada pela Escala de Karnofsky (Anexo J), desenvolvida por David A. Karnofsky e Joseph H. Burchenal (Karnofsky, Burchenal, 1949), que busca medir a capacidade funcional, ou seja, a capacidade de desempenhar as atividades de vida diária. Esta foi uma variável independente deste estudo. Na oncologia, esse tipo de medida é amplamente utilizado, entre outras razões, para determinar se o paciente pode receber quimioterapia e se é necessário ajuste de dose (Schag, Heinrich, Ganz, 1984). O seu escore varia de 100\%, que indica saúde plena, a $0 \%$, que indica morte.

Apesar de seu amplo uso, não se conhece estudo que tenha testado suas propriedades psicométricas na cultura brasileira. No presente estudo testou-se a validade divergente da Escala de Karnofsky (correlação entre performance status e fadiga) e identificou-se uma correlação negativa fraca porém estatisticamente significante ( $\mathrm{r}=-$ $0,278 ; \mathrm{p}=0,014)$.

\subsubsection{Inventário de Depressão de Beck}

O Inventário de Depressão de Beck (Anexo H) foi utilizado para avaliar estado depressivo, variável independente deste estudo. Foi validado para a língua portuguesa por Gorenstein e Andrade (1996) e apresentou consistência interna em indivíduos brasileiros sem diagnóstico prévio de depressão (alfa de Cronbach igual a 0,81) semelhante à encontrada no presente estudo (alfa de Cronbach igual a 0,83). É uma escala composta por 21 itens, com afirmações graduadas de 0 a 3, que refletem a intensidade do sintoma, sendo o escore mínimo 0 e o máximo, 63. As categorias avaliadas nos 21 itens são: 1. humor deprimido, 2. pessimismo, 3. sensação de fracasso, 4. perda de satisfação, 5. sentimentos de culpa, 6. sensação de punição, 7. auto-rancor 
(ódio, aversão), 8. auto-acusação, 9. ideação suicida, 10. choro, 11. irritabilidade, 12. isolamento social, 13. indecisão, 14. imagem corporal alterada, 15. inibição para o trabalho, 16. anormalidades do sono, 17. fatigamento, 18. perda de apetite, 19. perda de peso, 20. preocupações somáticas e 21. perda de libido.

\subsubsection{Categorias das variáveis e pontos de corte}

\section{Variável Dependente}

A fadiga, variável dependente do estudo, foi incluída nas análises como medida nominal (sem fadiga e com fadiga) e contínua (escala numérica de 0 a 10), conforme apresentado no Quadro 1.

Quadro 1- Categorização da variável dependente (fadiga). São Paulo, 2007.

\begin{tabular}{|c|c|c|}
\hline $\begin{array}{c}\text { Variável } \\
\text { Dependente }\end{array}$ & Categorias & Tipo de variável \\
\hline \multirow{2}{*}{$\begin{array}{c}\text { FADIGA } \\
\text { (Escala de Fadiga de } \\
\text { Piper - revisada) }\end{array}$} & Sem fadiga (fadiga <4) & Nominal \\
\cline { 2 - 3 } & Com fadiga (fadiga $\geq 4)$ & Contínua \\
\hline
\end{tabular}

Para determinar o ponto de corte da fadiga, observaram-se dois critérios: a distribuição dos escores da versão brasileira da Escala de Fadiga de Piper-revisada em percentis (para todos os pacientes, $\mathrm{n}=584$ ) e o consenso sobre fadiga relacionada ao câncer do National Comprehensive Cancer Network (2007). Na distribuição dos escores em percentis identificou-se o escore 3,1 no percentil 25 , o escore 4,6 no percentil 50 e o escore 6,0 no percentil 75. O consenso do National Comprehensive Cancer Network sugere que, em escala numérica de 0 a 10, escore de 1 a 3 seja considerado fadiga leve, 
4 a 6 seja fadiga moderada, e 7 a 10 seja fadiga intensa. Reunindo esses critérios, adotou-se no presente estudo a seguinte classificação:

- $\quad$ escore $0=$ ausência de fadiga

- escore maior que 0 e menor que 4 = fadiga leve

- escore igual a 4 e menor que 6 = fadiga moderada

- escore igual ou maior a 6 até $10=$ fadiga intensa

A partir dessa classificação estabeleceu-se o ponto de corte no escore 4 para discriminar indivíduos fatigados dos não-fatigados. Assim, o grupo de pacientes "com fadiga" correspondeu aos pacientes com fadiga moderada e intensa e o grupo de pacientes "sem fadiga" correspondeu aos pacientes que apresentaram ausência de fadiga e fadiga leve. A opção por adotar-se 4 como ponto de corte visou a que se tivesse maior segurança na identificação de casos com fadiga relevante na clínica.

\section{$\underline{\text { Variáveis Independentes }}$}

Ao todo, foram incluídas no estudo 20 variáveis independentes. Algumas foram categorizadas de mais de uma forma para que suas relações com a fadiga fossem mais bem exploradas.

As variáveis sócio-demográficas foram utilizadas para caracterização da amostra e investigação de suas relações com a variável fadiga, pois as informações sobre tais relações ainda são contraditórias na literatura científica internacional. O modo como foram classificadas está apresentado no Quadro 2. 
Quadro 2- Classificação das variáveis sócio-demográficas. São Paulo, 2007.

\begin{tabular}{|c|c|c|}
\hline Variáveis & Categorias & Tipo de Variável \\
\hline \multicolumn{3}{|c|}{ SÓCIO-DEMOGRÁFICAS } \\
\hline \multirow{2}{*}{ Idade } & 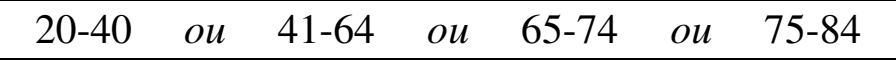 & Ordinal \\
\hline & Idade do doente (variação entre 28 e 84 ) & Contínua \\
\hline Sexo & Feminino ou Masculino & Nominal \\
\hline Estado civil & Casado/amasiado ou Solteiro, divorciado ou viúvo. & Nominal \\
\hline Cor da pele & $\begin{array}{c}\text { Branca ou Não-branca (preta, parda, amarela ou } \\
\text { indígena) }\end{array}$ & Nominal \\
\hline \multirow{2}{*}{ Escolaridade } & $\begin{array}{c}\text { Até } 8 \text { anos de estudo ou 9-12 anos de estudo } \\
\text { ou } 13-26 \text { anos de estudo }\end{array}$ & Ordinal \\
\hline & Escolaridade do doente (variação entre 0 e 26) & Contínua \\
\hline Emprego & $\begin{array}{c}\text { Não trabalha ou Trabalha meio período } \\
\text { ou trabalha período integral }\end{array}$ & Ordinal \\
\hline \multirow{2}{*}{$\begin{array}{c}\text { Renda familiar } \\
\text { mensal (em salários } \\
\text { mínimos) }\end{array}$} & $\begin{array}{c}\text { Até } 10 \text { salários ou de } 10 \text { a } 20 \text { salários } \\
\text { ou mais de } 20 \text { salários }\end{array}$ & Ordinal \\
\hline & Número de salários mínimos (variação entre 1 e 69) & Contínua \\
\hline $\begin{array}{c}\text { Tipo de serviço de } \\
\text { saúde }\end{array}$ & Público ou Privado & Nominal \\
\hline
\end{tabular}

A variável estado civil foi trabalhada para refletir a conceituação de estar ou não vivendo com companheiro, que poderia ser considerado suporte para enfrentamento da doença. A variável cor da pele foi classificada segundo o Instituto Brasileiro de Geografia e Estatística (Oliveira, 2004) em branca, preta, parda, amarela e indígena. Porém, devido ao pequeno número de sujeitos que se auto-avaliaram com cor de pele preta, parda, amarela ou indígena, reuniram-se essas cores e denominou-se de cor de pele não-branca para que fosse possível efetuar testes estatísticos. Escolaridade foi categorizada conforme a divisão nacional de educação, em que 8 anos de estudo corresponde ao ensino fundamental, 12 anos corresponde ao ensino médio e acima de 12, ensino superior. A variável renda foi classificada a partir da distribuição em percentis da renda dos sujeitos do estudo. A renda média foi igual a 11,9 salários mínimos e, considerado o grande desvio padrão (12,5 salários mínimos), classificou-se a renda em três faixas: menor que 10 salários mínimos, entre 10 e 20 salários mínimos e maior que 20 salários mínimos. 
As variáveis da doença, do tratamento, clínicas e de sintomas apresentam grande potencial de serem fatores de risco para fadiga em pacientes com câncer. Por isso, além de terem sido utilizadas para caracterização dos sujeitos do estudo foram testadas para confirmação de suas relações com a variável fadiga. A classificação está apresentada no Quadro 3.

Quadro 3- Classificação das variáveis clínicas, da doença e do tratamento. São Paulo, 2007.

\begin{tabular}{|c|c|c|}
\hline Variáveis & Categorias & $\begin{array}{l}\text { Tipo de } \\
\text { Variável }\end{array}$ \\
\hline \multicolumn{3}{|c|}{ DA DOENÇA E TRATAMENTO } \\
\hline Estadiamento & $\begin{array}{lllllll}\text { I } & o u & \text { II } & o u & \text { III } & o u & \text { IV } \\
\end{array}$ & Ordinal \\
\hline $\begin{array}{l}\text { Tratamento atual } \\
\text { para o câncer }\end{array}$ & $\begin{array}{c}\begin{array}{c}\text { Qtx e/ou Rtx } \\
\text { (hormônioterapia, bisfosfonatos, terapias alvo- } \\
\text { específicas) }\end{array} \\
\begin{array}{c}\text { Outros tratamentos para o câncer } \\
\text { ou } \quad \text { Não faz tratamento para o câncer }\end{array}\end{array}$ & Nominal \\
\hline $\begin{array}{c}\text { Cirurgia para o } \\
\text { cancer }\end{array}$ & $\begin{array}{c}\text { Não fez cirurgia } \text { ou } \begin{array}{c}\text { Fez cirurgia há } 3 \text { meses ou } \\
\text { menos }\end{array} \\
\text { ou } \quad \text { Fez cirurgia há mais de } 3 \text { meses }\end{array}$ & Nominal \\
\hline \multicolumn{3}{|l|}{ CLÍNICAS } \\
\hline \multirow{2}{*}{$\begin{array}{c}\text { Índice de Massa } \\
\text { Corporal } \\
(\text { peso/altura } \\
\end{array}$} & $\begin{array}{c}\text { Magreza ou Peso normal ou Sobrepeso ou } \\
\text { Obesidade ou Obesidade mórbida }\end{array}$ & Ordinal \\
\hline & IMC do doente (variação entre 13 a 37) & Contínua \\
\hline \multirow{2}{*}{$\begin{array}{c}\text { Nível de } \\
\text { hemoglobina }\end{array}$} & \begin{tabular}{cccc} 
Sem anemia & ou & \multicolumn{2}{c}{ Anemia grau 1 } \\
Anemia Grau 2 & ou $\quad$ Anemia Grau 3
\end{tabular} & Ordinal \\
\hline & Nível de hemoglobina (variação entre 9,8 e 17,0 ) & Contínua \\
\hline Co-morbidades & Sim ou Não & Nominal \\
\hline \multirow{3}{*}{ Medicamentos } & $\begin{array}{rrr}\text { Sim } & \text { ou } & \text { Não } \\
\end{array}$ & Nominal \\
\hline & Antidepressivos $=$ Sim ou $\quad$ Não & Nominal \\
\hline & Ansiolíticos = Sim ou Não & Nominal \\
\hline Colostomia & 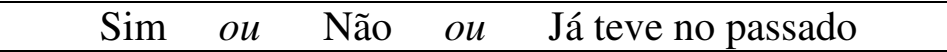 & Nominal \\
\hline \multirow{3}{*}{ Dor } & Não & Nominal \\
\hline & $\operatorname{Sim}(\geq 6) \quad$ ou $\quad$ Não $(<6)$ & Nominal $(R O C)$ \\
\hline & Escala numérica 0 a 10 & Contínua \\
\hline \multirow{3}{*}{ Prejuízo do sono } & Sim ou Não & Nominal \\
\hline & $\operatorname{Sim}(\geq 5) \quad$ ou $\quad$ Não $(<5)$ & Nominal $(R O C)$ \\
\hline & Escala numérica 0 a 10 & Contínua \\
\hline \multirow{3}{*}{$\begin{array}{c}\text { Depressão } \\
\text { (Inventário de } \\
\text { Depressão de } \\
\text { Beck) }\end{array}$} & $\operatorname{Sim}(\geq 13)$ ou $\quad$ Não $(<13)$ & Nominal $(R O C)$ \\
\hline & 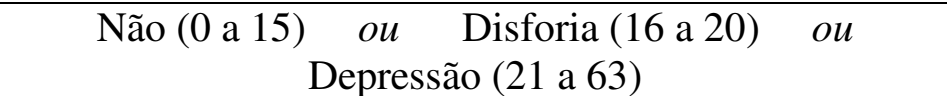 & Ordinal \\
\hline & Escore do IDB do doente (entre 0 e 37) & Contínua \\
\hline \multirow{2}{*}{$\begin{array}{l}\text { Performance } \\
\text { Status (Escala de } \\
\text { Karnofsky) }\end{array}$} & Prejudicada $(\leq 80 \%) \quad$ ou $\quad$ Preservada $(>80 \%)$ & Nominal $(R O C)$ \\
\hline & Performance do doente (variação entre $50 \%$ e $100 \%$ ) & Contínua \\
\hline
\end{tabular}


A classificação e interpretação do IMC obedeceram às recomendações da Sociedade Brasileira de Endocrinologia e Metabolismo (2007): magreza (IMC< 18,5), peso normal $(\mathrm{IMC}=18,5$ a 24,9$)$, sobrepeso $(\mathrm{IMC}=25-29,9)$ e obeso $(\mathrm{IMC}=30$ a 39,9$)$ e obeso mórbido (IMC $\geq 40$ ). A classificação do nível de anemia seguiu as recomendações do National Cancer Institute (Groopman, Itri, 1999): sem anemia (12,0 - 16,0 g/dL para mulheres; 14,0 - 18,0 g/dL para homens); anemia grau 1 (de 10g/dL aos valores normais); anemia grau 2 (de 8,0 a 9,9 g/dL); anemia grau 3 (de 6,5 a 7,9 $\mathrm{g} / \mathrm{dL}$ ) e anemia grau 4 (menor que 6,5 g/dL). A variável co-morbidade expressou a verbalização do paciente de que tinha ou não outras doenças e a variável medicamento visou à identificação de uso de qualquer medicamento além do utilizado para o tratamento do câncer e, mais especificamente, à detecção do uso de antidepressivos e ansiolíticos que poderiam influenciar a intensidade de fadiga. A valorização da colostomia deveu-se à interferência desta na funcionalidade e humor dos pacientes e consequentemente, na fadiga. As variáveis dor, prejuízo do sono e depressão foram valorizadas pois há chance de terem influência sobre a fadiga e assim foram analisadas de diversas formas: sim x não; em escala contínua; e em pontos de corte obtidos pela análise da curva ROC (Receiver Operating Characteristic). A variável depressão foi também analisada segundo os pontos de corte preconizados por Gorenstein e Andrade (1996): ausência de depressão (escores entre 0 e 15), disforia (escore entre 16 e 20), e compatibilidade com depressão (escore superior a 20).

\subsection{Análise dos dados}

Os dados foram organizados no programa Excel® e as análises estatísticas foram realizadas no programa estatístico SPSS v.15 (Statistical Package for Social Science - versão 15.0). 
As variáveis nominais e ordinais foram trabalhadas em números absolutos e percentagens e as variáveis contínuas foram expressas em médias, medianas, desvios padrão, valor mínimo e máximo.

Para caracterização da fadiga buscou-se a prevalência e a gravidade e explorouse a relação entre as dimensões de fadiga e determinadas variáveis de interesse (duração da queixa do sintoma, sexo, idade, sintomas depressivos e capacidade funcional). A comparação entre os escores das subescalas da Escala de Fadiga de Piper-revisada de um mesmo indivíduo foi realizada por meio do teste de análise de variância (ANOVA) para medidas repetidas, e quando se compararam escores de fadiga de indivíduos diferentes realizou-se o teste de ANOVA.

As questões abertas da Escala de Fadiga de Piper foram organizadas em categorias e, posteriormente, trabalhadas em números absolutos e percentagens.

Para identificar os fatores de risco e preditivos de fadiga (objetivo 1), realizou-se análise univariada e multivariada. Tanto para a análise univariada quanto para a análise multivariada, a fadiga foi analisada como variável nominal (ponto de corte $<4$ e $\geq 4$ ). Assumiu-se valor de $\mathrm{p}<0,05$ como estatisticamente significante para todos os testes.

Análises univariadas. Para analisar a relação entre a fadiga e as variáveis nominais e ordinais, utilizou-se o teste de Qui-quadrado ou Razão de Verossimilhança. Para analisar a relação entre a fadiga e as variáveis contínuas, utilizou-se o teste de Mann-Whitney quando a variável independente não apresentou distribuição normal, e o teste T-Student quando a variável independente apresentou distribuição normal. As variáveis que apresentaram associações estatisticamente significantes foram fatores de risco e incluídas na análise de regressão logística.

Análise múltipla - Regressão logística. Antes de inserir as variáveis contínuas no modelo de regressão, estabeleceram-se os pontos de corte por meio da análise da 
curva de $R O C$, atendo-se ao melhor conjunto de sensibilidade, especificidade, área sob a curva $R O C$ e nível de significância da curva $R O C$. Após a identificação dos pontos de corte, as variáveis foram inseridas no modelo utilizando forward stepwise e os resultados da regressão logística foram apresentados em tabela contendo parâmetro estimado, erro padrão, Odds Ratio, Intervalo de Confiança em 95\% e nível de significância. Tais procedimentos permitiram conhecer sensibilidade e a especificidade do modelo resultante da regressão. 


\section{RESULTADOS}

Os resultados estão apresentados em três partes. A primeira refere-se à caracterização da população, a segunda, à caracterização da fadiga e a terceira, à identificação dos fatores de risco (análises univariadas) e fatores preditivos (regressão logística).

\subsection{Caracterização da População}

Participaram do estudo 157 pacientes com câncer colo-retal. A Tabela 1 apresenta a caracterização dos participantes quanto às variáveis sócio-demográficas (idade, sexo, estado civil, cor da pele, escolaridade, emprego, renda familiar mensal e tipo de serviço de atendimento à saúde) e variáveis da doença e seu tratamento (estadiamento clínico do câncer, tratamento atual para o câncer e tempo após realização de cirurgia). 
Tabela 1- Caracterização dos pacientes segundo as variáveis sócio-demográfica, do câncer e tratamento. São Paulo, 2007.

\begin{tabular}{|c|c|c|c|}
\hline & \multicolumn{2}{|c|}{ Pacientes } \\
\hline & & $\mathbf{N}$ & $\%$ \\
\hline \multirow[t]{5}{*}{ Idade $(n=157)$} & $20-40$ & 8 & 5,1 \\
\hline & $41-64$ & 90 & 57,3 \\
\hline & $65-74$ & 40 & 25,5 \\
\hline & 75 ou mais & 19 & 12,1 \\
\hline & 1a; mín-máx & 60 , & $8-84$ \\
\hline
\end{tabular}

$\operatorname{Sexo}(n=157)$

Média (DP); mediana; mín-máx

$60,0( \pm 11,7) ; 60,0 ; 28-84$

Estado civil $(\mathbf{n}=157)$

$\begin{array}{rrr}\text { Masculino } & 85 & 54,1 \\ \text { Feminino } & 72 & 45,9\end{array}$

Casado ou amasiado

$107 \quad 68,2$

Solteiro, divorciado ou viúvo $\quad 50 \quad 31,8$

Cor da pele $(n=157)$

Branco $\quad 102 \quad 65,0$

Não-branco $\quad 55 \quad 35,0$

Escolaridade $(\mathbf{n}=157)$

Até 8 anos $\quad 55 \quad 35,0$

9-12 anos $\quad 42 \quad 26,8$

13 ou mais anos $\quad 60 \quad 28,2$

Média (DP); mediana; mín-máx $\quad 10,7( \pm 5,4) ; 11,0 ; 0$-26

Emprego (n=157)

Não trabalha

Trabalha $(\mathrm{n}=45)$

- Meio período

- Período integral

Renda familiar ( $n=142)$

Até 10 salários mínimos

$\begin{array}{lr}112 & 71,3 \\ 45 & 28,7 \\ 4 & 8,9 \\ 41 & 91,1 \\ & \\ 86 & 60,6 \\ 32 & 22,5 \\ 24 & 16,9 \\ 11,9( \pm 12,5) ; 8,6 ; 1-68,6\end{array}$

Serviço de saúde (n=157)

De 10 a 20 salários mínimos

Mais de 20 salários mínimos

$11,9( \pm 12,5) ; 8,6 ; 1-68,6$

Estadiamento clínico $(n=134)$

Público

44

28,0

Privado

113

72,0

Estadiamento clínico (n-134)

I $\quad 12 \quad 9,0$

II $\quad 29 \quad 21,6$

$\begin{array}{lll} & 33 & 24,6\end{array}$

Tratamento atual para câncer $(n=157)$

$\begin{array}{lll}\text { IV } & 60 & 44,8\end{array}$

Não faz tratamento

$54 \quad 34,4$

Faz tratamento $(\mathrm{n}=103)$

103

65,6

- Quimioterapia e/ou radioterapia

99

96.1

- Outros tratamentos (hormônio,

4

3,9 bisfosfonato, anticorpo monoclonal,

Cirurgia $(\mathrm{n}=156)$

etc)

Não realizou cirurgia

Realizou cirurgia $(n=148)$

$\begin{array}{cr}8 & 5,1 \\ 148 & 94,9 \\ 36 & 23,1 \\ 112 & 71,8 \\ 23,5( \pm 37,0) ; 7,0 ; & 1-240\end{array}$

meses ou menos Média (DP); mediana; mín-máx

$23,5( \pm 37,0) ; 7,0 ; 1-240$ 
Houve discreto predomínio de homens e a maior parte dos avaliados foi de adultos de meia-idade (41-64 anos), casados e brancos. A média e mediana de escolaridade foram em torno de 11 anos, a variação de renda familiar foi grande e a mediana foi de 9 salários mínimos. A maior parte dos sujeitos não trabalhava e recebia atendimento em serviço privado (Tabela 1).

Dos 157 sujeitos, $110(70,1 \%)$ tinham tumor de cólon e 47 (29,9\%) tinham tumor de reto (dado não apresentado em Tabela). Em grande número de sujeitos o estadiamento era avançado (III e IV) e a quase totalidade dos que estavam em tratamento recebia tratamento quimioterápico e/ou radioterápico. Quase a totalidade foi submetida à cirurgia para o câncer e a maior parte foi há mais de 3 meses (Tabela 1).

A Tabela 2 apresenta a caracterização dos participantes quanto as variáveis clínicas Índice de Massa Corporal (IMC), nível de hemoglobina, presença de comorbidades, uso de medicamentos, presença de colostomia, performance status, depressão, presença e intensidade de dor, prejuízo do sono e presença de outros sintomas. 
Tabela 2- Caracterização dos pacientes segundo as variáveis clínicas. São Paulo, 2007.

\begin{tabular}{|c|c|c|}
\hline & \multicolumn{2}{|c|}{ Pacientes } \\
\hline & $\mathbf{N}$ & $\%$ \\
\hline \multicolumn{3}{|l|}{ IMC (n=151) } \\
\hline Baixo peso $(<18,5)$ & 3 & 2,0 \\
\hline Peso normal $(18,5-24,9)$ & 64 & 42,4 \\
\hline Sobrepeso $(25,0-29,9)$ & 63 & 41,7 \\
\hline Obeso $(30,0-39,9)$ & 21 & 13,9 \\
\hline Média (DP); mediana; mín-máx & \multicolumn{2}{|c|}{$25,5( \pm 4,0) ; 25,6 ; 13,6-36,3$} \\
\hline \multicolumn{3}{|l|}{ Nível de hemoglobina $(n=124)$} \\
\hline Sem anemia & 88 & 71,0 \\
\hline Com anemia & 36 & 29,0 \\
\hline - Anemia grau I & 35 & 97,2 \\
\hline - Anemia grau II & 1 & 2,8 \\
\hline Média (DP); mediana; mín-máx & \multicolumn{2}{|c|}{$13,1( \pm 1,7) ; 13,1 ; 9,8-17,0$} \\
\hline \multicolumn{3}{|l|}{ Co-morbidades $(n=157)$} \\
\hline Não & 70 & 44,6 \\
\hline Sim & 87 & 55,4 \\
\hline \multicolumn{3}{|l|}{ Medicamentos $(\mathrm{n}=157)$} \\
\hline Não & 37 & 23,6 \\
\hline $\operatorname{Sim}(n=120)$ & 120 & 76,4 \\
\hline - Antidepressivos & 16 & 13,3 \\
\hline - Ansiolíticos & 16 & 13,3 \\
\hline \multicolumn{3}{|l|}{ Colostomia $(n=155)$} \\
\hline Não & 99 & 63,9 \\
\hline Sim & 56 & 36,1 \\
\hline - No presente & 33 & 58,9 \\
\hline - No passado & 23 & 41,1 \\
\hline \multicolumn{3}{|l|}{ Presença de Dor $(n=157)$} \\
\hline Não & 102 & 65,0 \\
\hline Sim & 55 & 35,0 \\
\hline Média (DP); mediana; mín-máx & \multicolumn{2}{|c|}{$4,6( \pm 2,1) ; 4,0 ; 1-10$} \\
\hline \multicolumn{3}{|l|}{ Presença de Prejuízo do sono $(n=156)$} \\
\hline Não & 96 & 61,5 \\
\hline Sim & 60 & 38,5 \\
\hline Média (DP); mediana; mín-máx & \multicolumn{2}{|c|}{$5,9( \pm 2,4) ; 6,0 ; 1-10$} \\
\hline \multicolumn{3}{|l|}{ Depressão $(n=156)$} \\
\hline Não (0-15) & 132 & 84,6 \\
\hline Disforia (16-20) & 13 & 8,3 \\
\hline Depressão ( $\geq 21)$ & 11 & 7,1 \\
\hline Média (DP); mediana; mín-máx & \multicolumn{2}{|c|}{$9,3( \pm 7,1) ; 9,0 ; 0-37$} \\
\hline Performance Status $(\mathrm{n}=153)$ & & \\
\hline Média (DP); mediana; mín-máx & $86,7($ & $50-100$ \\
\hline
\end{tabular}

Parcela significativa de sujeitos apresentou IMC alterado $(57,6 \%)$ e a maior parte $(71 \%)$ não apresentou alteração nos níveis de hemoglobina. Cerca da metade dos doentes (55\%) tinha doenças em co-morbidade, $20 \%$ fazia uso de antidepressivos e/ou ansiolíticos. A presença de qualquer sintoma, incluindo dor e prejuízo do sono, ocorreu 
em $60 \%$ dos avaliados (n=93). A ocorrência de dor e de prejuízo do sono foi semelhante (em cerca $35 \%$ dos doentes), mas o prejuízo do sono foi maior (mediana=6) que a intensidade da dor (mediana=4). Escores compatíveis com disforia e depressão estiveram presentes em $15,4 \%$ dos sujeitos e aproximadamente um quinto dos participantes mostrou-se parcialmente ou totalmente dependente de terceiros para realização de atividades diárias (Tabela 2).

\subsection{Caracterização da Fadiga}

A Tabela 3 apresenta a distribuição dos pacientes segundo a intensidade de fadiga e a Tabela 4 apresenta o escore médio da fadiga avaliada pela Escala de Fadiga de Piper.

Tabela 3- Distribuição dos pacientes segundo a intensidade da fadiga avaliada pela Escala de Fadiga de Piper - revisada (n=157). São Paulo, 2007.

\begin{tabular}{rlc}
\hline & \multicolumn{2}{c}{$\begin{array}{c}\text { Cólon e Reto } \\
(\mathbf{N}=157)\end{array}$} \\
\hline Escala de Fadiga de Piper & N & \% \\
\hline Ausência $(0)$ & 80 & 50,9 \\
Leve $(1<4)$ & 35 & 22,3 \\
Moderada $(4<6)$ & 27 & 17,2 \\
Intensa $(6-10)$ & 15 & 9,6 \\
\hline
\end{tabular}

Metade dos pacientes não referiu fadiga no momento da entrevista e $26,8 \%$ referiram fadiga de moderada a intensa. As categorias de fadiga leve, moderada e intensa foram estabelecidas conforme distribuição em percentis, descrita no método. 
Tabela 4- Escore médio de fadiga segundo a Escala de Fadiga de Piper ( $\mathrm{n}=77)$. São Paulo, 2007.

\begin{tabular}{ccc}
\hline $\begin{array}{c}\text { Escala de Fadiga de Piper } \\
\text { (Escore possível varia entre 0 e 10) }\end{array}$ & $\begin{array}{c}\text { Pacientes } \\
(\mathbf{n}=\mathbf{1 5 7})\end{array}$ \\
\hline & Total & $4,4( \pm 1,9) ; 4,4 ;$ \\
& & $0,8-9,6$ \\
Escore médio (DP); & Dimensão Comportamental & $4,2( \pm 2,4) ; 4,0 ;$ \\
mediana; mín-máx & Dimensão Afetiva & $4,6( \pm 2,9) ; 4,8 ;$ \\
& Dimensão Sensitiva/Psicológica & $4,4( \pm 2,0) ; 4,5 ;$ \\
& $0,0-9,3$ \\
\hline ANOVA para medidas repetidas (comparação das \\
dimensões)
\end{tabular}

O escore total e o escore das dimensões indicam fadiga moderada. Não houve diferença entre os escores das dimensões, isto é, nenhuma dimensão contribuiu de forma especial para a intensidade de fadiga $(\mathrm{p}=0,576)$.

Levantou-se a hipótese de que algumas características individuais poderiam estar relacionadas com alguma das dimensões da fadiga. Portanto, investigou-se a relação entre as dimensões de fadiga e as variáveis sexo, idade, duração da queixa de fadiga, depressão e capacidade funcional.

A primeira característica a ser explorada em relação às dimensões da fadiga foi o sexo e os resultados estão apresentados na Tabela 5.

Tabela 5- Comparação dos escores de fadiga segundo o sexo (n=77). São Paulo, 2007.

\begin{tabular}{ccccc}
\hline \multicolumn{5}{c}{ Escala de Fadiga de Piper-revisada } \\
\hline SEXO & $\begin{array}{c}\text { Dimensão } \\
\text { comportamental } \\
\text { média (DP); med; } \\
\text { mín-máx }\end{array}$ & $\begin{array}{c}\text { Dimensão afetiva } \\
\text { média (DP); med; } \\
\text { mín-máx }\end{array}$ & $\begin{array}{c}\text { Dimensão sensorial/ } \\
\text { psicológica } \\
\text { média (DP); med; } \\
\text { mín-máx }\end{array}$ & $\begin{array}{c}\text { Significância } \\
\boldsymbol{P}\end{array}$ \\
\hline $\begin{array}{c}\text { Feminino } \\
(\mathbf{n}=\mathbf{4 1})\end{array}$ & $4,3( \pm 2,3) ; 3,7 ;$ & $4,3( \pm 2,8) ; 4,2 ;$ & $4,3( \pm 2,0) ; 4,4 ; 0,0-9,3$ & $\begin{array}{c}\text { ANOVA para } \\
\text { medidas }\end{array}$ \\
Masculino & $0,0-10,0$ & $0,0-10,0$ & & \\
$(\mathbf{n}=\mathbf{3 6})$ & $4,1( \pm 2,4) ; 4,2 ;$ & $5,0( \pm 2,9) ; 4,8 ;$ & $4,5( \pm 2,0) ; 4,5 ; 1,1-9,0$ & repetidas \\
\hline Significância & $0,0-8,7$ & $0,0-10,0$ & & 0,454 \\
$\boldsymbol{P}$ & ANOVA & ANOVA & ANOVA & \\
\hline
\end{tabular}


Comparando-se doentes do mesmo sexo, não se observou diferença entre os escores dimensão da escala de fadiga (Tabela 5). Também não foi observada diferença entre os escores das dimensões comparando-se pacientes do sexo feminino e masculino (Tabela 5).

A relação entre as dimensões de fadiga e idade está apresentada na Tabela 6.

Tabela 6- Comparação dos escores de fadiga segundo a idade (n=77). São Paulo, 2007.

\begin{tabular}{ccccc}
\hline \multicolumn{5}{c}{ Escala de Fadiga de Piper-revisada } \\
\hline IDADE & $\begin{array}{c}\text { Dimensão } \\
\text { comportamental } \\
\text { média (D); med; } \\
\text { mín-máx }\end{array}$ & $\begin{array}{c}\text { Dimensão afetiva } \\
\text { média (DP); med; } \\
\text { mín-máx }\end{array}$ & $\begin{array}{c}\text { Dimensão sensorial/ } \\
\text { Psicológica } \\
\text { média (DP); med; } \\
\text { mín-máx }\end{array}$ & $\begin{array}{c}\text { Significância } \\
\boldsymbol{P}\end{array}$ \\
\hline $\mathbf{2 0 - 4 0}$ & $3,3( \pm 1,7) ; 3,7 ;$ & $4,3( \pm 1,5) ; 4,2 ;$ & $4,0( \pm 1,2) ; 4,4 ; 2,1-$ & \\
$\mathbf{( n = 5 )}$ & $0,8-5,5$ & $2,0-6,0$ & 5,3 & \\
$\mathbf{4 1 - 6 4}$ & $4,7( \pm 2,5) ; 4,3 ;$ & $5,1( \pm 2,8) ; 5,0 ;$ & $4,7( \pm 2,2) ; 4,8 ; 1,1-$ & ANOVA para \\
$(\mathbf{n = 4 7})$ & $0,3-10,0$ & $0,0-10,0$ & 9,3 & medidas \\
$\mathbf{6 5 - 7 4}$ & $3,8( \pm 2,3) ; 3,9 ;$ & $3,7( \pm 3,0) ; 3,8 ;$ & $4,0( \pm 1,9) ; 3,9 ; 0,0-$ & repetidas \\
$(\mathbf{n = 1 5})$ & $0,0-7,8$ & $0,0-8,8$ & 6,6 & 0,900 \\
$\mathbf{7 5 - 8 4}$ & $2,8( \pm 1,1) ; 2,7 ;$ & $3,5( \pm 3,3): 3,8 ;$ & $3,6( \pm 1,0) ; 3,2 ; 2,6-$ & \\
$(\mathbf{n = 1 0})$ & $1,0-4,5$ & $0,0-9,4$ & 5,3 & \\
\hline Significância & ANOVA & ANOVA & ANOVA & \\
$\boldsymbol{P}$ & 0,058 & 0,206 & 0,290 & \\
\hline
\end{tabular}

Comparando-se indivíduos com a mesma faixa etária, não se observou diferença entre as dimensões da escala de fadiga (Tabela 6). Também não foi observada diferença quando se compararam os escores das dimensões segundo as faixas etárias (Tabela 6).

A relação entre as dimensões de fadiga e a duração da queixa da fadiga, avaliada pela questão 1 da Escala de Fadiga de Piper, está apresentada na Tabela 7.

Tabela 7- Comparação dos escores de fadiga segundo a duração do sintoma ( $\mathrm{n}=77)$. São Paulo, 2007.

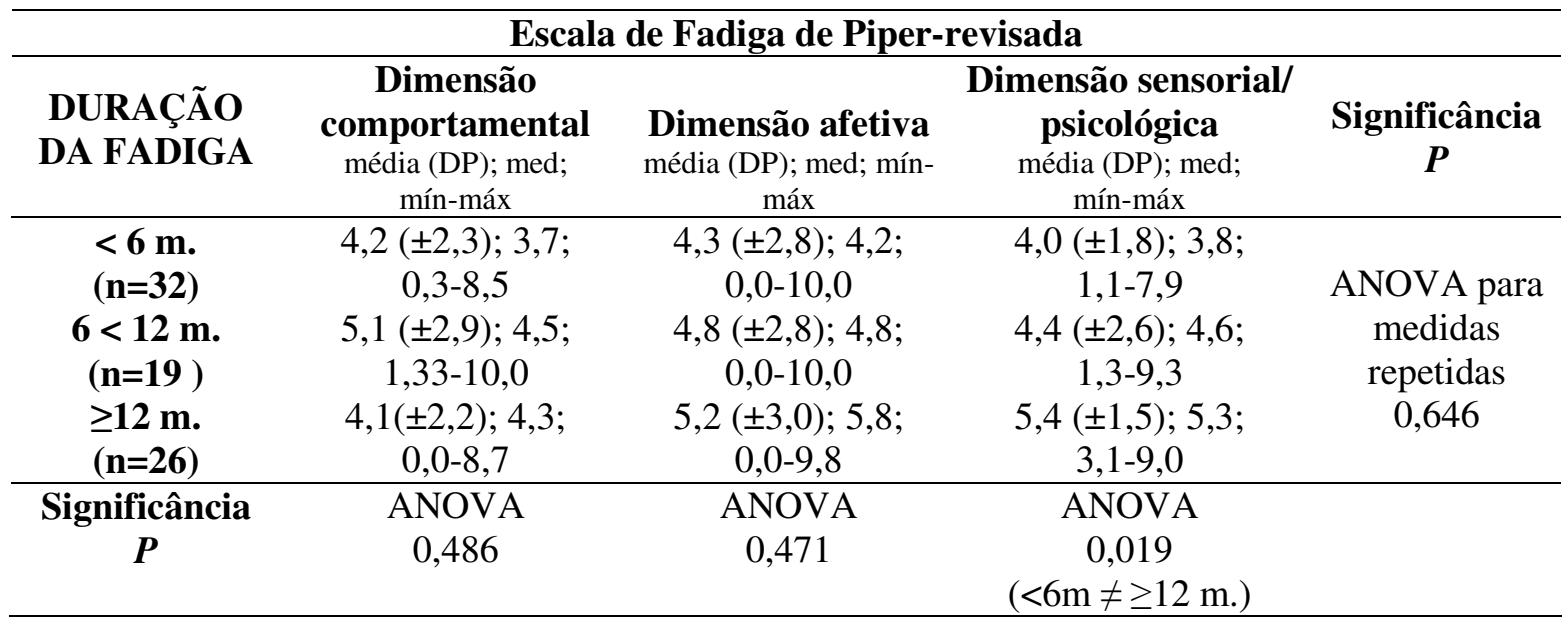


Analisando-se a Tabela 7 nota-se que em indivíduos com a mesma duração da fadiga não houve diferença nos escores de fadiga. No entanto, comparando-se os doentes com fadiga há menos de 6 meses e aqueles com mais de 12 meses, observou-se diferença na intensidade da fadiga na dimensão sensorial/psicológica. A fadiga nessa dimensão foi mais intensa nos pacientes com queixa igual ou superior há 12 meses.

A relação entre as dimensões de fadiga e depressão está apresentada na Tabela 8.

Tabela 8- Comparação dos escores de fadiga segundo a depressão (n=77). São Paulo, 2007.

\begin{tabular}{|c|c|c|c|c|}
\hline \multicolumn{5}{|c|}{ Escala de Fadiga de Piper-revisada } \\
\hline IDB & $\begin{array}{c}\text { Dimensão } \\
\text { comportamental } \\
\text { média (DP); med; } \\
\text { mín-máx }\end{array}$ & $\begin{array}{l}\text { Dimensão afetiva } \\
\text { média (DP); med; } \\
\text { mín-máx }\end{array}$ & $\begin{array}{c}\text { Dimensão sensorial/ } \\
\text { Psicológica } \\
\text { média (DP); med; } \\
\text { mín-máx }\end{array}$ & $\begin{array}{c}\text { Significância } \\
P\end{array}$ \\
\hline $\begin{array}{c}\text { Sem depressão } \\
\quad(n=56)\end{array}$ & $\begin{array}{c}3,9( \pm 2,1) ; 3,8 \\
0,0-8,7\end{array}$ & $\begin{array}{c}4,2( \pm 2,7) ; 4,2 \\
0,0-10,0\end{array}$ & $\begin{array}{c}4,0( \pm 1,8) ; 4,2 ; 0,0- \\
9,0\end{array}$ & ANC \\
\hline $\begin{array}{c}\text { Disforia } \\
(\mathbf{n}=10)\end{array}$ & $\begin{array}{c}4,1( \pm 2,7) ; 3,3 \\
0,3-7,8\end{array}$ & $\begin{array}{c}5,8( \pm 3,6) ; 6,8 \\
0,0-10,0\end{array}$ & $\begin{array}{c}5,0( \pm 2,0) ; 6,0 ; 1,6- \\
7,2\end{array}$ & $\begin{array}{l}\text { medidas } \\
\text { repetidas }\end{array}$ \\
\hline $\begin{array}{c}\text { Depressão } \\
(\mathbf{n}=11)\end{array}$ & $\begin{array}{c}6,0( \pm 2,8) ; 6,2 \\
1,3-10,0\end{array}$ & $\begin{array}{c}5,9( \pm 2,7) ; 6,2 ; \\
2,2-10,0\end{array}$ & $\begin{array}{c}5,6( \pm 2,3) ; 6,0 ; 2,2- \\
9,3\end{array}$ & 0,505 \\
\hline $\begin{array}{c}\text { Significância } \\
P\end{array}$ & $\begin{array}{c}\text { ANOVA } \\
0,022 \\
\text { Sem dep } \neq \text { Dep }\end{array}$ & $\begin{array}{l}\text { ANOVA } \\
0,077\end{array}$ & $\begin{array}{c}\text { ANOVA } \\
0,035 \\
\text { Sem dep } \neq \text { Dep }\end{array}$ & \\
\hline
\end{tabular}

Observou-se que, entre indivíduos com a mesma faixa de escore no Inventário de Depressão de Beck, não houve diferença entre as dimensões (Tabela 8). No entanto, comparando-se os doentes sem depressão e os com depressão, observou-se diferença na intensidade da fadiga nas dimensões comportamental e sensorial/psicológica. A fadiga nessas dimensões foi mais intensa nos pacientes com escore compatível com depressão (Tabela 8).

E, por fim, a relação entre as dimensões de fadiga e a capacidade funcional está apresentada na Tabela 9. 
Tabela 9- Comparação dos escores de fadiga segundo a capacidade funcional $(n=77)$. São Paulo, 2007.

\begin{tabular}{ccccc}
\hline \multicolumn{5}{c}{ Escala de Fadiga de Piper-revisada } \\
\hline IDB & $\begin{array}{c}\text { Dimensão } \\
\text { comportamental } \\
\text { média (DP); med; } \\
\text { mín-máx }\end{array}$ & $\begin{array}{c}\text { Dimensão } \\
\text { afetiva } \\
\text { média (DP); med; } \\
\text { mín-máx }\end{array}$ & $\begin{array}{c}\text { Dimensão sensorial/ } \\
\text { psicológica } \\
\text { média (DP); med; } \\
\text { mín-máx }\end{array}$ & $\begin{array}{c}\text { Significância } \\
\boldsymbol{P}\end{array}$ \\
\hline KPS $>\mathbf{8 0 \%}$ & $3,8( \pm 2,3) ; 3,7$ & $4,0( \pm 2,7) ; 4,0 ;$ & & \\
$(\mathbf{n}=\mathbf{4 1})$ & $0,0-8,3$ & $0,0-10,0$ & $4,0( \pm 1,9) ; 4,2 ; 0,0-7,7$ & $\begin{array}{c}\text { ANOVA para } \\
\text { medidas }\end{array}$ \\
$\mathbf{K P S} \leq \mathbf{8 0 \%}$ & $4,5( \pm 2,4) ; 2,4$ & $5,1( \pm 2,8) ; 5,3 ;$ & & repetidas \\
$(\mathbf{n}=\mathbf{3 6})$ & $0,3-10,0$ & $0,0-10,0$ & $4,7( \pm 2,0) ; 4,5 ; 1,1-9,3$ & 0,639 \\
\hline Significância & ANOVA & ANOVA & ANOVA & \\
$\boldsymbol{P}$ & 0,222 & 0,096 & 0,121 & \\
\hline
\end{tabular}

Comparando-se indivíduos com a mesma capacidade funcional, não se observou diferença entre as dimensões (Tabela 9). Também não se observou diferença entre os escores das dimensões quando se compararam doentes com as diferentes capacidades funcionais (Tabela 9).

Os dados sobre a duração da queixa da fadiga foi investigada a partir da questão 1 da Escala de Fadiga de Piper-revisada. Os resultados foram padronizados em meses e estão apresentados na Tabela 10.

Tabela 10- Distribuição dos pacientes segundo duração da fadiga (n=77). São Paulo, 2007.

\begin{tabular}{lcc}
\hline Duração (em meses) & $\mathbf{N}$ & $\mathbf{\%}$ \\
\hline$<1 \mathrm{~m}$. & 3 & 3,9 \\
$1<3 \mathrm{~m}$. & 14 & 18,2 \\
$3<6 \mathrm{~m}$. & 15 & 19,5 \\
$6<12 \mathrm{~m}$. & 19 & 24,7 \\
$12<60 \mathrm{~m}$ & 20 & 25,9 \\
$\geq 60 \mathrm{~m}$. & 6 & 7,8 \\
\hline Média (DP); mediana; mín-máx & $14,4( \pm 20,7) ; 6,0 ; 0-96$ \\
\hline
\end{tabular}

Observando-se os padrões mais freqüentemente adotados, ao se considerar fadiga crônica aquela com duração superior a 3 meses, observa-se que aproximadamente $80 \%$ dos doentes referiu fadiga crônica (Tabela 10). Ao se considerar fadiga crônica aquela com duração superior há 6 meses, observa-se que 
aproximadamente $60 \%$ referiram fadiga aguda (Tabela 10). Nota-se, ainda, que um terço dos pacientes relatou queixa de fadiga havia 12 meses ou mais (Tabela 10).

A questão 24 da Escala de Fadiga de Piper investigou o que os pacientes acreditavam ser a causa da fadiga. Oitenta e nove respostas foram dadas por 77 pacientes e a distribuição delas está apresentada na Tabela 11.

Tabela 11- Causas para fadiga citadas pelos pacientes (n=77). São Paulo, 2007.

\begin{tabular}{lcc}
\hline \multicolumn{1}{c}{ Causa } & N & \% \\
\hline Tratamentos para o câncer & 26 & 29,3 \\
Excesso de atividades (trabalhos) & 18 & 20,2 \\
lesforço físico & & \\
Aspectos psicológicos & 14 & 15,7 \\
O câncer/ a doença & 11 & 12,4 \\
Falta de ar, falta de sono, pouco & 8 & 9,0 \\
apetite, dores & & \\
Falta de atividade & 4 & 4,5 \\
Idade avançada & 3 & 3,4 \\
Excesso de peso/obesidade & 2 & 2,2 \\
Tudo causa fadiga & 2 & 2,2 \\
Colostomia & 1 & 1,1 \\
Total & $\mathbf{8 9}$ & $\mathbf{1 0 0 , 0}$ \\
\hline
\end{tabular}

Os tratamentos para o câncer (quimioterapia, radioterapia e cirurgia, entre outros) foram as causas para a fadiga mais citadas, seguidas por excesso de atividades/trabalhos e esforço físico, aspectos psicológicos (preocupação, ansiedade, medo, depressão, desânimo, nervoso, tensão e estresse) e a própria doença.

A questão 25 da Escala de Fadiga de Piper questionou aos pacientes o que acreditavam aliviar a sua fadiga. Setenta e cinco pessoas deram 102 respostas e a distribuição delas está apresentada na Tabela 12. 
Tabela 12- Ações que aliviam fadiga relatadas pelos pacientes $(n=75)$. São Paulo, 2007.

\begin{tabular}{lcc}
\hline \multicolumn{1}{c}{ Ações para alívio da fadiga } & No & \% \\
\hline Deitar, sentar, descansar, relaxar & 30 & 29,4 \\
Atividades de distração & 18 & 16,7 \\
Dormir & 17 & 17,6 \\
Atividades sociais & 9 & 8,8 \\
Medicamentos (medicina ortomolecular, & 6 & \\
vitaminas, medicamentos) & & 5,9 \\
Estar em movimento/atividade física & 5 & 4,9 \\
Auto-ajuda (ter notícias boas e positivas, & 4 & 2,0 \\
manter a calma, paciência) & & 2,0 \\
Oração, fé, bíblia, esperança & 3 & 2,9 \\
Trabalhar/resolver problemas & 3 & 3,9 \\
Recuperação da doença & 2 & 2,9 \\
Ausência de tratamento & 2 & 1,0 \\
Eliminar gases e evacuar & 1 & 1,0 \\
Vomitar & 1 & 1,0 \\
Nada & 1 & $\mathbf{1 0 0 , 0}$ \\
Total & $\mathbf{1 0 2}$ &
\end{tabular}

Descansar, relaxar (erguer as pernas, tomar banho quente, ficar quieto), ficar sentado ou deitado foram as ações mais citadas (Tabela 12). Realizar atividades de distração (assistir televisão, leitura, ouvir música, desenvolver trabalhos manuais), dormir e realizar atividades sociais (sair com família, filhos e amigos, conversar com vizinha, viajar, passear, sair da rotina) também foram ações citadas em número considerável.

A questão 26 da Escala de Fadiga de Piper- revisada permitiu que os pacientes expressassem algo mais sobre as suas experiências com fadiga. Trinta e um pacientes expuseram suas vivências e elas referiram-se a sensação de cansaço ruim com sintomas físicos (falta de ar, dores, insônia, mal-estar generalizado, moleza no corpo, lentidão), sintomas emocionais (depressão, irritabilidade, ansiedade, nervosismo) e sociais (isolamento). Diferentes fatores causais foram apontados: a doença (o próprio câncer), os tratamentos (quimioterapia e hormonioterapia), as alterações bioquímicas (alterações hormoniais) e a realização de atividades (trabalho ou tarefas domésticas). A fadiga 
decorrente do tratamento quimioterápico foi referida como cíclica, pois varia conforme a realização do tratamento e como aceitável, pois acredita-se que ela terá fim após o término do tratamento. Em relação ao seu enfrentamento, houve relatos de que não adianta lutar contra o sintoma, é preciso paciência.

A questão 27 da Escala de Fadiga de Piper-revisada investigou a presença de outros sintomas, diferentes da fadiga. Além de dor e prejuízo do sono, apresentados na Tabela 2, 3 pacientes referiram mal-estar generalizado, 1 paciente referiu náusea, 1 referiu diarréia e 1 referiu falta de ar.

4.3 Identificação dos fatores de risco e dos fatores preditivos

\subsubsection{Análises univariadas}

Para identificar os fatores de risco para fadiga testou-se a relação entre a presença ou não de fadiga e todas as variáveis do estudo, segundo o ponto de corte estabelecido (sem fadiga $=$ escore $<4$; com fadiga $=$ escore $\geq 4$ ). As variáveis que apresentaram relação estatisticamente significante foram incluídas no modelo de regressão múltipla. A Tabela 13 apresenta as análises relativas às variáveis sociodemográficas. 
Tabela 13- Testes de associação, testes de diferença de médias e níveis de significância entre fadiga e variáveis sócio-demográficas. São Paulo, 2007.

\begin{tabular}{|c|c|c|c|c|c|}
\hline & \multicolumn{2}{|c|}{ Sem fadiga } & \multicolumn{2}{|c|}{ Com fadiga } & \multirow[b]{2}{*}{ Significância } \\
\hline & $\mathbf{N}$ & $\%$ & $\mathbf{N}$ & $\%$ & \\
\hline \multicolumn{6}{|l|}{ Idade $(n=157)$} \\
\hline $20-40$ & 7 & 87,5 & 1 & 12,5 & Qui-quadrado \\
\hline $41-64$ & 60 & 66,7 & 30 & 33,3 & 0,178 \\
\hline $65-74$ & 32 & 80,0 & 8 & 20,0 & \\
\hline $75-84$ & 16 & 84,2 & 3 & 15,8 & \\
\hline $\begin{array}{r}\text { Média (DP); mediana; } \\
\text { mín-máx (em anos) }\end{array}$ & \multicolumn{2}{|c|}{$\begin{array}{c}60,6( \pm 12,3) ; 61,0 \\
28-84\end{array}$} & \multicolumn{2}{|c|}{$\begin{array}{c}58,2( \pm 9,9) ; 58,0 \\
38-78\end{array}$} & $\begin{array}{l}\text { T-Student } \\
0,368\end{array}$ \\
\hline \multicolumn{6}{|l|}{ Estado Civil (n=157) } \\
\hline Casado & 80 & 74,8 & 27 & 25,2 & Qui-quadrado \\
\hline Solteiro, Divorciado, Viúvo & 35 & 70,0 & 15 & 30,0 & 0,530 \\
\hline \multicolumn{6}{|l|}{ Sexo $(n=157)$} \\
\hline Homem & 63 & 74,1 & 22 & 25,9 & Qui-quadrado \\
\hline Mulher & 52 & 72,2 & 20 & 27,8 & 0,789 \\
\hline \multicolumn{6}{|l|}{ Cor da pele $(n=153)$} \\
\hline Branco & 74 & 72,5 & 28 & 27,5 & Qui-quadrado \\
\hline Não-branco & 41 & 74,5 & 14 & 25,5 & 0,787 \\
\hline \multicolumn{6}{|l|}{ Escolaridade $(\mathbf{n}=157)$} \\
\hline Até 8 anos de estudo & 43 & 78,2 & 12 & 21,8 & Qui-quadrado \\
\hline De 9 a 12 anos de estudo & 28 & 66,7 & 14 & 33,3 & 0,447 \\
\hline 13 ou mais anos de estudo & 44 & 73,3 & 16 & 26,7 & \\
\hline $\begin{array}{r}\text { Média (DP); mediana; } \\
\text { mín-máx (em anos) }\end{array}$ & \multicolumn{2}{|c|}{$\begin{array}{c}10,4( \pm 5,4) ; 11,0 \\
0,0-21,0\end{array}$} & \multicolumn{2}{|c|}{$\begin{array}{c}11,5( \pm 5,5) ; 11,0 \\
2,0-26,0\end{array}$} & $\begin{array}{c}\text { Mann-Whitney U } \\
0,741\end{array}$ \\
\hline \multicolumn{6}{|l|}{ Trabalho $(n=157)$} \\
\hline Não trabalha & 83 & 74,1 & 29 & 25,9 & Razão de \\
\hline Meio-período & 2 & 50,0 & 2 & 50,0 & Verossimilhança \\
\hline Período Integral & 30 & 73,2 & 11 & 26,8 & 0,601 \\
\hline \multicolumn{6}{|l|}{ Renda familiar $(n=142)$} \\
\hline Até 10 salários mínimos & 59 & 68,6 & 27 & 31,4 & Qui-quadrado \\
\hline De 10 a 20 salários mínimos & 28 & 87,5 & 4 & 12,5 & 0,114 \\
\hline Mais de 20 salários mínimos & 18 & 75,0 & 6 & 25,0 & \\
\hline $\begin{array}{r}\text { Média (DP); mediana; } \\
\text { Mín-máx (em salários mínimos) }\end{array}$ & \multicolumn{2}{|c|}{$\begin{array}{c}12,7( \pm 12,9) ; 8,6 \\
1,0-68,6\end{array}$} & \multicolumn{2}{|c|}{$\begin{array}{l}9,6( \pm 11,4) ; 5,1 \\
\quad 1,0-57,1\end{array}$} & $\begin{array}{c}\text { Mann-Whitney U } \\
0,090\end{array}$ \\
\hline \multicolumn{6}{|l|}{ Serviço $(n=157)$} \\
\hline Privado & 88 & 77,8 & 25 & 22,2 & Qui-quadrado \\
\hline Público & 27 & 61,4 & 17 & 38,6 & 0,036 \\
\hline
\end{tabular}

Nota-se que apenas o serviço onde o paciente recebe assistência foi fator de risco para fadiga (Tabela 13).

A Tabela 14 apresenta os resultados dos testes entre fadiga e as variáveis da doença e seu tratamento, e entre fadiga e as variáveis clínicas. 
Tabela 14- Testes de associação, testes de diferença de médias e níveis de significância entre fadiga e variáveis da doença, do seu tratamento e variáveis clínicas. São Paulo, 2007.

\begin{tabular}{|c|c|c|c|c|c|}
\hline & \multicolumn{2}{|c|}{ Sem fadiga } & \multicolumn{2}{|c|}{ Com fadiga } & \multirow[b]{2}{*}{ Significância } \\
\hline & $\mathbf{N}$ & $\%$ & $\mathbf{N}$ & $\%$ & \\
\hline \multicolumn{6}{|l|}{ Estádio $(n=134)$} \\
\hline I & 10 & 83,3 & 2 & 16,7 & \multirow{4}{*}{$\begin{array}{l}\text { Qui-quadrado } \\
\quad 0,284\end{array}$} \\
\hline II & 25 & 86,2 & 4 & 13,8 & \\
\hline III & 27 & 81,8 & 6 & 18,2 & \\
\hline IV & 42 & 70,0 & 18 & 30,0 & \\
\hline \multicolumn{6}{|l|}{ Tratamento atual (n=157) } \\
\hline Qtx e/ou Rtx & 72 & 72,7 & 27 & 27,3 & \multirow{3}{*}{$\begin{array}{l}\text { Qui-quadrado } \\
\quad 0,981\end{array}$} \\
\hline Outros tratamentos & 3 & 75,5 & 1 & 25,0 & \\
\hline Não faz tratamento & 40 & 74,1 & 14 & 25,9 & \\
\hline \multicolumn{6}{|l|}{ Tratamento cirúrgico $(n=156)$} \\
\hline Não fez & 4 & 50,0 & 4 & 50,0 & \multirow{3}{*}{$\begin{array}{l}\text { Qui-quadrado } \\
\quad 0,277\end{array}$} \\
\hline Fez há até $3 \mathrm{~m}$. & 28 & 77,8 & 8 & 22,2 & \\
\hline Fez há mais de 3 m. & 82 & 73,2 & 30 & 26,8 & \\
\hline $\begin{array}{l}\text { Média (DP); mediana; } \\
\text { mín-máx (em meses) }\end{array}$ & \multicolumn{2}{|c|}{$\begin{aligned} 25,3 & ( \pm 41,1) ; 7,0 ; \\
& 1-240\end{aligned}$} & \multicolumn{2}{|c|}{$\begin{array}{c}18,5( \pm 21,7) ; 8,0 \\
1-84\end{array}$} & $\begin{array}{l}\text { Mann-Whitney U } \\
0,819\end{array}$ \\
\hline \multicolumn{6}{|l|}{ IMC $(n=151)$} \\
\hline Baixo peso & 3 & 100,0 & 0 & 0,0 & Razão de \\
\hline Peso Normal & 43 & 67,2 & 21 & 32,8 & Verossimilhança \\
\hline Sobrepeso & 50 & 79,4 & 13 & 20,6 & 0,314 \\
\hline Obeso & 15 & 71,4 & 6 & 28,6 & \\
\hline $\begin{array}{r}\text { Média (DP); mediana; } \\
\text { Mín-máx (em IMC) }\end{array}$ & \multicolumn{2}{|c|}{$\begin{array}{c}25,7( \pm 4,2) ; 25,7 \\
13,6-36,3\end{array}$} & \multicolumn{2}{|c|}{$\begin{array}{c}25,0( \pm 3,5) ; 24,7 \\
19,4-33,1\end{array}$} & $\begin{array}{l}\text { Mann-Whitney U } \\
0,711\end{array}$ \\
\hline \multicolumn{6}{|l|}{ Nível de Hemoglobina $(n=124)$} \\
\hline Sem anemia & 63 & 71,6 & 25 & 28,4 & Razão de \\
\hline Anemia Grau I & 29 & 82,9 & 6 & 17,1 & Verossimilhança \\
\hline Anemia Grau II & 1 & 100,0 & 0 & 0,0 & 0,308 \\
\hline $\begin{array}{r}\text { Média (DP); mediana; } \\
\text { mín-máx (em nível de } \\
\text { hemoglobina) }\end{array}$ & \multicolumn{2}{|c|}{$\begin{array}{c}13,0( \pm 1,6) ; 13,1 \\
9,8-16,3\end{array}$} & \multicolumn{2}{|c|}{$\begin{array}{c}13,3( \pm 1,8) ; 13,0 \\
10,0-17,0\end{array}$} & $\begin{array}{l}\text { Mann-Whitney U } \\
0,479\end{array}$ \\
\hline \multicolumn{6}{|l|}{ Colostomia $(n=155)$} \\
\hline Não & 77 & 77,8 & 22 & 22,2 & \multirow{3}{*}{$\begin{array}{l}\text { Qui-quadrado } \\
0,146\end{array}$} \\
\hline Sim & 20 & 60,6 & 13 & 39,4 & \\
\hline No passado & 16 & 69,6 & 7 & 30,4 & \\
\hline \multicolumn{6}{|l|}{ Co-morbidades $(n=157)$} \\
\hline Não & 51 & 72,9 & 19 & 27,1 & \multirow{2}{*}{$\begin{array}{l}\text { Qui-quadrado } \\
\quad 0,921\end{array}$} \\
\hline Sim & 64 & 73,6 & 23 & 26,4 & \\
\hline \multicolumn{6}{|c|}{ Medicamentos (Antidepressivo, $n=157$ ) } \\
\hline Não & 102 & 72,3 & 39 & 27,7 & \multirow{2}{*}{$\begin{array}{c}\text { Razão de } \\
\text { verossimilhança } \\
0,430\end{array}$} \\
\hline Sim & 13 & 81,2 & 3 & 18,8 & \\
\hline \multicolumn{6}{|l|}{ Medicamentos (Ansiolítico, $\mathbf{n = 1 5 7}$ ) } \\
\hline Não & 105 & 74,5 & 36 & 25,5 & \\
\hline Sim & 10 & 62,5 & 6 & 37,5 & $\begin{array}{l}\text { verossimilhança } \\
\quad 0,320\end{array}$ \\
\hline Karnofsky $(n=153)$ & & & & & \\
\hline $100 \%-90 \%$ & 80 & 83,3 & 16 & 16,7 & Qui-quadrado \\
\hline $80 \%$ ou menos & 33 & 57,9 & 24 & 42,1 & 0,001 \\
\hline $\begin{array}{r}\text { Escore médio (DP); mediana; } \\
\text { mín-máx }\end{array}$ & 89 , & 90,0 & 79 & 30,0 & $\begin{array}{c}\text { Mann-Whitney U } \\
\text { 0,000 } \\
\end{array}$ \\
\hline
\end{tabular}

Nenhuma variável relacionada à doença ou seu tratamento apresentou associação com fadiga (Tabela 14). Dentre as variáveis clínicas, apenas capacidade funcional foi 
considerada fator de risco, sendo que quanto menor o escore na Escala de Karnofsky, maior a fadiga (Tabela 14).

A Tabela 15 apresenta os resultados dos testes entre fadiga e a presença e intensidade de sintomas.

Tabela 15- Testes de associação, testes de diferença de médias e níveis de significância entre fadiga e sintomas. São Paulo, 2007.

\begin{tabular}{|c|c|c|c|c|c|}
\hline & \multicolumn{2}{|c|}{ Sem fadiga } & \multicolumn{2}{|c|}{ Com fadiga } & \multirow{2}{*}{ Significância } \\
\hline & $\mathbf{N}$ & $\%$ & $\mathbf{N}$ & $\%$ & \\
\hline \multicolumn{6}{|l|}{ Dor $(n=157)$} \\
\hline Não & 81 & 79,4 & 21 & 20,6 & Qui-quadrado \\
\hline Sim & 34 & 61,8 & 21 & 38,2 & 0,018 \\
\hline $\begin{array}{l}\text { Intensidade média (DP); } \\
\text { mediana; mín-máx }\end{array}$ & \multicolumn{2}{|c|}{$\begin{array}{c}1,3( \pm 2,2) ; 0,0 \\
0,0-8,0\end{array}$} & \multicolumn{2}{|c|}{$\begin{array}{c}2,6( \pm 3,1) ; 1,0 \\
0,0-10,0\end{array}$} & $\begin{array}{l}\text { T-Student } \\
0,000\end{array}$ \\
\hline \multicolumn{6}{|l|}{ Prejuízo do Sono $(n=156)$} \\
\hline - & 80 & 83,3 & 16 & 16,7 & Qui-quadrado \\
\hline Sim & 34 & 56,7 & 26 & 43,3 & $\mathbf{0 , 0 0 0}$ \\
\hline $\begin{array}{r}\text { Intensidade média (DP); } \\
\text { mediana; mín-máx }\end{array}$ & \multicolumn{2}{|c|}{$\begin{array}{c}1,6( \pm 2,7) ; 0,0 \\
0,0-10,0\end{array}$} & \multicolumn{2}{|c|}{$\begin{array}{c}4,2( \pm 3,7) ; 5,0 \\
0,0-10,0\end{array}$} & $\begin{array}{l}\text { T-Student } \\
<0,001\end{array}$ \\
\hline \multicolumn{6}{|l|}{ Depressão (IDB, $n=156$ ) } \\
\hline Sem depressão & 106 & 80,3 & 26 & 19,7 & Razão de \\
\hline Disforia & 6 & 46,2 & 7 & 53,8 & verossimilhança \\
\hline Depressão & 3 & 27,3 & 8 & 72,7 & 0,000 \\
\hline $\begin{array}{l}\text { Escore IDB médio (DP); } \\
\text { mediana; mín-máx }\end{array}$ & \multicolumn{2}{|c|}{$\begin{array}{c}7,1( \pm 5,3) ; 7,0 \\
0-26\end{array}$} & \multicolumn{2}{|c|}{$\begin{array}{c}15,4( \pm 7,8) ; 14,0 \\
0-37\end{array}$} & $\begin{array}{c}\text { Mann-Whitney U } \\
\mathbf{0 , 0 0 0} \\
\end{array}$ \\
\hline
\end{tabular}

Todos os sintomas investigados apresentaram relação com fadiga (Tabela 15). Observa-se que doentes com dor, prejuízo do sono e alteração do humor apresentaram mais fadiga que aqueles sem esses sintomas e quanto maior a intensidade dos sintomas, mais intensa foi a fadiga (Tabela 15).

Resumindo os achados das análises univariadas, 5 das 20 variáveis independentes testadas neste estudo foram identificadas como fatores de risco para fadiga em doentes com câncer colo-retal. Atendimento em hospital público, dor (presença e intensidade), prejuízo do sono (presença e intensidade), depressão (em categorias e intensidade) e capacidade funcional (prejudicada/preservada e intensidade) foram considerados fatores de risco. 


\subsubsection{Regressão Logística}

As 5 variáveis que apresentaram relação significativa com a fadiga foram incluídas na análise múltipla utilizando a técnica de regressão logística (Tabela 18). Porém, antes de inserir as variáveis contínuas (intensidade de dor, intensidade de prejuízo do sono, capacidade funcional e depressão), buscou-se estabelecer o ponto-decorte de cada uma delas usando a curva $R O C$. O ponto-de-corte visou a identificar o escore que refletia a maior sensibilidade e especificidade de cada variável. A Tabela 16 e a Figura 1 sintetizam os achados de sensibilidade, especificidade, área sob a curva $R O C$, o nível de significância da área sob a curva e o ponto-de-corte.

Tabela 16- Sensibilidade, especificidade, área sob a curva $R O C$, nível de significância e ponto-de corte das variáveis contínuas incluídas na análise de regressão múltipla. São Paulo, 2007.

\begin{tabular}{cccccc}
\hline & Sensibilidade & Especificidade & $\begin{array}{c}\text { Área sob } \\
\text { curva }\end{array}$ & $\begin{array}{c}\text { Nível de } \\
\text { significância }\end{array}$ & $\begin{array}{c}\text { Ponto-de- } \\
\text { corte }\end{array}$ \\
\hline $\begin{array}{c}\text { Intensidade de } \\
\text { dor }\end{array}$ & 0,667 & 0,790 & 0,629 & 0,016 & $5,5^{*}$ \\
$\begin{array}{c}\text { Intensidade de } \\
\text { prejuízo de }\end{array}$ & 0,733 & 0,632 & 0,694 & $<0,001$ & $4,5^{\dagger}$ \\
$\begin{array}{c}\text { sono } \\
\text { Capacidade } \\
\text { funcional } \\
\text { (Karnofsky) } \\
\begin{array}{c}\text { Depressão } \\
\text { (IDB) }\end{array}\end{array}$ & 0,600 & 0,708 & 0,705 & $<0,001$ & $85 \%^{\ddagger}$ \\
\hline
\end{tabular}

* Escore $<6$ = sem dor; escore $>6=$ com dor

${ }^{\dagger}$ Escore $<5=$ sem prejuízo do sono; escore $\geq 5$ = com prejuízo do sono

$¥$ Escore $>80 \%$ = capacidade funcional preservada; escore $\leq 80 \%=$ capacidade funcional prejudicada

${ }^{\delta}$ Escore $<13$ = sem depressão; escore $\geq 13$ = provável depressão 
Figura 1: Curva ROC das variáveis contínuas dor, prejuízo do sono, depressão e capacidade funcional. São Paulo, 2007.

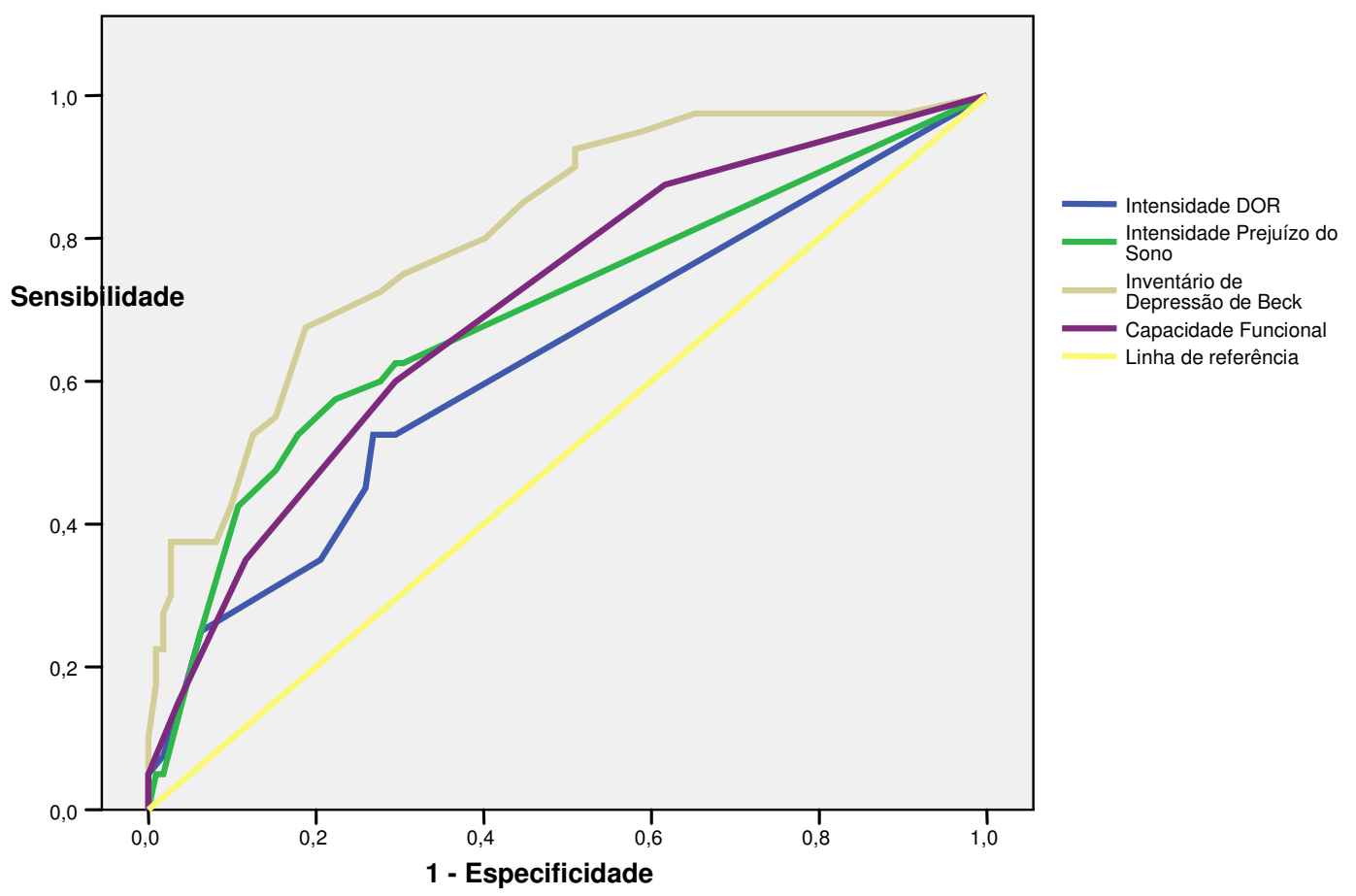

Os dados da Tabela 16 e Figura 1 indicam que as áreas sob as curvas $R O C$ das quatro variáveis contínuas foram boas e apresentaram níveis de significância adequados. O ponto de corte da variável depressão obteve o melhor conjunto de valores de sensibilidade e especificidade comparada ao conjunto de valores de sensibilidade e especificidade das variáveis dor, prejuízo de sono e capacidade funcional.

A Tabela 17 apresenta a associação entre os fatores de risco de fadiga.

Tabela 17- Associação entre os fatores de risco de fadiga. São Paulo, 2007.

\begin{tabular}{|c|c|c|c|c|c|}
\hline & $\begin{array}{c}\text { Serviço de } \\
\text { saúde público }\end{array}$ & Dor $(\geq 6)$ & $\begin{array}{l}\text { Prejuízo do } \\
\text { sono }(\geq 5)\end{array}$ & $\begin{array}{l}\text { Depressão } \\
(\geq 13)\end{array}$ & $\begin{array}{c}\text { Capacidade } \\
\text { funcional }(\leq \mathbf{8 0 \%})\end{array}$ \\
\hline \multicolumn{6}{|l|}{$\begin{array}{l}\text { Serviço de saúde } \\
\text { público }\end{array}$} \\
\hline $\operatorname{Dor}(\geq 6)$ & $\begin{array}{c}\text { Qui-quadrado } \\
\mathrm{P}=0,662\end{array}$ & & & & \\
\hline $\begin{array}{c}\text { Prejuízo do sono } \\
(\geq 5)\end{array}$ & $\begin{array}{l}\text { Qui-quadrado } \\
\mathrm{P}=0,371\end{array}$ & $\begin{array}{c}\text { Qui-quadrado } \\
\mathbf{p}<0,001\end{array}$ & & & \\
\hline Depressão ( $\geq 13$ ) & $\begin{array}{c}\text { Qui-quadrado } \\
\quad \mathbf{P = 0 , 0 0 6}\end{array}$ & $\begin{array}{c}\text { Qui-quadrado } \\
\mathbf{p}=\mathbf{0 , 0 3 1}\end{array}$ & $\begin{array}{c}\text { Qui-quadrado } \\
\text { p }<0,001\end{array}$ & & \\
\hline $\begin{array}{c}\text { Capacidade } \\
\text { funcional }(<\mathbf{8 0 \%})\end{array}$ & $\begin{array}{l}\text { Qui-quadrado } \\
\mathrm{P}=0,103\end{array}$ & $\begin{array}{l}\text { Qui-quadrado } \\
\mathrm{p}=0,156\end{array}$ & $\begin{array}{c}\text { Qui-quadrado } \\
\mathrm{p}=0,303\end{array}$ & $\begin{array}{c}\text { Qui-quadrado } \\
\text { p=0,036 }\end{array}$ & \\
\hline
\end{tabular}


A Tabela 17 permitiu identificar que a variável serviço de saúde público se associou à variável depressão, que a variável dor se associou às variáveis prejuízo do sono e depressão, que a variável prejuízo do sono se associou às variáveis dor e depressão, que a variável depressão se associou a todas as variáveis de risco e que capacidade funcional de associou somente a depressão.

Na Tabela 18 apresenta-se a análise de regressão para identificação dos fatores preditivos de fadiga.

Tabela 18- Modelo de regressão logística para fadiga (n= 151). São Paulo, 2007.

\begin{tabular}{|c|c|c|c|c|c|c|}
\hline Variável & $\begin{array}{c}\text { Padrão } \\
\text { estimado }(\beta)\end{array}$ & $\begin{array}{l}\text { Erro } \\
\text { Padrão }\end{array}$ & $\begin{array}{l}\text { Odds } \\
\text { Ratio }\end{array}$ & \multicolumn{2}{|c|}{ IC $95 \%$} & $P$ \\
\hline Privado (0) x Público (1) & & & & & & \\
\hline $\begin{array}{l}\text { Dor } \\
\text { Não (0) x Sim (1) }\end{array}$ & & & & & & 0,302 \\
\hline $\begin{array}{l}\text { Dor } \\
\text { Escore }<6(0) \times \text { Escore } \geq 6(1)\end{array}$ & & & & & & 0,093 \\
\hline $\begin{array}{l}\text { Prejuízo do sono } \\
\text { Não (0) x Sim (1) }\end{array}$ & & & & & & 0,964 \\
\hline $\begin{array}{l}\text { Prejuízo do sono } \\
\text { Escore <5 (0) x Escore } \geq 5 \text { (1) }\end{array}$ & 1,176 & 0,467 & 3,241 & 1,299 & 8,087 & 0,012 \\
\hline $\begin{array}{l}\text { Depressão } \\
\text { Sem depressão (0) x Disforia (1) x } \\
\text { Depressão (2) }\end{array}$ & & & & & & $\begin{array}{l}0,670 \\
0,543 \\
0,868\end{array}$ \\
\hline $\begin{array}{l}\text { Depressão } \\
\text { Escore < } 13 \text { (0) x Escore } \geq 13(1)\end{array}$ & 1,430 & 0,465 & 4,180 & 1,681 & 10,393 & 0,002 \\
\hline $\begin{array}{l}\text { Capacidade funcional } \\
\text { Escore }>80 \%(0) \times \text { Escore } \leq 80 \%(1)\end{array}$ & 1,167 & 0,433 & 3,212 & 1,373 & 7,511 & 0,006 \\
\hline
\end{tabular}

O modelo da regressão logística (Tabela 19) identificou 3 fatores preditivos independentes para a fadiga e eles são prejuízo do sono (ponto de corte em 5), capacidade funcional (ponto de corte em 80) e depressão (ponto de corte em 13). A razão de risco para fadiga foi maior para depressão $(\mathrm{OR}=4,2)$ do que para prejuízo do sono $(\mathrm{OR}=3,2)$ e capacidade funcional $(\mathrm{OR}=3,2)$. 
A partir dos padrões estimados para as variáveis preditivas independentes, calculou-se a probabilidade do indivíduo ter ou não fadiga com base na presença ou não de cada variável (Tabela 19). A fórmula matemática usada foi:

$$
\text { Probabilidade de ter fadiga }=\frac{\operatorname{EXP}(-2,409+1,167 * \mathrm{~A} 6+1,174 * \mathrm{~B} 6+1,421 * \mathrm{C} 6)}{1+\operatorname{EXP}(-2,409+1,167 * \mathrm{~A} 6+1,174 * \mathrm{~B} 6+1,421 * \mathrm{C} 6)}
$$

Tabela 19- Probabilidade de ter fadiga na presença dos fatores preditivos independentes*. São Paulo, 2007.

\begin{tabular}{cccc}
\hline $\begin{array}{c}\text { Prejuízo do } \\
\text { sono }\end{array}$ & Karnofsky & Depressão & $\begin{array}{c}\text { Probabilidade de ter } \\
\text { fadiga }\end{array}$ \\
\hline 0 & 0 & 0 & 0,082489 \\
1 & 0 & 0 & 0,224088 \\
0 & 1 & 0 & 0,225308 \\
0 & 0 & 1 & 0,271307 \\
1 & 1 & 0 & 0,483007 \\
1 & 0 & 1 & 0,544631 \\
0 & 1 & 1 & 0,546366 \\
1 & 1 & 1 & 0,79462 \\
\hline$* 0=$ não; $1=$ sim & &
\end{tabular}

Analisando-se a Tabela 19, observa-se que o doente que não tem nenhum dos três fatores preditivos independentes tem aproximadamente $8 \%$ de chance de ter fadiga e aquele que apresenta os três fatores preditivos independentes tem aproximadamente $80 \%$ de chance de ter fadiga. Observa-se que não só o número de fatores presentes, mas também a natureza do fator influi na probabilidade de se ter fadiga. A depressão aumenta mais a probabilidade de se ter fadiga que os demais fatores.

A sensibilidade (proporção de casos positivos identificados corretamente) do modelo encontrado neste estudo foi igual a 58,6\%. A especificidade (proporção de casos negativos identificados corretamente) foi igual a 81,9\%. Esses dados indicam que, aplicando o modelo construído neste estudo, a possibilidade de se identificar corretamente uma pessoa fatigada é de aproximadamente $60 \%$ e de se identificar corretamente uma pessoa não fatigada é de aproximadamente $82 \%$. 


\section{DISCUSSÃO}

O estudo encontrou resultados inéditos no cenário nacional e internacional. Pouco se conhecia sobre a prevalência e a caracterização da fadiga em pacientes com câncer colo-retal e não havia estudos sobre fatores preditivos de fadiga nessa população, o que foi disponibilizado no presente estudo.

A discussão foi organizada em três partes. A primeira refere-se aos procedimentos adotados no método e à casuística, a segunda, à caracterização da fadiga e a terceira, aos fatores de risco e fatores preditivos identificados.

A busca por uma estratégia para avaliar fadiga, válida e confiável, começou por meio de uma revisão sistemática da literatura sobre instrumentos de auto-relato para avaliação de fadiga em adultos (Mota, Pimenta, 2006). Nesse estudo identificaram-se 18 instrumentos que apresentavam descrição detalhada sobre o processo de construção e validação e observou-se que não havia instrumento em língua portuguesa. Optou-se, então, pela validação da Escala de Fadiga de Piper-revisada, instrumento com boas propriedades psicométricas, amplamente utilizado no mundo e que possibilita a avaliação de vários domínios de fadiga.

O processo de validação para a cultura brasileira, descrito no método, contou com grande número de sujeitos (584 pacientes com diferentes cânceres, 184 acompanhantes dos pacientes e 189 estudantes de enfermagem), o que superou o número recomendado para validação de instrumentos, 10 indivíduos por item do 
instrumento (Mota, Pimenta, Piper, 2008; Kerlinger, 1986). O grande número de sujeitos e a abrangência da avaliação possibilitaram a realização de vários testes confirmatórios (validade convergente, validade divergente, validade de critério, validade discriminante, análise de confiabilidade, teste-reteste e análise fatorial) e os resultados indicaram alta confiabilidade, adequada validade de construto, convergente, divergente e de critério e bons indícios de capacidade de discriminação dos sujeitos. A forte correlação entre escala numérica de fadiga ( 0 a 10) e a Escala de Fadiga de Piperrevisada leva a imaginar que a escala numérica seja capaz de representar a presença e intensidade do fenômeno fadiga. Além disso, o fato de os pacientes, sujeitos da validação, apresentarem cânceres de diversos tipos (colo-retal, mama, próstata, pulmão etc..) foi muito vantajoso, pois indicou que o instrumento pode ser utilizado em pacientes com cânceres variados (Mota, Pimenta, Piper, 2008).

Os dados foram coletados em quatro serviços de oncologia com características diferentes (hospital público e privado, clínica independente e ambulatório hospitalar) e isso melhorou a representação de pacientes com câncer colo-retal, isto é, aumentou a validade externa do estudo. Validade externa de um estudo é a possibilidade de generalização dos resultados para outros cenários.

A amostra, de conveniência, teve distribuição de frequiência semelhante entre os quatro serviços. Embora a aleatorização da amostra fosse desejável, isso não foi realizado, visto que em alguns serviços não foi possível obter a relação dos doentes com câncer colo-retal para proceder ao sorteio. Assim, acredita-se que a opção de utilizar quatro serviços de oncologia minimizou a limitação de se trabalhar com amostras de conveniência.

Os dados foram coletados por cinco coletadores e isso pode ser motivo de críticas. Cabe ressaltar que o uso de auxiliares de pesquisa está cada vez mais 
consagrado nas pesquisas internacionais e nacionais, especialmente em estudos epidemiológicos e naqueles em que se necessita de amostras maiores. Para garantir a homogeneidade e a fidedignidade das informações, os coletadores foram treinados e supervisionados continuamente.

A opção por estudar pacientes com o diagnóstico de câncer colo-retal deveu-se a que esse câncer é o segundo mais prevalente no mundo, depois do câncer de mama, e por ser o câncer mais prevalente quando se consideram os dois sexos (Instituto Nacional do Câncer, 2008). Câncer de mama é o mais freqüente em mulheres e próstata em homens mas, como se desejava testar a influência do sexo na fadiga, eles não eram adequados ao estudo. No Brasil, estima-se que em 2008 o câncer de cólon e reto será o $3^{\circ}$ mais freqüente entre mulheres ( $1^{\circ}$ câncer de mama, $2^{\circ}$ câncer de colo de útero) e o $4^{\circ}$ mais freqüente entre homens $\left(1^{\circ}\right.$ câncer de próstata, $2^{\circ}$ câncer de pulmão, traquéia e brônquios e $3^{\circ}$ câncer de estômago), segundo o Instituto Nacional do Câncer (2008). O câncer de pulmão também é muito freqüente em ambos os sexos, porém sabe-se que sujeitos com câncer de pulmão apresentam dispnéia, o que seria fator de confusão para a apreciação da fadiga. Influiu também na opção de se estudar fadiga em pacientes com câncer colo-retal o pequeno número de estudos na área, quando comparado ao câncer de mama e próstata.

O câncer de cólon representa dois terços do total de casos de câncer colo-retal e aproximadamente $70 \%$ de todos os cânceres de intestino (Ellenhorn et al., 2002) e, 90\% a 95\% das neoplasias são adenocarcinomas (Ellenhorn et al., 2002). A proporção entre casos com câncer de cólon e reto, observada no presente estudo (2,3 / 1), assemelhou-se ao descrito na literatura (Ellenhorn et al., 2002).

O câncer de cólon ocorre em igual proporção entre homens e mulheres e o câncer de reto é entre $20 \%$ a $50 \%$ mais freqüente em homens (Instituto Nacional do 
Câncer, 2008). Neste estudo, 54,1\% dos pacientes eram do sexo masculino e a idade média e a mediana foram 60 anos (Tabela 1). A proporção entre sexos da amostra da presente pesquisa foi semelhante à de outros estudos envolvendo pacientes com câncer colo-retal e a idade média foi discretamente inferior, cerca de cinco anos (Schmidt et al., 2005; Arndt et al., 2004; Ashbury et al., 2003; Holzner et al., 2002; Majumdar, Fletcher, Evans, 1999).

A incidência de câncer colo-retal é mais alta em regiões industrializadas e, no Brasil, observa-se nítido aumento no número de casos, provavelmente devido às mudanças ambientais e dietéticas (Libutti et al., 2005; Ellenhorn et al., 2002; Kessler, Milsom, 1999). A sobrevida em cinco anos é de aproximadamente $90 \%$ em pacientes com câncer colo-retal estádio I, 65\% em estádio II e III e 8\% em estádio IV (Ellenhorn et al., 2002). O principal sítio de metástase é o fígado, seguido do pulmão (Libutti et al., 2005; Kessler, Milsom, 1999). Grande parcela dos pacientes do presente estudo apresentavam câncer colo-retal avançado (estádio III e IV =69,4\%) e 44,8\% dos doentes tinham metástase, estádio IV (Tabela 1), o que representa doentes em condições mais graves que em estudos com populações de estudos em outros países (Arndt et al., 2004; Ashbury et al., 2003; Holzner et al., 2002; Kurtz et al., 2002; Majumdar, Fletcher, Evans, 1999; Ness et al., 1998).

Na presente pesquisa, a quase a totalidade $(94,9 \%)$ dos pacientes fez cirurgia para tratamento do câncer (Tabela 1), o que está em acordo com a literatura, visto que o principal tratamento do câncer colo-retal é a extirpação cirúrgica do tumor, dos linfonodos e mesentério adjacentes (Libutti et al., 2005; Ellenhorn et al., 2002; Kessler, Milsom, 1999). A recidiva local do câncer de cólon é menos freqüente do que do câncer de reto e, por isso, o tratamento neo-adjuvante (tratamento feito antes da cirurgia), radioterapia associada ou não a quimioterapia, é indicado apenas nos cânceres retais. 
Excetuando esse tratamento neo-adjuvante, os demais tratamentos para câncer de cólon e de reto são semelhantes, permitindo a composição de um só grupo de pacientes com tumores colo-retais, procedimento adotado no presente estudo.

Existem diferentes protocolos de quimioterapia utilizados como tratamento adjuvante dos cânceres colo-retais (tratamento realizado após cirurgia). Neste estudo, 65,6\% estavam em tratamento antineoplásico adjuvante (Tabela 1). O tipo de droga e o esquema terapêutico não foram explorados devido à diversidade de procedimentos adotados pelos oncologistas dos serviços onde os dados foram coletados. Sabendo-se que a fadiga de pacientes com câncer colo-retal tende a piorar com tratamentos quimio ou radioterápicos (Tsutsumi et al., 2006; Iop, Manfredi, Bonura, 2004), apenas investigou-se se o paciente estava ou não em tratamento.

A maioria dos indivíduos que participou deste estudo recebeu atendimento de saúde em serviços privados (72\%, Tabela 1), o que deve estar relacionado à alta escolaridade, renda familiar e cor da pele. Esses dados, somados ao estado civil e vínculo empregatício, foram semelhantes aos dos estudos com doentes com câncer coloretal desenvolvidos nos países europeus e nos Estados Unidos (Arndt et al., 2004; Holzner et al., 2002; Kurtz et al., 2002; Majumdar, Fletcher, Evans, 1999; Ness et al., 1998), o que permite comparações.

Quanto ao Índice de Massa Corporal (IMC), apenas 2\% tinha baixo peso, 42,4\% apresentou índice normal e, ao contrário do esperado, a maioria apresentou peso acima do normal (Tabela 2). Importante lembrar que obesidade é fator de risco para câncer colo-retal (Libutti et al., 2005). Não se encontrou estudo que tenha avaliado IMC em doentes com câncer colo-retal, mas em estudo com pacientes com câncer avançado, calculou-se IMC médio igual a 22,4 (Stone et al., 1999), o que foi inferior ao observado no presente estudo. 
Sangramento é um dos sintomas presentes no diagnóstico do câncer colo-retal (Libutti et al., 2005; Majumdar, Fletcher, Evans, 1999) e, por isso, anemia é uma variável importante a ser investigada em estudos que envolvem essa população. Cerca de $30 \%$ dos sujeitos do presente estudo apresentaram anemia e na quase totalidade foi anemia leve (Tabela 2). O resultado de prevalência aqui encontrado foi inferior ao encontrado em estudo que identificou, em amostra de 194 pacientes com câncer coloretal, 57\% dos doentes com algum grau de anemia (Majumdar, Fletcher, Evans, 1999). Em relação à gravidade da anemia, estudo com 22 pacientes com câncer colo-retal referiu que o nível médio de hemoglobina foi de 12,0, valor categorizado como anemia leve (Holzner et al., 2002), o que foi inferior ao nível médio de hemoglobina do presente estudo (13,1g/dl, Tabela 2$)$.

$\mathrm{Na}$ presente pesquisa, a quase metade dos doentes $(44,6 \%)$ relatou doenças em co-morbidades (Tabela 2). A princípio, esse valor pareceu alto, porém observaram-se estudos que relataram presença de co-morbidades em $70 \%$ dos pacientes com câncer colo-retal e outro que encontrou presença de doenças em co-morbidades em 30\% (Arndt et al., 2004; Kurtz et al., 2002). Nota-se que a população do presente estudo apresentou co-morbidades em valores contidos na prevalência no Brasil de doenças crônicas como a hipertensão arterial (20\% em população adulta e de $50 \%$ a $70 \%$ em idosos (Brasil, 2004).

Cerca de $65 \%$ dos doentes referiram fazer uso de medicamentos e 13,3\% referiram fazer uso de antidepressivos (Tabela 2). O número de pacientes que fazia uso de antidepressivos no presente estudo foi semelhante ao encontrado no estudo com 299 pacientes com câncer de cólon que identificou $11 \%$ dos doentes fazendo uso desses medicamentos (Ashbury et al., 2003). O uso de ansiolíticos foi referido por $11 \%$ dos 
doentes (Tabela 2) e não se encontraram estudos sobre isso em populações como a deste estudo, o que impossibilitou comparações.

Uso de colostomia foi informado por $36,1 \%$ dos doentes (Tabela 2). Um estudo envolvendo 309 pacientes com câncer colo-retal indicou que 20\% dos pacientes tinham colostomia, que é um valor inferior ao encontrado no presente estudo.

A dor foi relatada por um terço dos pacientes com câncer em tratamento ativo e entre $60 \%$ a $90 \%$ dos pacientes com câncer avançado (Foley, 2005). Em doentes com câncer colo-retal recém-diagnosticados $(n=194)$, dor abdominal foi referida por $52 \%$ dos doentes e dor no reto, 5\% (Majumdar, Fletcher, Evans, 1999). Um ano após receber o diagnóstico de câncer, dor foi referida por $43,1 \%$ dos doentes com câncer colo-retal (Arndt et al., 2004). Em cuidados paliativos, a prevalência de dor foi mais alta. Aproximadamente $80 \%$ dos pacientes com câncer colo-retal referiram dor leve, moderada ou intensa (Vainio, Aurinen, 1996). No presente estudo, a dor teve prevalência de 35\%, o que foi inferior aos estudos citados, e a sua intensidade média e mediana foi de 4,6 e 4,0, respectivamente (Tabela 2).

Alterações de sono atingem cerca de 50\% dos pacientes com câncer (Mills, Graci, 2004) e em doentes com câncer colo-retal, encontrou-se relato de prevalência em torno de 54,7\% (Arndt et al., 2004). No presente estudo, prejuízo do sono foi relatado por $38,5 \%$, o que foi inferior ao estudo que avaliou tal sintoma, e a sua intensidade média e mediana foi de 5,9 e 6,0, respectivamente (Tabela 2).

Sintomas depressivos acometem entre $13 \%$ e $25 \%$ dos doentes com câncer coloretal, segundo levantamento bibliográfico (Massie, 2004). No presente estudo, 15,4\% dos pacientes apresentou algum tipo de alteração do humor (disforia ou depressão), e esse valor se assemelha à prevalência encontrada na literatura (Tabela 2). 
A segunda parte da discussão refere-se à caracterização da fadiga (prevalência e intensidade, total e por dimensão, e opinião dos doentes sobre o que causa e o que alivia fadiga) e à análise de diferenças entre as dimensões da fadiga segundo o sexo, a idade, a duração do sintoma, a presença de depressão e a capacidade funcional.

Para se determinar a prevalência da fadiga, no presente estudo, adotou-se o ponto de corte igual ou maior que 4 . O ponto de corte $\geq 4$, que se refere ao percentil 25 da distribuição dos escores de fadiga e atende ao critério preconizado pela National Comprehensive Câncer Network (2007), representa a fadiga apresentada por $75 \%$ dos indivíduos da amostra que referiram fadiga. Na revisão de literatura observou-se que outros autores também adotaram esses mesmos pontos de corte (Chang et al., 2007), o que é vantajoso para que se possam padronizar avaliações e compará-las. Além disso, ter como ponto de corte para a ocorrência da fadiga escores maiores que 1,2 ou 3 contribuiu para se trabalhar com queixas que tenham relevância clínica, visto que desconfortos mínimos ou menores (1,2 e 3) podem ter significado estatístico, mas nem sempre têm significado clínico.

Quando se analisou a intensidade da fadiga em escala de 0 a 10 notou-se que a metade dos doentes referiu escore 0 de fadiga e cerca de $1 / 5$ referiu escores entre $>0$ e $<4$ e, no presente estudo, não foram considerados como fatigados $(73,3 \%)$. Escores $\geq 4$, que no presente estudo foi considerado fadiga, ocorreu em $26,8 \%$ dos doentes (Tabela 3) e essa prevalência foi semelhante à encontrada em doentes com câncer colo-retal e em sobreviventes de câncer colo-retal (Schneider et al., 2007; Majumdar, Fletcher, Evans, 1999), e foi inferior ao estudo que avaliou fadiga por meio de uma subescala de qualidade de vida e identificou $80 \%$ relato de fadiga entre pacientes com câncer coloretal após um ano do diagnóstico (Arndt et al., 2004). 
Os estudos sobre fadiga no câncer colo-retal são em número reduzido mas, de modo geral, os achados se assemelham aos da presente pesquisa. No presente estudo, a fadiga total teve intensidade média e mediana igual a 4,4, o que indicou fadiga moderada (Tabela 4), compatível com o descrito por outros autores (Schmidt et al., 2005; Arndt et al., 2004; Holzner et al., 2002; Galloway, Graydon, 1996).

Quando se comparou a prevalência e a intensidade da fadiga dos doentes da presente pesquisa (câncer colo-retal) com estudos envolvendo doentes com outros cânceres, observou-se que a fadiga foi menos freqüente e menos intensa do que a dos estudos com pacientes em cuidados paliativos e em tratamentos químio ou radioterápicos (Herrinton et al., 2007; De Jong et al., 2002; Jenkins et al., 2000). Quando tal comparação foi feita com sobreviventes de câncer (Knobel et al., 2001), a fadiga foi semelhante.

No presente estudo, fadiga foi considerada um conceito multidimensional e foi avaliado pela Escala de Fadiga de Piper, pois havia grande interesse em caracterizar as diferentes dimensões da fadiga. Além disso, julgava-se que algumas variáveis poderiam influir na maior ou menor expressão de alguma dimensão da fadiga, e isso foi testado.

Os escores médios e medianos das dimensões comportamental, afetiva e sensitiva/psicológica foram semelhantes e de intensidade moderada, todos acima de $4 \mathrm{e}$ abaixo de 5 (Tabela 4). Tais achados parecem coerentes com a fisiopatologia da fadiga na doença oncológica, que é multideterminada, influencia e sofre a influência de inúmeros fatores. O emagrecimento, a desidratação, o descondicionamento físico, entre outros, podem ter contribuído para a vivência da dimensão comportamental da fadiga. Os medos, a alteração do humor e as incertezas, entre outros, poderiam contribuir com a dimensão sensorial/psicológica. A atribuição de significado à fadiga (boa/má, aceitável/inaceitável, destruidora/protetora, agradável/desagradável etc.), que na Escala 
de Fadiga de Piper corresponde ao componente afetivo, foi variada entre os doentes e isso também parece coerente, visto que a apreciação de qualquer desconforto, entre eles a fadiga, não é visto e vivenciado da mesma forma pelas pessoas; se para alguns o desconforto é visto como algo mais catastrófico, para outros há uma aceitação mais serena e isso está relacionado, entre outras razões, às experiências passadas, à aspectos culturais de tolerância ao estresse e frustração. Desse imbricado resultou que todos os componentes foram igualmente importantes. Talvez a avaliação da fadiga de outras populações, por exemplo, de atletas, mostrasse predomínio de alguma dimensão, por exemplo a comportamental, visto que, diferentemente da doença oncológica, os fatores envolvidos seriam mais de natureza física.

Quando se compararam os escores das dimensões de fadiga entre indivíduos de diferentes sexos, faixas etárias, duração da queixa, escores de depressão e capacidade funcional, foi possível observar que a duração da fadiga e o humor influíram na magnitude das dimensões (Tabelas 7 e 8). Indivíduos com fadiga há 12 meses ou mais apresentaram escores mais altos na dimensão sensorial/psicológica que aqueles com fadiga há menos que 6 meses $(\mathrm{p}=0,019)$. Indivíduos com escores compatíveis com depressão ( $>20)$ apresentaram escores mais altos nas dimensões comportamental $(\mathrm{p}=$ 0,022) e sensorial/psicológica $(p=0,035)$ que aqueles sem depressão.

A influência da duração da fadiga no domínio sensitivo/psicológico talvez esteja relacionada ao fato de que a convivência crônica com o desconforto leva à apreciação negativa da vivacidade, energia e resistência corporal e mental. A influência do humor expressou-se na dimensão comportamental. Os pacientes mais tristes ou deprimidos mostraram maior prejuízo em atividades pessoais, sociais e maior limitação global que os não deprimidos. Considerando-se esses resultados, as estratégias para o manejo da fadiga devem incluir intervenções para todas as dimensões e, nos pacientes deprimidos 
e naqueles com queixa de longa duração, deve ser dada atenção especial para intervenções que envolvam as áreas sensorial/psicológica e comportamental. É interessante notar que a dimensão afetiva da fadiga, que retrata a interpretação ou o significado da fadiga, não diferiu segundo a duração da queixa do sintoma e intensidade da depressão. Provavelmente existem outros fatores que levem o indivíduo a avaliar sua fadiga como um sintoma mais ou menos negativo, destruidor, desagradável, anormal ou inaceitável e é desejável que esses fatores sejam identificados pois, possivelmente, estarão relacionados ao modo de lidar com o sintoma.

Quando se testou se haveria diferenças nas dimensões da fadiga em pacientes do mesmo sexo, mesma faixa etária, mesmo tempo de queixa do sintoma, mesma categoria de escore de depressão e dentro da mesma categoria de escore de capacidade funcional, observou-se que nenhuma dimensão influenciou mais a fadiga que a outra (Tabela 5, 6, 7, 8 e 9). Esses resultados causaram surpresa pois levantou-se a hipótese de que, por exemplo, mulheres apresentariam escore da dimensão sensorial/psicológica mais alto, idosos e pacientes com pior capacidade funcional apresentariam escore da dimensão comportamental mais alto e adultos jovens apresentariam escore da dimensão afetiva mais alto. Não foram encontrados estudos que avaliassem tais relações para compararmos os achados e questiona-se a utilidade da avaliação de tais dimensões na prática clínica. Portanto, é desejável que análises como essas sejam repetidas em outros estudos para que se possa esclarecer se tais hipóteses são realmente refutáveis, se os instrumentos precisam ser mais refinados e, assim, saber se as estratégias de controle de fadiga deverão considerar particularidades segundo o perfil do paciente.

Não se encontrou estudo que tivesse usado qualquer instrumento multidimensional para avaliar a fadiga exclusivamente em pacientes com câncer coloretal. Mas analisando-se estudos com a Escala de Fadiga de Piper em outras populações, 
observou-se que um estudo encontrou aumento significativo dos escores médios da dimensão comportamental quando se compararm doentes com câncer de pulmão (n=45) em diferentes fases de tratamento quimioterápico (Beach et al., 2001). Outro estudo com doentes com câncer de pulmão e mama (n=64) encontrou escore médio da dimensão comportamental mais alto entre os doentes previamente tratados com quimioterapia do que entre aqueles não tratados (Dagnelie et al., 2006). Nesse mesmo estudo, observou-se que, na dimensão sensorial/psicológica, os pacientes com câncer de pulmão apresentaram escores mais altos que as pacientes com câncer de mama (Dagnelie et al., 2006).

Além da Escala de Piper, o Multidimensional Fatigue Inventory (MFI) foi usado em outras populações com câncer para se avaliar a fadiga de modo compreensivo. Pesquisa com 130 pacientes com câncer avançado não identificou diferença entre as dimensões do instrumento (geral, física, mental, redução de atividade e redução de motivação) quando se considerou a amostra total (Munch et al., 2006), assim como o presente estudo. Mas quando se compararam sub-amostras, algumas diferenças foram observadas. Doentes deprimidos apresentaram escores médios de fadiga geral, mental, redução de atividade e redução de motivação mais altos que os não deprimidos; doentes ansiosos apresentaram escore médio de fadiga mental mais alto que os não ansiosos; doentes que tomavam analgésicos mais potentes apresentaram escore médio de fadiga física mais alto que os pacientes que não faziam uso de analgésicos; e os doentes que faziam uso de antidepressivos apresentaram escore médio de fadiga geral e mental mais altos que os pacientes que não usavam tais drogas (Munch et al., 2006).

Em outra pesquisa com pacientes terminais hospitalizados $(n=100)$ que também utilizou o MFI, observou-se que os escores medianos das dimensões redução de 
motivação e fadiga mental foram estatisticamente inferiores aos escores medianos das dimensões fadiga geral, física e redução de atividade (Echteld et al., 2007).

Ainda utilizando o MFI, estudos que avaliaram a fadiga de mulheres em tratamento quimioterápico observaram que a fadiga mental, a redução da motivação e o nível de atividade não variaram segundo o esquema de tratamento (De Jong et al., 2004, 2005, 2006). E outro estudo que avaliou a fadiga no decorrer do tratamento radioterápico observou que entre a terceira semana e o término do tratamento, a fadiga continuou a se intensificar, exceto na dimensão mental (Ahlberg, Ekman, GastonJohansson, 2005).

Outra pesquisa utilizou o Brief Fatigue Inventory (BFI) para avaliar as dimensões da fadiga (física, mental e total). Nesse estudo, os domínios físico e total foram bem mais altos em pacientes paliativos $(n=434)$ que na população geral $(n=2323)$. A fadiga mental foi semelhante entre os grupos (Kaasa et al., 1999).

Percebeu-se que os estudos que avaliaram a mutlidimensionalidade da fadiga são em pequeno número e em populações com características muito diferentes, o que dificulta alcançarem-se conclusões sobre o tema.

A duração média da fadiga foi de 14 meses, o que indica a cronicidade da queixa no paciente com câncer (Tabela 10). Não foram encontrados estudos que permitam comparação mas, em pacientes recém-diagnosticados com câncer colo-retal (n=194), a duração média da fadiga foi igual a 14 semanas (Majumdar, Fletcher, Evans, 1999) e, em estudo de coorte com duração de 24 meses após cirurgia envolvendo pacientes com câncer retal $(n=519)$, observou-se fadiga média, de leve a moderada, durante todo o período do estudo (Schmidt et al., 2005), o que reforça que a fadiga é um sintoma crônico. 
Conhecimentos e crenças dos doentes a respeito da fadiga foram investigados por meio das questões abertas da Escala de Fadiga de Piper-revisada (Tabelas 11 e 12).

Quando indagados sobre o que causa fadiga, cerca de $30 \%$ dos doentes relataram o tratamento para o câncer, e isso foi desejável, pois é importante que o doente reconheça a fadiga como efeito adverso das terapias anti-câncer e não como fracasso do tratamento. Um quinto dos pacientes referiu que o excesso de atividade ou esforço físico é causa de fadiga e essa compreensão pode não ser adequada. Em geral, atividade ou esforço físico está mais relacionado à fadiga aguda, que melhora após o descanso, o que não ocorre com a fadiga crônica, como aquela relacionada ao câncer.

Foram também apontados como causadores de fadiga os aspectos psicológicos (16\% dos doentes) e o câncer em si (12\% doentes), o que foi adequado mas esperava-se que maior número de pacientes tivesse descrito tais fatos. A influência da psiquê e do câncer sobre a fadiga também foi observada em outros estudos (Brown, McMillan, Milroy, 2005; Carpenter et al., 2004; Servaes et al. 2003; Kuo, Ma, 2002; Loge et al., 2000; Okuyama et al., 2000).

A presença de outros sintomas como causa de fadiga foi apontada por apenas $9 \%$ das pessoas (Tabela 11), no entanto, seria desejável que maior número de pacientes tivesse tal compreensão visto que sintomas podem causar ou agravar a fadiga, conforme visto no presente estudo e em outros estudos internacionais (Carpenter et al., 2004; Anderson et al., 2003; Servaes et al. 2003; Wang et al., 2002).

A falta de atividade como causa de fadiga foi referida por $4,4 \%$ dos indivíduos e, apesar de ser um número pequeno, foi interessante descobrir que alguns pacientes reconhecem que a inatividade causa a fadiga. Sabe-se que a inatividade tende a agravar a fadiga, pois descansar, ou estar inativo, reduz a força muscular e diminui a resistência do indivíduo à atividade. Nessas condições, a pessoa se fatiga mais rapidamente e tende 
a descansar novamente, fechando-se o ciclo inatividade-descondicionamentoinatividade.

A idade avançada e o excesso de peso foram relatados por aproximadamente $5 \%$ dos doentes como causa de fadiga, o que não tem sustentação na literatura e não foi observado no presente estudo (Tabelas 11 e 14). Estudos que controlem variáveis como o condicionamento físico, dieta, humor, desempenho físico, etc., devem ser feitos para se esclarecer essas relações.

O uso de colostomia como causa da fadiga foi relatado por $1,1 \%$ dos sujeitos e, apesar de não se ter observado associação entre fadiga e colostomia no presente estudo, levanta-se a hipótese de que a fadiga do paciente com colostomia pode estar relacionada ao aspecto psicológico de ter que viver com um artefato incômodo e desconhecido e à adaptação a novos hábitos alimentares, higienização de bolsa, etc. E 2,2\% apresentaram relato catastrófico referindo que "tudo" causa fadiga e esse tipo de relato é mais freqüente em indivíduos deprimidos.

De modo geral, as pessoas apontaram corretamente os principais fatores causais da fadiga (o câncer e seu tratamento, aspectos psicológicos e sintomas relacionados), porém poucas o fizeram. Notou-se a necessidade de promover orientação sobre os fatores causais para que pessoas com câncer não tenham concepções erradas sobre a fadiga como, por exemplo, de que a fadiga é sinal de que a doença está avançada ou de que o tratamento não está atingindo seus objetivos e de que esforço físico causa fadiga.

As respostas dadas pelos doentes para as ações para alívio da fadiga refletiram a falta de conhecimento sobre o conceito. Deitar, sentar, descansar, relaxar e dormir foram ações referidas por $47 \%$ dos sujeitos, o que representa um grande número de pessoas desenvolvendo atividades inadequadas para o controle da fadiga crônica. A fadiga crônica é aquela que não melhora após as estratégias usuais para restauração de 
energia, caso da fadiga relacionada ao câncer (Tabela 12). Tais ações não devem ser incentivadas pelos profissionais de saúde, pois sabe-se que a inatividade faz parte do ciclo inatividade-descondicionamento-inatividade. Por outro lado, realizar atividade física, ação referida por apenas 4,9\% dos sujeitos (Tabela 12) é desejável, e exercício físico é a intervenção para fadiga com melhor nível de evidência (Markes, Brockow, Resch, 2006). Atividades de distração e sociais, trabalhar e resolver problemas, também devem ser incentivadas, pois tiram o foco do doente da fadiga. Uso de medicamentos (vitaminas, minerais e bebidas energéticas) para controle da fadiga foi citado por $5,9 \%$ dos doentes e ainda não há evidência sobre a efetividade desses fármacos. Apenas $1 \%$ dos sujeitos apresentou relato catastrófico quanto à realização de ações para o controle da fadiga do tipo "nada melhora minha fadiga".

Diversos fatores podem contribuir para a ocorrência, agravamento e predição da fadiga e, por meio de análises univariadas e multivariada buscou-se identificá-los. Os resultados das análises univariadas e regressão logística estão discutidos a seguir.

A partir dos testes de associação e de diferença de médias, os fatores de risco para fadiga identificados foram o serviço onde o paciente recebeu atendimento (público), a dor (presença e intensidade), prejuízo de sono (presença e intensidade), pior capacidade funcional e depressão (presença e intensidade).

O fator de risco "serviço de saúde público" foi o único fator de risco para fadiga de ordem sócio-demográfica (Tabela 13). Não foi encontrado estudo que buscasse identificar a relação entre fadiga e serviço de saúde, provavelmente porque os pesquisadores que mais publicam sobre o assunto vivem em países desenvolvidos onde os serviços de assistência têm qualidades semelhantes independentemente da fonte financiadora. Em nosso país, pela carência de recursos materiais e humanos dos serviços de saúde públicos, poder-se-ia supor que os indivíduos atendidos nesses locais 
receberam o diagnóstico de câncer mais tardiamente, tiveram menor número de possibilidades de tratamento e pior manejo de sintomas.

No presente estudo, dor foi fator de risco para a fadiga. A média de dor dos pacientes fatigados $(2,6 \pm 3,1)$ foi mais alta que a média de dor dos pacientes nãofatigados $(1,3 \pm 2,2 ; \mathrm{p}=0,018$; Tabela 15$)$. A dor perturba o sono, compromete o repouso, restringe a atividade física, induz sofrimento e altera o humor. Esses prejuízos acarretam desgaste emocional e descondicionamento físico, que estão associados à fadiga. Encontrou-se um estudo sobre a relação dor e fadiga em pacientes com câncer colo-retal que observou correlação moderada, porém não-significante, se fosse considerado o nível de significância adotado no presente estudo $(r=0,45 ; p=0,06)$. A associação dor e fadiga, encontrada na presente pesquisa, também condiz com estudos em outras populações com câncer (Gélinas, Fillion, 2004; Kuo, Ma, 2002; Wang et al., 2002; Kaasa et al., 1999; Stone et al., 1999).

No presente estudo, prejuízo do sono foi fator de risco para a fadiga. Observouse que a média do prejuízo do sono dos pacientes fatigados $(4,2 \pm 3,7)$ foi mais alta que nos não-fatigados $(1,6 \pm 2,7 ; \mathrm{p}<0,001$; Tabela 15) e isso era esperado. O sono é um estado de inconsciência reversível em que o cérebro é menos responsivo a estímulos externos. O sono não é um estado passivo e, dentre as suas funções, ele visa à restauração de energia, ao alívio da fadiga física e mental. Quando o sono encontra-se prejudicado, funções orgânicas de várias naturezas (vasculares, cerebrais, hormonais, entre outras) deixam de atuar normalmente e ocorre fadiga (Velluti, 1996). A insônia é o prejuízo do sono mais freqüente e ocorre quando há dificuldade para se iniciar o sono, acorda-se freqüentemente durante a noite e desperta-se muito cedo (Organização Mundial de Saúde, 1993a). Não se encontrou estudo sobre a relação sono e fadiga em pacientes com câncer colo-retal, mas a associação aqui observada condiz com estudos 
em outras populações com câncer (Carpenter et al., 2004; Anderson et al., 2003; Servaes et al. 2003; Kuo, Ma, 2002; Wang et al., 2002; Stone et al., 1999).

No presente estudo, depressão foi fator de risco para a fadiga. A média do escore de depressão dos pacientes fatigados $(15,4 \pm 7,8)$ foi significativamente mais alta que a média dos pacientes não-fatigados $(7,1 \pm 5,3 ; \mathrm{p}<0,001$; Tabela 15) e essa associação era esperada, visto que sensação de fadiga é um dos componentes da depressão. Depressão é um transtorno do humor caracterizado por queixas de tristeza, desesperança, perda de prazer generalizada, perda de apetite, perturbações do sono, alterações psicomotoras, diminuição de energia, sentimentos de desvalia ou culpa e pensamentos suicidas, entre outras, que persistem por, pelo menos, duas semanas e envolvem, ao menos, quatro sintomas (DSM IV - Organização Mundial de Saúde, 1993b). Não se encontrou estudo que analisasse a relação fadiga e depressão em doentes com câncer colo-retal, mas estudos correlacionais sobre fadiga e depressão em pacientes com outros cânceres condizem com os achados do presente estudo (Brown, McMillan, Milroy, 2005; Carpenter et al., 2004; Servaes et al. 2003; Kuo, Ma, 2002; Loge et al., 2000; Okuyama et al., 2000; Dimeo et al., 1997).

No presente estudo, a capacidade funcional foi fator de risco para fadiga. $\mathrm{O}$ desempenho funcional (Escala de Karnofsky) dos pacientes fatigados $(79,8 \pm 13,7)$ foi pior que em pacientes não fatigados $(89,4 \pm 11$; $\mathrm{p}=0,001$; Tabela 14). Desempenho funcional é a capacidade do indivíduo de realizar atividades de vida diária. O desempenho funcional, além da dimensão física, depende de componentes emocionais, cognitivos e sociais (Holzner et al., 2002) e talvez isso justifique a influência da fadiga na funcionalidade. Em estudo que avaliou a correlação entre fadiga e desempenho físico em 25 doentes com câncer colo-retal, observou-se que quanto a maior fadiga, pior o desempenho funcional (Holzner et al., 2002). Estudos que analisaram a correlação 
fadiga e desempenho funcional em outras populações com câncer, também encontraram correlações negativas e moderadas ( $\mathrm{r}$ entre -0,393 e -0,56; Brown, McMillan, Milroy, 2005; Servaes et al., 2003; Simmonds, 2002; Kaasa et al., 1999).

As variáveis sexo, idade, estado civil, cor da pele, escolaridade, vínculo empregatício, renda familiar, estadiamento clínico do câncer, tratamentos, índice de massa corporal, nível de hemoglobina, presença de doenças em co-morbidades, uso de antidepressivos ou ansiolíticos e colostomia não se relacionaram à fadiga. Há estudos que observaram algumas dessas variáveis como fator de risco e em outros, tais achados não foram encontrados.

Um estudo de coorte avaliou a relação entre fadiga e sexo em pacientes com câncer retal $(n=519)$ e encontrou resultados que diferiram ao longo do tempo. A fadiga foi semelhante antes da cirurgia, foi mais intensa nas mulheres da alta hospitalar até o $6^{\circ}$ mês pós-cirurgia e, após esse período e até 24 meses pós-cirurgia, voltou a ser semelhante (Schmidt et al., 2005).

No presente estudo, não se observou relação entre idade e fadiga, o que diferiu do estudo com 309 pacientes com câncer colo-retal, que observou correlação negativa entre fadiga e idade, isto é, os indivíduos mais jovens apresentaram fadiga menos intensa que os mais velhos (Arndt et al., 2004). Apesar de ser observável que pessoas mais idosas tenham maior propensão à fadiga aguda é importante relembrar que a fadiga do paciente com câncer é crônica, aquela que não está necessariamente relacionada ao excesso de atividade, ao esforço físico e mental. A fadiga no câncer está relacionada ao tumor, ao tratamento, ao humor e a outros fatores ainda desconhecidos. Tais fatores precisam ser controlados para que se possa, de fato, analisar a influência da idade na fadiga. 
Nenhum estudo envolvendo pacientes com câncer colo-retal investigou a relação entre fadiga e anos de estudo/nível de escolaridade, vínculo empregatício e renda familiar. Considerando que o serviço de atendimento de saúde foi fator de risco para a fadiga, poder-se-ia cogitar que tais variáveis também estariam relacionados ao sintoma, o que não ocorreu.

Ao contrário do esperado, no presente estudo, o estadiamento clínico do câncer e o fato de estar ou não em tratamento não influíram na ocorrência de fadiga (Tabela 14).

Não se encontrou estudo que comparasse estatisticamente a prevalência de fadiga de acordo com o estadiamento da doença em doentes com câncer colo-retal. Dos três estudos que envolveram pacientes com câncer colo-retal, um caracterizou pacientes recém-diagnosticados com câncer colo-retal e a fadiga, que esteve presente em $25 \%$ dos doentes, não foi identificada como um dos sintomas mais comuns (Majumdar, Fletcher, Evans, 1999). Outro estudo envolveu grupos focais de pacientes com câncer colo-retal e analisou-se a intensidade do sintoma. Pacientes com câncer retal em estádio I ou câncer de cólon em estádio I/II tratados com ressecção negaram fadiga enquanto que pacientes com doença avançada referiram que a fadiga foi o sintoma mais intenso (Ness et al., 1998). O terceiro estudo envolveu pacientes com doença metastática e a fadiga foi referida como o sintoma mais intenso e limitante (Herrinton et al., 2007; Ness et al., 1998). Essas pesquisas convergem com dados da literatura de que, nas fases mais avançadas da doença, a fadiga aumenta em freqüência de ocorrência e intensidade.

No presente estudo, a influência do tratamento na ocorrência de fadiga foi testada, dividindo-se os doentes em dois grupos: fazendo ou não radio/quimioterapia e não se observaram diferenças. Revisão sobre fadiga em pacientes com câncer colo-retal recebendo quimioterapia mostrou que todas as drogas utilizadas (capecitabina, leucovorin, 5-Fluouracil, irinotecano, trimetrexate, raltitrexed, oxaliplatina, eniluracil e 
ácido folínico), independente da combinação ou esquema de infusão, causaram fadiga em algum grau, segundo o Critério Comum de Toxicidade do National Cancer Institute (Iop, Manfredi, Bonura, 2004). Em estudo publicado após essa revisão que testou fármaco para o tratamento do câncer colo-retal, a fadiga grau 3, também segundo o Critério Comum de Toxicidade do National Cancer Institute, foi descrita em $25 \%$ dos doentes (Tsutsumi et al., 2006).

O tempo após cirurgia também não se relacionou com fadiga (Tabela 14). No presente estudo, estabeleceu-se o corte do tempo após cirurgia em 3 meses acreditandose que esse tempo seria razoável para que uma pessoa submetida à cirurgia tivesse apta a desempenhar suas atividades diárias. Além disso, no presente estudo, o ponto de corte para fadiga foi igual ou superior a 4 . Estudo que mostrou a fadiga de pacientes entrevistados até 72 horas após a cirurgia de cólon relataram intensidade de fadiga igual a 28, em escala de 0 a 100, (Galloway, Graydon, 1996), o que no presente estudo não seria considerado fadiga.

No presente estudo, não se observou relação entre fadiga e a as variáveis índice de massa corporal, doenças em co-morbidade ao câncer e uso de fármacos (antidepressivos ou ansiolíticos) em doentes com câncer colo-retal e não se encontrou estudo que tenha investigado a relação entre fadiga e essas variáveis. São poucos os estudos que avaliaram tais relações em pacientes com câncer, o que impossibilitou comparações.

Ao contrário do encontrado no presente estudo, pesquisa com pacientes com câncer colo-retal $(n=309)$ identificou que pacientes com estomas apresentaram fadiga mais intensa do que os pacientes sem estomas (Arndt et al., 2004). Em outro estudo com 18 pacientes com câncer colo-retal observou-se relação positiva entre fadiga e o tempo de estoma, dado não avaliado no presente estudo (Kameo, 2006). 
Sabendo que sangramento é um sinal freqüente e importante no doente com câncer colo-retal e que anemia e fadiga, em muitos estudos, se correlacionaram, o resultado do presente estudo impressionou visto que não se identificou relação entre anemia e fadiga. Concorda-se que a quase totalidade dos sujeitos já haviam sido tratados cirurgicamente, impedindo a progressão do sangramento, e que estavam sendo assistidos em serviços privados, com maior facilidade de receber tratamento para a anemia, mas mesmo assim, sabe-se que a anemia é um problema na oncologia. Encontrou-se apenas um estudo com 25 pacientes com câncer colo-retal em tratamento quimioterápico e o nível de hemoglobina se correlacionou com fadiga apenas no segundo ciclo do tratamento (Holzner et al., 2002), o que suscita dúvidas sobre a real importância da anemia para a fadiga.

No presente estudo, foram identificados 5 fatores de risco de fadiga: serviço de saúde público, dor (presença e intensidade), prejuízo do sono (presença e intensidade), capacidade funcional prejudicada e depressão (presença e intensidade), conforme Tabelas 13, 14 e 15 .

Após a identificação dos fatores de risco (variáveis cuja freqüência de ocorrência diferiu no grupo com e sem fadiga) investigaram-se os fatores preditivos independentes de fadiga. Fator preditivo independente é aquele que prediz a probabilidade de um dado fenômeno (fadiga) ocorrer, independentemente das outras características (variáveis) envolvidas na situação. Para essa investigação a fadiga foi considerando uma variável dicotômica (com ou sem fadiga), utilizando-se o ponto de corte $\geq 4$. A maior ou menor probabilidade de um fator prever um desfecho (fadiga), pode ser calculado por meio da regressão logística.

Uma alternativa de análise à regressão logística é a regressão múltipla, que busca identificar os fatores que explicam a variação da intensidade do sintoma. A opção 
pela regressão logística deveu-se ao julgamento de que conhecer a probabilidade de um fator predizer fadiga é mais útil na clínica do que se conhecer o quanto um fator influencia na intensidade da fadiga. Pareceu-nos mais útil identificar variáveis que auxiliem no diagnóstico de fadiga do que conhecer a intensidade da fadiga que uma dada variável prediz. Fadiga, embora freqüente entre doentes com câncer (no presente estudo ocorreu em $26,8 \%$ da amostra), passa despercebida, é sub-identificada e subtratada. Alem disso, os instrumentos para sua identificação são recentes, pouco conhecidos, a maior parte só é validada para a cultura anglo-saxônica, demandam longo tempo de preenchimento e a quase totalidade não faz diagnóstico, apenas distingue zero (ausência de fadiga) de não zero (algum grau). A identificação dos fatores preditivos permite aos profissionais inferir a presença de fadiga. Acrescente-se também que, ao se tratar os fatores preditivos tratáveis, melhora-se o controle da fadiga.

Os pontos de corte para as variáveis contínuas (intensidade de dor, intensidade de prejuízo do sono, capacidade funcional e depressão) foram determinados pela análise da curva $R O C$ (Tabela 16). A curva $R O C$ mostra a relação entre a sensibilidade e a especificidade de um teste e o melhor ponto de corte é aquele que distingue quem tem de quem não tem o agravo, evitando-se ao máximo os falsos positivos e falsos negativos.

Os pontos de corte da intensidade de prejuízo do sono, da capacidade funcional e da depressão apresentaram nível de significância $\mathrm{p}<0,001$ e área sob a curva $R O C$ aproximada $\geq 0,7$. O ponto de corte da intensidade da dor apresentou $\mathrm{p}=0,016 \mathrm{e}$ área sob curva $R O C=0,6$. Destacou-se a variável depressão que apresentou a maior área sob a curva $(0,8)$ e o melhor conjunto de valores de sensibilidade e especificidade $(0,73$ e 0,79, respectivamente), conforme Tabela 16. Esses procedimentos permitiram estabelecer os seguintes pontos de corte: dor $\geq 6$, prejuízo sono $\geq 5$, capacidade 
funcional $\leq 80$ e depressão $\geq 13$. Após a obtenção dos pontos de corte das variáveis contínuas, essas e os demais fatores de risco identificados por meio da análise univariada foram inseridos no modelo da regressão logística.

Os fatores preditivos independentes para a fadiga foram prejuízo do sono, depressão e capacidade funcional (Tabela 18). Esse resultado indica que, ao se avaliar sono, depressão e capacidade funcional, têm-se a probabilidade de o paciente ter fadiga e essa probabilidade pode ser avaliada pela Tabela de Predição de Fadiga (Tabela 19). Observou-se que, se os três fatores preditivos estiverem presentes (prejuízo do sono, depressão e capacidade funcional), a probabilidade de o paciente ter fadiga é de aproximadamente $80 \%$, e se nenhum desses fatores estiver presente, a probabilidade de ocorrer fadiga é de apenas de $8 \%$. Obviamente, a probabilidade de ter fadiga é maior quando se tem dois fatores preditivos do que quando se tem apenas um fator, e a probabilidade de ter fadiga é maior quando se tem depressão do que quando se tem qualquer um dos demais fatores. Não se encontrou estudo sobre fatores preditivos de fadiga em pacientes com câncer colo-retal.

Chamou a atenção o fato de que apenas três variáveis foram capazes de predizer fadiga com alta probabilidade $(80 \%)$ o que é muito útil na clínica, pois facilita a identificação de fadiga. No entanto, mesmo quando os três fatores preditivos independentes estão presentes, $20 \%$ dos pacientes têm fadiga por outros fatores, que ainda precisam ser conhecidos.

Os pacientes com prejuízo do sono (escore $\geq 5$ ) apresentaram uma razão de risco aproximadamente 3 vezes maior de ter fadiga que os pacientes sem prejuízo do sono (Tabela 18), o que foi um risco importante. Sono prejudicado foi observado como fator preditivo, em estudos de regressão múltipla, em doentes com câncer em diversos sítios (Anderson et al., 2003; Servaes, Verhagen, Bleijenberg, 2002a). 
Os doentes deprimidos (escore no Inventário de Depressão de Beck $\geq 13$ ) apresentaram razão de risco 4 vezes maior de ter fadiga que os doentes não-deprimidos (Tabela 18) e a depressão foi o fator preditivo independente mais importante. Fatigabilidade é um componente da depressão, o que significa que pacientes deprimidos comumente sofrem com fadiga. No presente estudo, fadiga ocorreu em 8 dos 11 pacientes deprimidos, conforme Tabela 15. A depressão, ou sintomas depressivos, foi fator preditivo em estudos com outras populações oncológicas, o que reforça a importância da depressão como fator preditivo de fadiga no paciente com câncer (Echteld et al., 2007; Young, White, 2006; Brown, McMillan, Milroy, 2005; Dimeo et al., 2004; Hwang et al., 2003; Servaes, Verhagen, Bleijenberg, 2002a; Akechi et al., 1999).

Os doentes com capacidade funcional prejudicada (escore na Escala de Karnofsky $\leq 80 \%$ ) apresentaram razão de risco aproximadamente 3 vezes maior que aqueles com capacidade funcional preservada (Tabela 18), e isso também é um risco importante. Capacidade/desempenho funcional foi identificado como fator preditivo de fadiga em vários estudos de regressão múltipla com doentes com câncer (Ahlberg, Ekman, Gaston-Johansson, 2005; Brown, McMillan, Milroy, 2005; Akechi et al., 1999).

Os fatores de risco serviço público de saúde e dor (presença e intensidade) foram excluídos do modelo da regressão logística. Nem todo fator de risco é fator preditivo, pois a análise de regressão múltipla diferencia as variáveis que são, de modo independente, importantes para a ocorrência de um desfecho (fadiga) daquelas que parecem ser importantes para o fenômeno, mas que, de fato estão sobrepostas a outras.

Buscando-se analisar as razões do "serviço público" não ter permanecido no modelo de regressão múltipla, observou-se que os pacientes desses serviços foram mais 
deprimidos do que aqueles dos serviços privados $(\mathrm{p}=0,006$; Tabela 17) o que sugere que esse fator de risco foi representado pela depressão.

A dor também foi excluída do modelo de regressão múltipla e, na busca de compreender sua exclusão, observou-se que maior prevalência de depressão e prejuízo no sono ocorreu em pacientes com dor $(\mathrm{p}=0,031$ e $\mathrm{p}<0,001$, respectivamente; Tabela 17). Desse modo, acredita-se que dor ficou representada no modelo de regressão logística pela depressão e prejuízo do sono.

Interessante observar que há uma relação complexa entre fadiga e os fatores preditivos e entre os próprios fatores preditivos. Fadiga, prejuízo do sono, depressão e capacidade funcional prejudicada coexistem e freqüentemente podem ser causa e consequiência um do outro (Velluti, 1996; Beck et al., 2005; North American Nursing Diagnosis Association, 2002). O paciente com sono prejudicado se sente fatigado e, por não dormir adequadamente, impede que funções orgânicas aconteçam não restabelecendo a energia. O paciente com depressão sente fadiga e pode apresentar alteração no padrão do sono, ora dormindo em excesso, ora não dormindo o necessário. E o paciente com capacidade funcional prejudicada se fatiga mais facilmente, pode sentir-se desmotivado e assim apresentar-se mais entristecido.

A especificidade do modelo foi boa $(81,9 \%)$, isto é, é baixa a chance de se considerar fatigado aquele sem fadiga, mas a sensibilidade do modelo foi moderada $(58,6 \%)$, o que aumenta a chance de não se diagnosticar fadiga num doente fatigado. Novos estudos que busquem identificar algum fator de risco que aumente a sensibilidade do modelo são necessários. Não se encontrou estudo com regressão logística para identificação de fatores preditivos de fadiga em pacientes com câncer colo-retal e, dos três estudos que utilizaram o método de regressão logística envolvendo pacientes com outros tumores, apenas um citou que a capacidade discriminativa do 
modelo foi de 0,88 (Hwang et al., 2003). Nesse estudo, com 180 homens com cânceres em diversos sítios, os fatores preditivos foram tristeza, tontura, dor, falta de apetite, irritabilidade e dispnéia (Hwang et al., 2003).

Se a avaliação do sono, da depressão e da capacidade funcional indica a probabilidade do paciente com câncer colo-retal ter ou não fadiga e, se em consultas ao paciente oncológico, o sono, os sintomas depressivos e a funcionalidade, muitas vezes, são avaliados, indaga-se a real necessidade de se utilizar escalas multidimensionais, como a Escala de Fadiga de Piper-Revisada, para diagnosticar a fadiga.

Com base nos resultados da avaliação do sono, depressão e da capacidade funcional, o profissional pode, de fato, estimar a probabilidade de o paciente ter ou não fadiga. Porém, visto a moderada sensibilidade do modelo $(58,6 \%)$, que aumenta a chance de falsos negativos, considera-se importante avaliar especificamente a fadiga, para confirmação de sua presença.

O uso de escala numérica para avaliação da fadiga pode ser alternativa aos instrumentos mais extensos para se confirmar a presença e intensidade da fadiga. Apresenta a vantagem de ser rápida e viável, diminuindo as barreiras para a avaliação do sintoma e agilizando o seu diagnóstico na assistência e pesquisa. No presente estudo, conforme descrito no método, testou-se a correlação entre escala numérica de fadiga e a Escala de Fadiga de Piper-revisada e observou-se correlação alta $(r=0,748 ; p<0,001)$, o que indica que pode ser útil no dia-a-dia da assistência ao paciente com câncer. A principal limitação da escala numérica é a falta de detalhamento sobre o sintoma, o que seria possível com instrumentos multidimensionais como o de Piper.

A Escala de Piper é um instrumento utilizado em pesquisas em todo o mundo e permite comparações entre doentes e grupos populacionais de diferentes países. Sua utilidade na prática clínica é a de mensurar a fadiga e detalhar os elementos que a 
compõem, e essa última utilidade talvez favoreça a proposição de intervenções mais individualizadas para cada doente.

Algumas limitações do presente estudo podem ser apontadas. A amostra não foi aleatória, o que impede generalizações; a classificação da variável tratamento atual para o câncer foi dicotômica, visto que se considerou apenas se o indivíduo fazia ou não tratamento químio ou radioterápico, e isso pode ter mascarado alguma diferença; e não houve investigação de alterações do funcionamento do tubo gastrintestinal, como diarréia e constipação. Ainda, a inclusão de pacientes com câncer colo-retal internados é desejável pois pode ampliar os achados referentes aos fatores de risco e preditivos nesta população. Tais limitações devem ser superadas em novos estudos. Pesquisas futuras devem, também, considerar a validação dos resultados desta tese, testando-se a Tabela de Predição de Fadiga. A realização de estudo prospectivo seria o método ideal de se validar os achados desta pesquisa e aperfeiçoar estratégias diagnósticas de fadiga na prática clínica.

Com o presente estudo, alguns avanços podem ser apontados. Em âmbito nacional, pela primeira vez, foi determinada a prevalência de fadiga em pacientes com câncer colo-retal, validou-se a Escala de Fadiga de Piper - revisada para a língua portuguesa e estabeleceu-se ponto de corte de fadiga. Fadiga foi freqüente, observada em $26,8 \%$ dos casos. As dimensões comportamental e sensorial/psicológica da fadiga foram mais elevadas nos doentes deprimidos e a dimensão sensorial/psicológica da fadiga foi mais elevada naqueles com fadiga mais prolongada ( $\geq 12$ meses).

Em âmbito mundial, alguns resultados são inovadores, pois não se conheciam os fatores preditivos independentes de fadiga em doentes com câncer colo-retal. O estudo disponibiliza Tabela de Predição de Fadiga (Tabela 19) que permite averiguar o risco de um doente ter fadiga. Prejuízo do sono, depressão e capacidade funcional prejudicada, 
em concomitância, predisseram $80 \%$ dos casos de fadiga na situação de câncer coloretal, o que é muito bom. Depressão aumentou em 4 vezes o risco de fadiga, e prejuízo do sono e capacidade funcional aumentaram em 3 vezes o risco de fadiga. Pela sensibilidade moderada do modelo resultante (58\%), há considerável chance de haver falsos negativos, o que talvez possa ser minimizado pelo uso de uma escala de numérica de 0 a 10. Caso o doente apresente fadiga (escore $\geq 4$ ), sugere-se a avaliação detalhada do fenômeno para que se possa ter um quadro mais refinado da fadiga do paciente. 


\section{CONCLUSÕES}

Os fatores preditivos independentes de fadiga no câncer colo-retal foram prejuízo do sono, depressão e capacidade funcional. Quando os três fatores estiveram presentes, a probabilidade de o doente ter fadiga foi de $80 \%$, o que indicou boa predição. Quando os três fatores estiveram ausentes, a probabilidade de ter fadiga foi de 8\%. A depressão aumentou em 4 vezes o risco para fadiga, e o sono e a capacidade funcional prejudicados aumentaram em 3 vezes o risco para fadiga.

A sensibilidade do modelo de predição foi moderada (58\%) e há considerável chance de haver falsos negativos, o que talvez possa ser minimizado pelo uso de escala numérica de 0 a 10, que teve forte correlação com Escala de Fadiga de Piper (padrão ouro). Caso o doente apresente fadiga na escala de 0 a 10 (escore $\geq 4$ ), sugere-se a avaliação do fenômeno utilizando-se instrumento multidimensional.

O estudo disponibiliza tabela de probabilidade de predição de fadiga e propõe que, por meio da avaliação da depressão, da capacidade funcional e do prejuízo do sono é possível conhecer a probabilidade de o paciente ter fadiga, o que é inédito nessa população e de grande utilidade na clínica. 


\section{REFERÊNCIAS BIBLIOGRÁFICAS}

- Ahlberg K, Ekman T, Gaston-Johansson F. Fatigue, psycholocial distress, coping resources, and functional status during radiotherapy for uterine cancer. Oncol Nurs Forum 2005; 32 (3): $633-40$.

- Akechi T, Kugaya A, Okamura H, Yamawaki S, Uchitome Y. Fatigue and its associated factors in ambulatory cancer patients: a preliminary study. J Pain Symptom Manage 1999; 17 (1): $42-8$.

- Anderson KO, Getto CJ, Mendoza TR, Palmer SN, Wang XS, Reyes-Gibby CC, Cleeland CS. Fatigue and sleep disturbance in patients with cancer, patients with clinical depression, and community-dwelling adults. J Pain Symptom Mange 2003; 25 (4): 307-18.

- Arndt V, Merx H, Stegmaier C, Ziegler H, Brenner H. Quality of life in patients with colorectal cancer 1 year after diagnosis compared with the general population: a populationbased study. J Clin Oncol 2004; 22 (23): 4829-36.

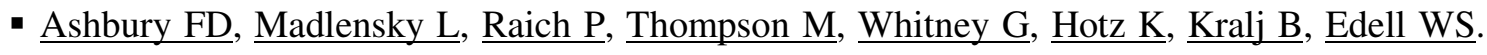
Antidepressant prescribing in community cancer care. Support Care Cancer 2003; 11 (5): 27885.

- Beach P, Siebeneck B, Buderer NF, Ferner T. Relationship between fatigue and nutritional status in patients receiving radiation therapy to treat lung cancer. Oncol Nurs Forum 2001; 28 (6): 1027-31.

- Beck SL, Dudley WN, Barsevick A. Pain, sleep disturbance, and fatigue in patients with cancer: using a mediation model to test a symptom cluster. Oncol Nurs Forum 2005; 32 (3): E48-E55. Disponível no site: http://www.ons.org/publications/journals/ONF, em 15/12/07.

- Bernardo W, Nobre M. Prática clínica baseada em evidência. São Paulo: Elsevier; 2006. 248p.

- BRASIL. Ministério da Saúde. Organização Pan-Americana de Saúde. Plano de reorganização da atenção à hipertensão arterial e ao diabetes Mellitus no Brasil. Brasília, Ministério da Saúde, 2004.

- Breitbart W, Rosenfeld B, Kaim M, Funesti-Esch J. A randomized, double-blind, placebocontrolled trial of psychostimulants for the treatment of fatigue in ambulatory patients with human immunodeficiency virus disease. Arch Intern Med 2001; 161 (3): 411-20.

- Brown DJF, McMillan DC, Milroy R. The correlation between fatigue, physical function, the systemic inflammatory response, and psychological distress in patients with advanced lung cancer. Cancer 2005; 103 (2): 377-82. 
- Burke MB. Fatigue and quality of life: a question of balance. In: King CR, Hinds PS (Eds). Quality of life: from nursing and patients perspectives. Jones \& Bartlett: Boston; 1998. p. 255-83.

- Carpenter JS, Elam JL, Ridner SH, Carney PH, Cherry GJ, Cucullu HL. Sleep, fatigue, and depressive symptoms in breast cancer survivors and matched healthy women experiencing hot flashes. Oncol Nurs Forum 2004; 31 (3): 591-8.

- Chang YJ, Lee JS, Lee CG, Lee WS, Lee KS, Bang SM, et al. Assessment of clinical relevant fatigue level in cancer. Support Care Cancer 2007; 15: 891-6.

- Cho HJ, Costa E, Menezes PR, Chalder T, Bhugra D, Wessely S. Cross-cultural validation of the Chalder Fatigue Questionnaire in Brazilian primary care. J Psychosom Res 2007; 62(3): 301-4.

- Clark PC, Ashford S, Burt R, Aycock DM, Kimble LP. Factor Analysis of the Revised Piper Fatigue Scale in a caregiver sample. J Nurs Measure 2006; 14 (2): 71-8.

- Coelho FMR, Sawada NO. A fadiga nos pacientes com câncer de laringe. Rev Latino-Am Enfermagem 1999; 7 (5): 103-7.

- Dagnelie PC, Pijls-Johannesma MCG, Lambin P, Beijer S, De Ruysscher D, Kempen GIJM. Impact of fatigue on overall quality of life in lung and breast cancer patients selected for highdose radiotherapy. Ann Oncol 2007; 18: 940-4.

- Dagnelie PC, Pijls-Johannesma MCG, Pijpe A, Boumans BJE, Skrabanja ATP, Lambin P, Kempen GIJM. Psychometric properties of the revised Piper Fatigue Scale in Dutch cancer patients were satisfactory. J Clin Epidemiol 2006; 59: 642-9.

- de Jong N, Candel MJ, Schouten HC, Abu-Saad HH, Courtens AM. Course of mental fatigue and motivation in breast cancer patients receiving adjuvant chemotherapy. Ann Oncol 2005;16(3): 372-82.

- de Jong N, Candel MJ, Schouten HC, Abu-Saad HH, Courtens AM. Course of the fatigue dimension "activity level" and the interference of fatigue with daily living activities for patients with breast cancer receiving adjuvant chemotherapy. Cancer Nurs 2006; 29(5): E113.

- de Jong N, Candel MJ, Schouten HC, Abu-Saad HH, Courtens AM. Prevalence and course of fatigue in breast cancer patients receiving adjuvant chemotherapy. Ann Oncol 2004;15(6): 896-905. 
- de Jong N, Courtens AM, Abu-Saad HH, Schouten HC. Fatigue in patients with breast cancer receiving adjuvant chemotherapy: a review of the literature. Cancer Nurs 2002; 25 (4): 28397.

- Dimeo F, Schmittel A, Fietz T, Schwartz S, Kohler P, Boning D, Thiel E. Physical performance, depression, immune status and fatigue in patients with hematological malignacies after treatment. Ann Oncol 2004; 15: 1237-42.

- Dimeo F, Stieglitz RD, Novelli-Fischer U, Fetscher S, Mertelsmann R, Keul J. Correlatioin betwee physical performance and fatigue in cancer patients. Ann Oncol 1997; 8: 1251-5.

- Dodd MJ, Miaskowski C, Lee KA. Occurrence of symptom clusters. JNCI Monographs 2004; 32: $76-8$.

- Dodd MJ, Miaskowski C, Paul SM. Symptom clusters and their effect on the functional status of patients with cancer. Oncol Nurs Forum 2001; 28 (3): 465-70.

- Donovan KA, Jacobsen PB. Fatigue, depression, and insomnia: evidence for a symptom cluster in cancer. Semin Oncol Nurs. 2007 May;23(2):127-35.

- Echteld MA, Passchier J, Teunissen S, Claessen S, de Wit R, van der Rijt CCD. Multidimensional fatigue and its correlates in hospitalised advanced cancer patients. Eu J Cancer 2007; 43: 1030-6.

- Ellenhorn JDI, Cullinane CA, Coia LR, Alberts SR. Colorectal and anal cancers. In: Pazdur R, Coia LR, Hoskins WJ, Wagman LD (Eds). Cancer management: a multidisciplinary approach. $6^{\text {th }}$ ed. New York: CMP; 2002. p. 323 - 54. Disponível no site: http://www.breastlink.com/downloads/16colorectal.pdf, em 11/01/08.

- Foley KM. Management of cancer pain. In: DeVita Jr, VT, Hellman S, Rosenberg SA (Eds). Cancer: principles and practice of oncology. Lippincott Williams \& Wilkins: Philadelphia; 2005. p. 2615.

- Formenti SC, Gidea-Addeo D, Goldberg JD, Roses DF, Guth A, Rosenstein BS, et al. Phase III trial of prone accelerated intensity modulated radiation therapy to the breast to optimally spare normal tissue. J Clin Oncol 2007; 25 (16): 2236-42.

- Fox SW, Lyon D, Farace E. Symptom clusters in patients with high-grade glioma. J Nurs Scholarsh 2007; 39 (1): 61-7.

- Fox SW, Lyon DE. Symptom clusters and quality of life in survivors of lung cancer. Oncol Nurs Forum 2006; 33 (5): 931-6. 
- Fu MR, Anderson CM, McDaniel R, Armer J. Patients's perceptions of fatigue in response to biochemotherapy for metastatic melanoma: a preliminary study. Oncol Nurs Forum 2002; 29 (6): 961-6.

- Galloway SC, Graydon JE. Uncertainty, symptom distress, and information needs after surgery for cancer of the colon. Cancer Nurs 1996; 19 (2): 112-7.

- Geels P, Eisenhauer E, Bezjak A, Zee B, Day A. Palliative effect of chemotherapy: objective tumor response is associated with symptom improvement in patients with metastatic breast cancer. J Clin Oncol 2000; 18 (12): 2395-405.

- Geinitz H, Zimmermann FB, Thamm R, Keller M, Busch R, Molls M. Fatigue in patients with adjuvant radiation therapy for breast cancer: long-term follow-up. J Cancer Res Clin Oncol 2004;130(6): 327-33.

- Gélinas C, Fillion L. Factors related to persistent fatigue following completion of breast cancer treatment. Oncol Nurs Forum 2004; 31 (2): 269-78.

- Given DW, Given B, Azzouz F, Kozachik S, Stommel M. Predictos of pain and fatigue in the year following diagnosis among elderly cancer patients. J Pain Symptom Manage 2001; 21 (6): 456-66.

- Glaus A, Müller S. Hemoglobin and fatigue in cancer patients: inseparable twins? Schweiz Med Wochenschr. 2000 Apr 1;130(13):471-7.

- Gledhill JA, Rodary C, Mahé C, Laizet C. Validation française de l'échelle de fatigue révisée de Piper [French validation of the revised Piper Fatigue Scale]. Rech Soins Infirm 2002; 68: $50-65$.

- Goldstein D, Bennett B, Friedlander M, Davenport T, Hickie I, Lloyd A. Fatigue states after cancer treatment occur both in association with, and independent of, mood disorder: a longitudinal study. BMC Cancer 2006; 6:240. Disponível no site: http://www.biomedcentral.com/1471-2407/6/240.

- Gorentein C, Andrade L. Validation of a Portuguese version of the Beck Depression Inventory and the State-Trait Anxiety Inventory in Brazilian subjects. Brazilian Journal of Medical and Biological Research 1996; 29: 453-7.

- Groenvold M, Petersen MA, Idler E, Bjorner JB, Fayers PM, Mouridsen HT. Psychological distress and fatigue predicted recurrence and survival in primary breast cancer patients. Breast Cancer Res Treat 2007; 105(2):209-19.

- Groopman J, Itri LM. Chemotherapy-induced anemia in. adults: Incidence and treatment. J Natl Cancer Inst 1999; 91: 1616-1634. 
- Herrinton LJ, Neslund-Dudas C, Rolnick SJ, Hornbrook MC, Bachman DJ, Darbinian JA, et al. Complications at the end of life in ovarian cancer. J Pain Symptom Manage 2007; 34 (3): $237-43$.

- Hickok JT, Morrow GR, McDonald S, Bellg AJ. Frequency and correlates of fatigue in lung cancer patients receiving radiation therapy: implications for management. J Pain Symptom Manage 1996; 11 (6): 370-7.

- Hickok JT, Roscoe JA, Morrow GR, Mustian K, Okunieff P, Bole CW. Frequency, severity, clinical course, and correlates of fatigue in 372 patients during 5 weeks of radiotherapy for cancer. Cancer 2005; 15;104 (8):1772-8.

- Holley S. Cancer-related fatigue. Suffering a different fatigue. Cancer Pract 2000; 8 (2):87-95.

- Holzner B, Kemmler G, Greil R, Zeimet A, Raderer M, Hejna M, et al. The impact of hemoglobin levels on fatigue and quality of life in cancer patients. Ann Oncol 2002; 13: 96573.

- Husain, 2007, Stewart K, Arseneault R, Moineddin R, Cellarius V, Librach SL, Dudgeon D. Women experience higher levels of fatigue than men at the end of life: a longitudinal home palliative care study. J Pain Symptom Manage 2007; 33 (4): 389-97.

- Hwang SS, Chang VT, Rue M, Kasimis B. Multidimensional independent predictors of cancer-related fatigue. J Pain Symptom Manage 2003; 26 (1): 604-14.

- INCA - Instituto Nacional do Câncer. Estimativa de Incidência de Câncer no Brasil para 2008. Disponível no site: Estimativa de Incidência de Câncer no Brasil para 2008, em $11 / 01 / 08$.

- Iop A, Manfredi AM, Bonura S. Fatigue in cancer patients receiving chemotherapy: an analysis of published studies. Ann Oncol 2004; 15: 712-20.

- Jenkins CA, Schulz M, Hanson J, Bruera E. Demographic, symptom, and medication profiles of cancer patients seen by a palliative care consult team in a tertiary referral hospital. J Pain Symptom Manage 2000; 19 (3): 174-84.

- Kaasa S, Loge JH, Knobel H, Jordhoy MS, Brenne E. Fatigue. Measures and relation to pain. Acta Anaesthesiologica Scandinavica 1999; 43: 939-47.

- Kameo SY. Qualidade de vida do paciente com estoma intestinal secundária ao câncer coloretal. Dissertação. Ribeirão Preto: Escola de Enfermagem, Universidade de São Paulo, 2006. $113 p$. 
- Karnofsky DA, Burchenal JH. The Clinical Evaluation of Chemotherapeutic Agents. In: MacLeod CM (Ed.). Evaluation of Chemotherapeutic Agents. Columbia Univ. Press, 1949. p 196.

- Kenefick AL. Patterns of symptom distress in older women after surgical treatment for breast cancer. Oncol Nurs Forum 2006; 33 (2): 327-35.

- Kerlinger FN. Foundations of behavioral research. $3^{\text {rd }}$ ed. New York: Holt, Rinehard and Winston; 1986. p. 415.

- Kessler H, Milsom JW. Cancer of the colon and rectum. In: Pollock RE (Ed). Manual of Clinical Oncology of the UICC - International Union Against Cancer. $7^{\text {th }}$ ed. New York: Wiley-Liss; 1999. p. 477-490.

- Knobel H, Loge JH, Lund MB, Forfang K, Nome O, Kaasa S. Late medical complications and fatigue in Hodgkin's disease survivors. J Clin Oncol 2001; 19 (13): 3226-33.

- Kuo TT, Ma FC. Symptom distress and coping strategies in patients with non-small cell lung cancer. Cancer Nurs 2002; 25 (4): 309-17.

- Kurtz ME, Kurtz JC, Stommel M, Given CW, Given B. Predictors of depressive symptomatology of geriatric patients with colorectal cancer: a longitudinal view. Support Care Cancer 2002; 10: 494-501.

- Lavdaniti M, Patiraki E, Dafni U, Katapodi M, Papathanasoglou E, Sotiropoulou A. Prospective assessment of fatigue and health status in greek patients with breast cancer undergoing adjuvant radiotherapy. Oncol Nurs Forum 2006; 33 (3): 603-10.

- Lawrence DP, Kupelnick B, Miller K, Devine D, Lau J. Evidence report on the occurrence, assessment, and treatment of fatigue in cancer patients. JNCI Monographs 2004; 32: 40-50.

- Liberman T, Derchain SFM, Sarian LOZ, Teixeira LC, Camargo CPP, Fonsechi-Carvasan GA. Fadiga, ansiedade e depressão em pacientes com câncer de mama durante a quimioterapia. Rev Ginecol Obstet 2004; 15 (1): 5-11.

- Libutti SK, Saltz LB, Rustgi AK, Tepper JE. Cancer of the colon. In: DeVita Jr, VT, Hellman S, Rosenberg SA (Eds). Cancer: principles and practice of oncology. Lippincott Williams \& Wilkins: Philadelphia; 2005. p. 1061-1109.

- Lis CG, Cambron JA, Grutsch JF, Granick J, Gupta D. Self-reported quality of life in users and nonusers of dietary supplements in cancer. Care Cancer 2006; 14: 193-9.

- Lissoni P. Is there a role for melatonin in supportive care? Support Care Cancer 2002; 10: 110-6. 
- Liu L, Marler MR, Parker BA, Jones V, Hohnson S, Cohen-Zion M, et al. The relationship between fatigue and light exposure during chemotherapy. Support Care Cancer 2005; 13: 1010-7.

- Llobera J, Esteva M, Rifá J, Benito E, Terrasa J, Rojas C, et al. Terminal cancer: duration and prediction of survival time. Eur J Cancer 2000; 36: 2036-43.

- Loge JH, Abrahamsen AF, Ekeberg, Kaasa S. Fatigue and psychiatric morbidity among Hodgkin's disease survivors. J Pain Symptom Manage 2000;19 (2):91-9.

- Majumdar SR, Fletcher RH, Evans AT. How does colorectal cancer present? Symptoms, duration, and clues to location. Am J Gastroenterol 1999; 94 (10): 3039-45.

- Markes M, Brockow T, Resch KL. Exercise for women receiving adjuvant therapy for breast cancer (Cochrane Review). In: The Cochrane Library, Issue 2; 2007.

- Massie MJ. Prevalence of depression in patients with cancer. JNCI Monographs 2004; 32: 57 71.

- Miaskowski C. Gender differences in pain, fatigue, and depression in patients with cancer. JNCI Monographs 2004; 32: 139-43.

- Mills M, Graci GM. Sleep disturbances. In: Yarbro CH, Frogge MH, Goodman M (Eds). Cancer symptom management. Jones \& Bartlett Publishers: Sudburry; 2004. p. 111-33.

- Molassiotis A, Chan CW. Fatigue patterns in Chinese patients receiving radiotherapy. Eur J Oncol Nurs 2004; 8(4): 334-40.

- Montazeri A, Jarvandi S, Haghighat S, Vahdani M, Sajadian A, Ebrahimi M, et al. Anxiety and depression in breast cancer patients before and after participation in a cancer support group. Patient Educ Couns 2001; 45(3): 195-8.

- Morant R, Stiefel F, Berchtold W, Radziwill A, Riesen W. Preliminary results of a study assessing asthenia and related psychological and biological phenomena in patients with advanced cancer. Support Care Cancer 1993; 1: 101-7.

- Mota DDCF, Cruz DALM, Pimenta CAM. Fadiga: uma análise do conceito. Acta Paulista de Enfermagem 2005; 18: 285 - 293.

- Mota DDCF, Pimenta CAM, Fitch MI. Fatigue Pictogram: an Easy to Use Self-Report Instrument to Assess Fatigue in Oncology Clinical Practice. In: 20th International Symporium Supportive Care in Cancer, 2007, St. Gallen. Supportive Care in Cancer. Heidelberg: Springer-Verlag, 2007; 15: 708 - 709. 
- Mota DDCF, Pimenta CAM, Piper BP. Measurement of fatigue in Brazilian cancer patients, caregivers and nursing students: A validation study of the Piper Fatigue Scale - Revised. 2007. (Submitido para publicação).

- Mota DDCF, Pimenta CAM. Self-report instruments for fatigue assessment: a systematic review. Research and Theory for Nursing Practice 2006; 20: 49 - 78.

- Mota DDCF. Instrumentos de auto-relato para avaliação de fadiga: uma revisão sistemática crítica [dissertação]. São Paulo: Escola de Enfermagem, Universidade de São Paulo; 2003.

- Munch TN, Stromgren AS, Pedersen L, Petersen MA, Hoermann L, Groenvold M. Multidimensional measurement of fatigue in advanced cancer patients in palliative care: an application of the multidimensional fatigue inventory. J Pain Symptom Manage 2006; 31 (6): $533-41$.

- NANDA (North American Nursing Diagnosis Association). Diagnósticos de Enfermagem da NANDA: definições e classificações - 2001-2002. Trad. de Jeanne Liliane Marlene Michel. Porto Alegre: Artmed; 2002. p. 115-6.

- NCCN - National Comprehensive Cancer Network. Cancer-related fatigue: NCCN Clinical Practice Guidelines in Oncology. Disponível online no site: www.nccn.org/professionals/physician gls/PDF/fatigue.pdf, em 13/08/07.

- Ness RM, Holmes A, Klein R, Greene J, Dittus R. Outcome states of colorectal cancer: identification and description using patient focus group. Am J Gastroenterol 1998; 93 (9): 1491-7.

- Okuyama T, Akechi T, Kuhaya A, Okamura H, Shima Y, Maruguchi M, et al. Development and validation of the Cancer Fatigue Scale: a brief, three-dimensional, self-rating scale for assessment of fatigue in cancer patients. J Pain Symptom Manage 2000; 19: 5-14.

- Oliveira F. Ser negro no Brasil: alcances e limites. Estud Av 2004; 18 (50). Disponível no site: http://www.scielo.br/scielo.php?script=sci_arttext\&pid=S0103-40142004000100006, em $11 / 01 / 08$.

- Olsson M, Lexell J, Söderberg S. The meaning of fatigue for women with multiple sclerosis. J Adv Nurs 2005; 49 (1):7-15.

- OMS - Organização Mundial da Saúde. Classificação de transtornos mentais e de comportamento da CID-10: descrições clínicas e diretrizes diagnósticas. Trad. Dorgival Caetano. Porto Alegre: Artes Médicas; 1993b. p. 5-14.

- OMS - Organização Mundial da Saúde. Divisão de Saúde Mental/Division of Mental Health. Insomnia in General Practice. Geneva: WHO, 1993a. 
- Ostlund U, Gustavsson P, Furst CJ. Translation and cultural adaptation of the Piper Fatigue Scale for use in Sweden. Eu J Oncol Nurs 2007; 11: 133-40.

- Payne JK, Piper BF, Rabinowitz I, Zimmerman MB. Biomarkers, fatigue, sleep, and depressive symptoms in women with breast cancer: a pilot study. Oncol Nurs Forum 2006; 33 (4): 775-83.

- Piper BF, Dibble SL, Dodd MJ, Weiss MC, Slaughter RE, Paul SM. The revised Piper Fatigue Scale: psychometric evaluation in women with breast cancer. Oncol Nurs Forum 1998; 25 (4): 677-84.

- Piper BF, Lindsey AM, Dodd MJ, Ferketich S, Paul SM, Weller S. The development of an instrument to measure the subjective dimension of fatigue. In: Funk SG, Tornquist EM, Champagne MT, Copp LA, Wiese RA, editors. Key aspects of comfort: management of pain, fatigue and nausea. New York: Springer; 1989. p. 199-208.

- Pirl WF, Greer JA, Goode M, Smith MR. Prospective study of depression and fatigue in men with advanced prostate cancer receiving hormone therapy. Psychooncology 2007

- Respini D, Jacobsen PB, Thors C, Tralongo P, Balducci L. The prevalence and correlates of fatigue in older cancer patients. Crit Rev Oncol Hematol 2003; 47: 273-9.

- Rogers LQ, Courneya KS, Robbins KT, Malone J, Seiz A, Koch L, et al. Physical activity and quality of life in head and neck cancer survivors. Support Care Cancer 2006; 14: 1012-9.

- Sarna L, Brecht ML. Dimensions of symptom distress in women with advanced lung cancer: a factor analysis. Heart Lung 1997; 26 (1): 23-30.

- SBEM - Sociedade Brasileira de Endocrinologia e Metabolismo. Calcule o seu IMC. Disponível no site: http://www.endocrino.org.br/conteudo/publico/imc.php, em 17/10/2007.

- Schag CC, Heinrich RL, Ganz PA. Karnofsky performance status revisited: reliability, validity, and guidelines. J Clin Oncol 1984; 2: 187-93.

- Schips L, Lipsky K, Zigeuner R, Salfellner M, Winkler S, Langner C et al. Impact of tumorassociated symptoms on the prognosis of patients with renal cell carcinoma: a single-center experience of 683 patients. Urology 2003; 62 (6): 1024-8.

- Schmidt CE. Bestmann B, Kuchler T, Longo WE, Kremer B. Ten-year historic cohort of quality of life and sexuality in patients with rectal cancer. Dis Colon Rectum 2005; 48: 48392.

- Schneider EC, Malin JL, Kahn KL, Ko CY, Adams J, Epstein AM. Surviving colorectal cancer: patient-reported symptoms 4 years after diagnosis. Cancer 2007; 110 (9): 2075-82. 
- Servaes P, Verhagen S, Bleijenberg G. Determinants of chronic fatigue in disease-free breast cancer patients: a cross-sectional study. Ann Oncol 2002a; 13: 589-98.

- Servaes P, Verhagen S, Bleijenberg G. Fatigue in cancer patients during and after treatment: prevalence, correlates and interventions. Eur J Cancer 2002b; 38: 27-43.

- Servaes P, Verhagen S, Schreuder B, Veth RPH, Bleijenberg G. Fatigue after treatment for malignant and benign bone and soft tissue tumors. J Pain Symptom Manage 2003; 26 (6): 1113-22.

- Simmonds MJ. Physical function in patients with cancer: psychometric characteristics and clinical usefulness of a physical performance test battery. J Pain Symptom Manage 2002; 24 (4): 404-14.

- Smets EMA, Garssen B, Cull A, de Haes JCJM. Application of the multidimensional fatigue inventory (MFI-20) in cancer patients receiving radiotherapy. Br J Cancer 1996; 73: 241-5.

- So WKW, Dogson J, Tai JWM. Fatigue and quality of life among chinese patients with hematologic malignancy after bone marrow transplantation. Cancer Nurs 2003; 26 (3): 211-9.

- Stone P, Hardy J, Broadly K, Tookman AJ, Kurowska A, A'Hern R. Fatigue in advanced cancer: a prospective controlled cross-sectional study. Br J Cancer 1999; 79 (9/10): 1479-86.

- Stone PC, Abdul-Wahab A, Gibson J, Wright RJ, Andrews PL. Fatigue in cancer patients is not related to changes in oxyhaemoglobin dissociation. Support Care Cancer 2005; 13: 854-8.

- Strohschein FJ, Kelly CG, Clarke AG, Westbury CF, Shuaib A, Chan KM. Applicability, validity, and reliability of the Piper Fatigue Scale in postpolio patients. Am J Phys Med Rehabil 2003;82(2):122-9.

- Sugawara Y, Akechi T, Okuyama T, Matsuoka Y, Nakano T, Inagaki M. Occurrence of fatigue and associated factors in disease-free breast cancer patients without depression. Support Care Cancer 2005; 13: 628-636.

- Tchen N, Juffs HG, Downie FP, Yi QL, Hu H, Chemerynsky I, et al. Cognitive function, fatigue, and menopausal symptoms in women receiving adjuvant chemotherapy for breast cancer. J Clin Oncol 2003; 21 (22): 4175-83.

- Truong PT, Berthelet E, Lee JC, Petersen R, Lim JT, Gaul CA, et al. Prospective evaluation of the prevalence and severity of fatigue in patients with prostate cancer undergoing radical external beam radiotherapy and neoadjuvant hormone therapy. Can J Urol 2006; 13 (3): 313946.

- Tsai LY, Li IF, Lai YH, Liu CP, Chang TY, Tu CT. Fatigue and its associated factors in hospice cancer patients in Taiwan. Cancer Nurs. 2007; 30(1): 24-30 
- Tsutsumi S, Yamaguchi S, Ide M, Tsuboi K, Fukasawa T, Yamaki S, et al. Second-line combination chemotherapy of oral S-1 with Cisplatin + Irinotecano for colorectal cancer resistant 5-FU. Hepatogastroenterol 2006; 53 (68): 196-200.

- Vainio A, Aurinen A. Prevalence of symptoms among patients with advanced cancer: na international collaborative study. Symptom Prevalence Group. J Pain Symptom Manage 1996; 12: 3-10.

- Velluti RA. Fisiologia do sono. In: Reimão R (Ed). Sono: estudo abrangente. $2^{\mathrm{a}}$ ed. Atheneu: São Paulo; 1996. p.1-19.

- Vordermark D, Schwab M, Flentje M, Sailer M, Kolbl O. Chronic fatigue after radiotherapy for carcinoma of the prostate: correlation with anorectal and genitourinary function. Radiotherapy and Oncology 2002; 62: 293-7.

- Walsh D, Rybicki L. Symptom clustering in advanced cancer. Support Care Cancer 2006; 14 : 831-6.

- Wang XS, Giralt SA, Mendoz TR, Engstrom MC, Johnson BA, Peterson N, et al. Clinical factors associated with cancer-related fatigue in patients being treated for leukemia and nonHodgkin's Lymphoma. J Clin Oncol 2002; 20 (5): 1319-28.

- Wilson KG, Chochinov HM, Skirko MG, Allard P, Chary S, Gagnon PR, et al. Depression and anxiety disorders in palliative cancer care. J Pain Symptom Manage 2007; 33(2):118-29.

- Winningham ML. Fatigue. In: Groenwald SL, Frogge MH, Goodman M, Yarbro CH. Cancer symptom management. Boston: Jones and Bartlett; 1996. p.42-53.

- Wisloff F, Kvam AK, Hjorth M, Lenhoff S. Serum calcium is an independent predictor of quality of life in multiple myeloma. Eur J Haematol 2006; 78: 29-34.

- Young KE, White CA. The prevalence and moderators of fatigue in people who have been successfully treated for cancer. J Psychosom Res 2006; 60: 29-38. 
ANEXO A 
ANEXO B 
ANEXO C 
ANEXO D 


\section{ANEXO E \\ Termo de Consentimento Livre e Esclarecido}

\section{Prezado (a) Senhor (a),}

Estamos realizando uma pesquisa entitulada "Fadiga em doentes com câncer: variáveis da doença e psicossociais", que tem como propósitos avaliar quantitativamente e qualitativamente a fadiga em pacientes com diferentes tipos de câncer e seus acompanhantes. Para isso será necessário responder a quatro instrumentos, em dois momentos, o que deve demorar aproximadamente 30 minutos.

O estudo não oferece risco e, se desejar, poderá participar da pesquisa. Sua participação é voluntária. Não há benefício direto para o participante e não há despesas ou compensações. Os resultados do estudo serão muito importantes porque irão contribuir para melhoria da assistência a pacientes que sentem fadiga, que é um sintoma freqüente.

As informações obtidas são confidenciais e os nomes dos participantes não serão divulgados. Caso recuse, o(a) sr(a) não terá prejuízo algum no seu atendimento nesta instituição de saúde. Ainda, lhe é garantida a liberdade da retirada de consentimento a qualquer momento, deixando de participar do estudo.

$\mathrm{O}$ (a) sr(a) poderá ter acesso, a qualquer momento, às informações sobre a pesquisa por meio de contato com os autores da pesquisa. Se o(a) sr(a) tiver alguma consideração ou dúvida sobre a ética da pesquisa, entre em contato com a Comissão de Ética em Pesquisa da Escola de Enfermagem da USP pelo telefone: (11) 3061-7548.

$\mathrm{Eu}$, acredito ter sido suficientemente

informado a respeito das informações que li sobre o estudo "Fadiga em doentes com câncer". Concordo voluntariamente em participar deste estudo, permito a busca de dados complementares no meu prontuário médico e poderei retirar o meu consentimento a qualquer momento, sem penalidades ou prejuízos ou perda de qualquer benefício que eu possa ter adquirido, ou no meu atendimento neste Serviço.

Assinatura do Participante:

Data: de de 200

Declaramos que obtivemos de forma apropriada e voluntária o Consentimento Livre e Esclarecido deste paciente para a participação neste estudo.

Dálete Delalibera Corrêa de Faria Mota

(11) 8483-9757
Cibele Andrucioli de Mattos Pimenta

(11) 3061-7544 


\section{ANEXO F \\ Ficha para Identificação}

Data:

$1+1$

Coletador:

Hora:

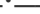

Nome:

Telefone:

Estado Civil: Sexo: ( ) F ( ) M

Idade:

Cor da pele: ( ) branco ( ) preto ( ) pardo ( ) amarelo ( ) indígena

Escolaridade: (anos)

Está trabalhando? ( )sim ( )não

Se SIM: Qual ocupação? Horas de trabalho/semana:

Se NÃO: ( ) afastado por licença médica

( ) aposentado ( ) aposentado por invalidez

Renda familiar mensal: $\mathrm{R} \$$ / No. pessoas que moram no domicílio:

Serviço de atendimento a saúde: ( ) público

( ) privado. Qual?

Início dos sintomas:

Data do diagnóstico:

Sítio do tumor primário: ( ) cólon ( ) reto ( ) outro:

Estadiamento: $\mathrm{T} \_\mathrm{N} \_\mathrm{M} \_$(data: ______ Evolução da doença:

Tratamento Atual: ( ) quimioterapia ( ) radioterapia

Data do início do tratamento:

Número de sessões realizadas/total:

Tipo:

Dose:

Tratamentos anteriores: ( ) quimioterapia ( ) radioterapia ( ) cirurgia. Há quanto tempo?

$\mathrm{Hb}$ : $\mathrm{mg} / \mathrm{dl}$ (data: ______

Peso/Altura:

Colostomia: ( ) Não ( ) Sim ( ) Sim (no passado/já fechou)

Co-morbidades:

Medicamentos em uso:

Dor na última semana? ( ) Sim ( ) Não

Média de Dor na última semana [0 (sem dor) - 10 (pior dor imaginável)]:

Prejuízo do sono na última semana? ( ) Sim ( ) Não

Média de Prejuízo do sono na última semana [0 (sem prejuízo) - 10 (totalmente prejudicado)]: 


\section{ANEXO G \\ Escala de Fadiga de Piper - revisada}

Instruções: Para cada questão a seguir, circule o número que melhor descreve a fadiga que você está sentindo AGORA. Por favor esforce-se para responder cada questão da melhor maneira possível. Muito obrigada.

1. Há quanto tempo você está sentindo fadiga? (assinale somente UMA resposta)
Dias
Semanas
Meses _ _-
Horas
Minutos
Outro (por favor descreva):

2. Quanto estresse a fadiga que você sente agora causa?

Nenhum estresse

Muito estresse

$\begin{array}{lllllllllll}0 & 1 & 2 & 3 & 4 & 5 & 6 & 7 & 8 & 9 & 10\end{array}$

3. Quanto a fadiga interfere na sua capacidade de completar suas atividades de trabalho ou escolares?

Nada

$\begin{array}{lllllllllll}0 & 1 & 2 & 3 & 4 & 5 & 6 & 7 & 8 & 9 & 10\end{array}$

4. Quanto a fadiga interfere na sua habilidade de visitar ou estar junto com seus amigos?

Nada

Muito

$\begin{array}{lllllllllll}0 & 1 & 2 & 3 & 4 & 5 & 6 & 7 & 8 & 9 & 10\end{array}$

5. Quanto a fadiga interfere na sua habilidade de ter atividade sexual?

Nada

Muito

$\begin{array}{lllllllllll}0 & 1 & 2 & 3 & 4 & 5 & 6 & 7 & 8 & 9 & 10\end{array}$

6. De modo geral, quanto a fadiga interfere na capacidade de realizar qualquer tipo de atividade que você gosta?

Nada

0

2

3

4

5

$\begin{array}{llll}6 & 7 & 8 & 9\end{array}$

Muito

7. Como você descreveria a intensidade ou a magnitude da fadiga que você está sentindo agora? Leve 0

$2 \quad 3$

$4 \quad 5$

Intensa

Como você descreveria a fadiga que você está sentindo agora?

8.

Agradável

9.

$$
0
$$

1

Aceitável

10.$$
0
$$

1

Protetora

11.$$
0
$$

Positiva

12.$$
0
$$

Normal$$
23
$$

4

5

6

7

8

Desagradável

Normal

0

1

23

$\begin{array}{ccccccc}4 & & & & & \text { Anormal } \\ & 5 & 6 & 7 & 8 & 9 & 10\end{array}$


13. Quanto você está se sentindo...

Forte

Fraco

$\begin{array}{lllllllllll}0 & 1 & 2 & 3 & 4 & 5 & 6 & 7 & 8 & 9 & 10\end{array}$

14. Quanto você está se sentindo...

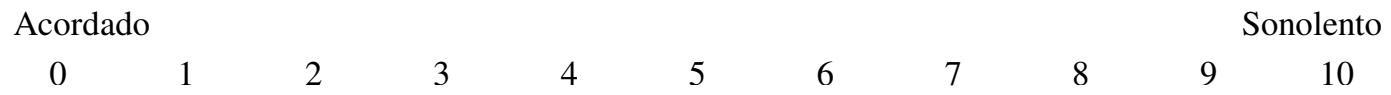

15. Quanto você está se sentindo...

Com vida 0

2

3

16. Quanto você está se sentindo...

Com vigor

0

23

4

5

6

$7 \quad 8$

Cansado

17. Quanto você está se sentindo...

Com energia

18. Quanto você está se sentindo...

Paciente

$\begin{array}{llll}0 & 1 & 2 & 3\end{array}$

19. Quanto você está se sentindo...

Relaxado

$\begin{array}{lll}0 & 1 & 2\end{array}$

20. Quanto você está se sentindo...

Extremamente feliz

$0 \quad 1$

23

21. Quanto você está se sentindo...

Capaz de se concentrar

$\begin{array}{lllllllllll}0 & 1 & 2 & 3 & 4 & 5 & 6 & 7 & 8 & 9 & 10\end{array}$

22. Quanto você está se sentindo...

Capaz de se lembrar

$\begin{array}{llllllllll}0 & 1 & 2 & 3 & 4 & 5 & 6 & 7 & 8 & 9\end{array}$

23. Quanto você está se sentindo...

Capaz de pensar com clareza

Incapaz de pensar com clareza

$\begin{array}{lllllllllll}0 & 1 & 2 & 3 & 4 & 5 & 6 & 7 & 8 & 9 & 10\end{array}$

24. De modo geral, o que você acha que contribui ou causa a sua fadiga?

25. De modo geral, o que mais alivia a sua fadiga é:

26. Existe mais alguma coisa que você gostaria de dizer para descrever melhor sua fadiga?

27. Você está sentindo qualquer outro sintoma agora?

( ) Não ( ) Sim. Por favor descreva 


\section{ANEXO H \\ Inventário de Depressão de Beck}

Neste questionário existem grupos de frases.

Escolha, em cada grupo, a frase que melhor descreve como você se sentiu na semana que passou, incluindo o dia de hoje.

Leia atentamente cada frase de cada grupo antes de fazer sua escolha.

1. $\quad 0$ Não me sinto triste.

1 Sinto-me triste.

2 Sinto-me triste o tempo todo e não consigo sair disso.

3 Estou tão triste ou infeliz que não posso agüentar.

2. $\quad 0$ Não estou sem coragem para o futuro.

1 Sinto-me sem coragem quanto ao futuro.

2 Sinto que não tenho nada por que esperar.

3 Sinto que o futuro é sem esperança e as coisas não podem melhorar.

3. $\quad 0$ Não me sinto fracassado(a).

1 Sinto que falhei mais que o indivíduo médio.

2 Quando olho para trás em minha vida, tudo que vejo é uma porção de fracassos.

3 Sinto que sou um fracasso completo como pessoa.

4. $\quad 0$ Obtenho tanta satisfação nas coisas como costumava ter.

1 Não gosto das coisas como costumava gostar.

2 Não consigo mais sentir satisfação real com coisa alguma.

3 Estou insatisfeito(a) ou entediado(a) com tudo.

5. $\quad 0$ Não me sinto particularmente culpado(a)

1 Sinto-me culpado(a) boa parte do tempo.

2 Sinto-me muito culpado(a) a maior parte do tempo.

3 Sinto-me culpado(a) o tempo todo.

6. $\quad 0$ Não sinto que esteja sendo castigado(a).

1 Sinto que possa ser castigado(a).

2 Espero ser castigado(a).

3 Sinto que estou sendo castigado(a).

7. 0 Não me sinto desapontado(a) comigo mesmo(a).

1 Sinto-me desapontado(a) comigo mesmo(a).

2 Sinto-me aborrecido(a) comigo mesmo(a).

3 Eu me odeio.

8. $\quad 0$ Não sinto que seja pior que qualquer outra pessoa.

1 Critico-me por minhas fraquezas ou erros.

2 Responsabilizo-me o tempo todo por minhas falhas.

3 Culpo-me por todas as coisas ruins que acontecem. 
9.

0 Não tenho nenhum pensamento a respeito de me matar.

1 Tenho pensamentos sobre me matar, mas não os levaria adiante.

2 Gostaria de me matar.

3 Eu me mataria, se tivesse uma oportunidade.

10. $\quad 0$ Não costumo chorar mais que o habitual.

1 Choro mais agora do que costumava fazer.

2 Atualmente choro o tempo todo.

3 Eu costumava conseguir chorar, mas agora não consigo, ainda que eu queira.

11. 0 Não me irrito mais agora do que em qualquer outra época.

1 Fico molestado(a) ou irritado(a) mais facilmente do que costumava.

2 Atualmente sinto-me irritado(a) o tempo todo.

3 Absolutamente não me irrito com as coisas que costumavam irritar-me.

12. $\quad 0$ Não perdi o interesse nas outras pessoas.

1 Interesso-me menos do que costumava pelas outras pessoas.

2 Perdi a maior parte de meu interesse nas outras pessoas.

3 Perdi todo o meu interesse nas outras pessoas.

13. 0 Tomo decisões mais ou menos tão bem como em qualquer outra época.

1 Adio minhas decisões mais do que costumava.

2 Tenho maior dificuldade em tomar decisões do que antes.

3 Não consigo mais tomar decisão alguma.

14. 0 Não sinto que minha aparência seja pior do que costumava ser.

1 Preocupo-me por estar parecendo mais velho(a) e sem atrativos.

2 Sinto que há mudanças permanentes em minha aparência que me fazem parecer sem atrativos.

3 Considero-me feio(a).

15. 0 Posso trabalhar mais ou menos tão bem quanto antes.

1 Preciso de um esforço extra para começar qualquer coisa.

2 Tenho que me forçar muito até fazer qualquer coisa.

3 Não consigo fazer nenhum trabalho.

16. $\quad 0$ Durmo tão bem quanto de hábito.

1 Não durmo tão bem como costumava.

2 Acordo 1 ou 2 horas mais cedo que de hábito e tenho dificuldade de voltar a dormir.

3 Acordo várias horas mais cedo do que costumava e não consigo voltar a dormir.

17. $\quad 0$ Não fico mais cansado(a) que de hábito.

1 Fico mais cansado(a) com mais facilidade do que costumava.

2 Sinto-me cansado(a) ao fazer qualquer coisa.

3 Estou cansado(a) demais para fazer qualquer coisa.

18. $\quad 0$ Meu apetite não está pior que de hábito.

1 Meu apetite não é tão bom quanto costumava ser.

2 Meu apetite está muito pior agora.

3 Não tenho mais nenhum apetite. 
19. 0 Não perdi muito peso, se é que perdi algum ultimamente.

1 Perdi mais de $2,5 \mathrm{Kg}$.

2 Perdi mais de $5 \mathrm{Kg}$.

3 Perdi mais de 7,5 Kg.

( ) Estou deliberadamente tentando perder peso, comendo menos.

20. $\quad 0$ Não me preocupo mais que de hábito com minha saúde.

1 Preocupo-me com problemas físicos, como dores ou aflições ou perturbações no estômago ou prisão de ventre.

2 Estou muito preocupado(a) com problemas físicos e é difícil pensar em muito mais do que isso.

3 Estou tão preocupado com meus problemas físicos que não consigo pensar em qualquer outra coisa.

21. 0 Não tenho observado qualquer mudança recente em meu interesse sexual

1 Estou menos interessado(a) em sexo do que costumava.

2 Estou bem menos interessado(a) em sexo atualmente.

3 Perdi completamente o interesse no sexo.

Escore total:........................... 


ANEXO I
$\begin{aligned} & \text { De: } \\ & \text { Barb Piper <bpiper@unmc.edu> [ salvar endereço ] [ bloquear } \\ & \text { Para:Dálete Mota < dalete.mota@globo.com> }\end{aligned}$
Cópia:
Assunto:Re: FW: Piper Fatigue Scale - Brazil
Data:Tue, 31 Jan 2006 15:50:04 -0600

\section{Anexos:}

Dear Dr. Pimenta,

You have my permission to use the Piper Fatigue Scale in your research and in your doctoral student's research. The scale has been translated into several languages, but unfortunately the results are not always published.

I would be happy to help you on the back translation of the PFS. The PFS and its scoring instructions were published in the May, 1998 issue of the Oncology Nursing Forum. If you need me to fax the article to you, please let me know.

BFP

Barbara F. Piper, DNSc, RN, AOCN, FAAN

Associate Professor

UNMC College of Nursing

Adult Health and Illness Department

985330 Nebraska Medical Center

Omaha, NE 68198-5330

(Office) 402-559-4345

(Fax) 402-559-4303

(Cell) 402-305-0737

bpiper@unmc.edu

Confidentiality Statement: This communication is intended only for the use of the individual or entity to which it is addressed and may contain information that is privileged and confidential. If you are not the intended recipient, or the employee or agent responsible for delivering the communication to the intended recipient, you have received this communication in error and are prohibited from reading, printing, or disclosing any of the information contained in it. If you have received this communication in error, please notify the sender immediately by telephone to arrange for the return or destruction of these documents. 
'>'Date: Thu, 01 Dec 2005 14:08:13 -0200

'>'From: Cibele Pimenta

'>'To: bpiper@unmc.edu

'>'Cc: Dalete, parpca@usp.br

'>'Subject: Piper Fatigue Scale - Brazil

'>'

'>'

'>'Dear Dr Barbara Piper,

'>'

'>'I?m a Professor of the Nursing School of the University of Sao Paulo, Brazil. I have been developing researches on pain and symptom management for many years. My doctorate student, Dálete DCF Mota, is preparing a project on fatigue, and it involves a multidimensional assessment of fatigue in cancer patients. No validated fatigue instrument for the Brazilian culture has been published. We would like to ask for your formal permission to translate and validate the Revised Piper Fatigue Scale to the Portuguese language.

'>'

'>'If you consent, we would like to have a copy of the Revised - Piper Fatigue Scale and the key score as well as invite you to compare and analyze the similarity and equivalence of the original and the back translation version.

'>'Yet, we would like to know if the Revised Piper Fatigue Scale has been validated to other languages /cultures besides French?

'>'I already thank you.

'> With best regards,

'>'Cibele Pimenta

'>'

'>'Cibele Andrucioli de Mattos Pimenta, RN, PhD

'> Professor. Nursing School, University of Sao Paulo

'>'Av Dr Enéas de Carvalho Aguiar, 419

'>'05403-000 Sao Paulo, Brazil

'>'phone 551130667544 Fax 551130667546

'>'e-mail: parpca@usp.br

'>'

'> 'Dalete Delalibera Corrêa de Faria Mota, RN

'>'Rua Três de Maio, 130, apto 82, Vila Clementino

'>'São Paulo ? SP

'>'4044-20 Brazil

'>'phone 5511 5575-7343

'>'e-mail: dalete.mota@globo.com 


\section{ANEXO J}

\section{ESCALA DE KARNOFSKY}

\begin{tabular}{|c|l|}
\hline 100 & Nenhuma queixa: ausência de evidência da doença \\
\hline 90 & Capaz de levar vida normal; sinais menores ou sintoma da doença \\
\hline 80 & Alguns sinais ou sintomas da doença \\
\hline 70 & $\begin{array}{l}\text { Capaz de cuidar de si mesmo; incapaz de levar suas atividades normais ou } \\
\text { exercer trabalho ativo }\end{array}$ \\
\hline 60 & $\begin{array}{l}\text { Necessita de assistência ocasional, mas ainda é capaz de prover a maioria } \\
\text { de suas atividades }\end{array}$ \\
\hline 50 & Requer assistência considerável e cuidados médicos freqüentes \\
\hline 40 & Incapaz; requer cuidados especiais e assistência \\
\hline 30 & Muito incapaz; indicada hospitalização, apesar da morte não ser iminente \\
\hline 20 & $\begin{array}{l}\text { Muito debilitado; hospitalização necessária; necessitando de tratamento de } \\
\text { apoio ativo }\end{array}$ \\
\hline 10 & Moribundo, processos letais progredindo rapidamente \\
\hline 0 & Morto \\
\hline
\end{tabular}

